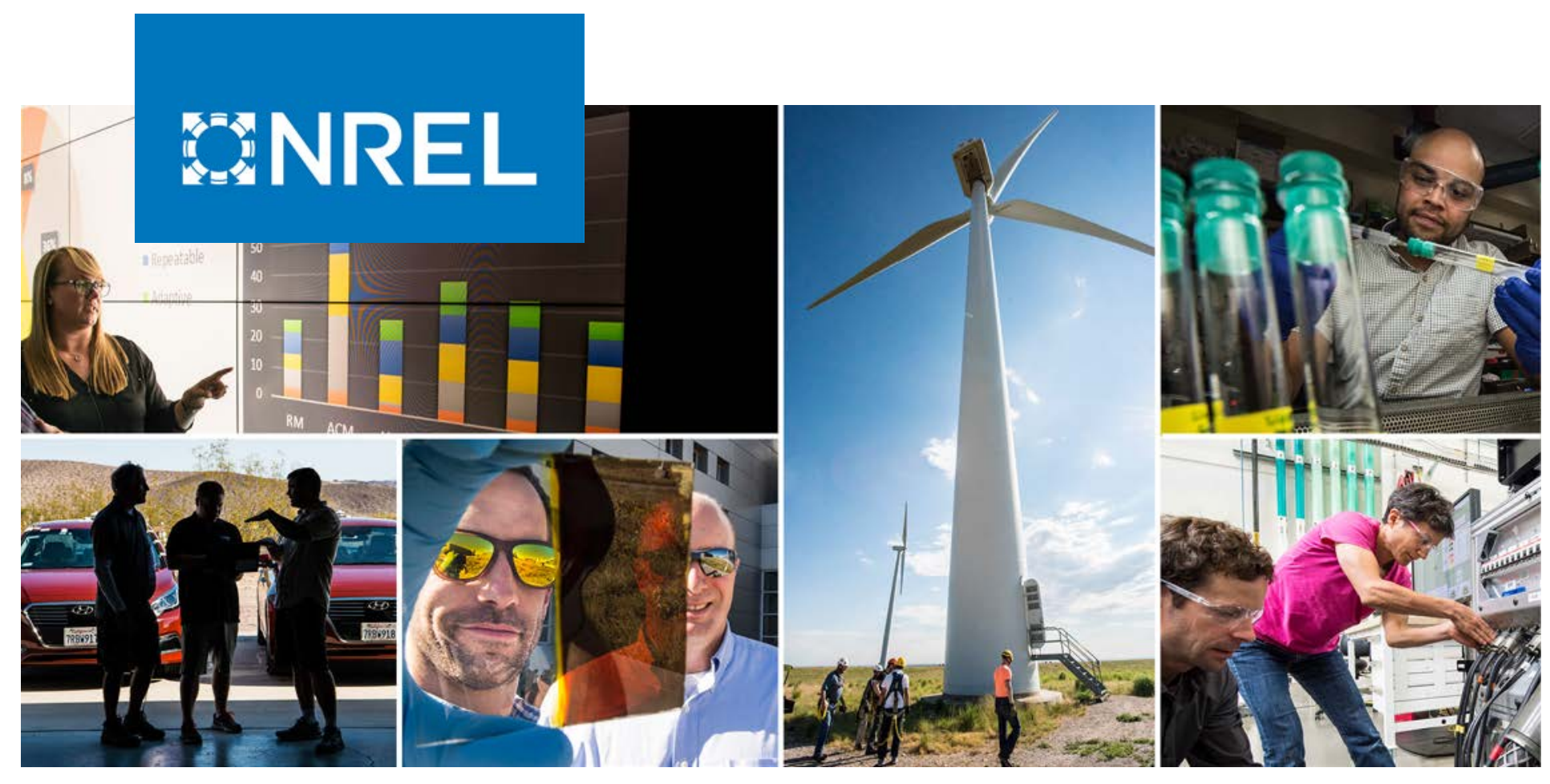

\title{
Evaluating the Grid Impact of Oregon Offshore Wind
}

Josh Novacheck and Marty Schwarz

National Renewable Energy Laboratory

NREL is a national laboratory of the U.S. Department of Energy

Office of Energy Efficiency \& Renewable Energy

Operated by the Alliance for Sustainable Energy, LLC

This report is available at no cost from the National Renewable Energy Laboratory (NREL) at www.nrel.gov/publications.
Technical Report

NREL/TP-6A40-81244

October 2021 


\title{
GNREL
}

\section{Evaluating the Grid Impact of Oregon Offshore Wind}

\author{
Josh Novacheck and Marty Schwarz \\ National Renewable Energy Laboratory
}

\author{
Suggested Citation \\ Novacheck, Josh, Marty Schwarz. 2021. Evaluating the Grid Impact of Oregon Offshore Wind. \\ Golden, CO: National Renewable Energy Laboratory. NREL/TP-6A40-81244. \\ https://www.nrel.gov/docs/fy22osti/81244.pdf.
}

The report is available from the Bureau of Ocean Energy Management by referencing OCS Study BOEM 2021-064. The report may be downloaded from BOEM's Recently Completed Environmental \& Technical Studies - Pacific webpage at http://www.boem.gov/Pacific-Completed-Studies.

This study was funded by the U.S. Department of the Interior, Bureau of Ocean Energy Management through Interagency Agreement M19PG00025 with the U.S. Department of Energy.

NREL is a national laboratory of the U.S. Department of Energy Office of Energy Efficiency \& Renewable Energy Operated by the Alliance for Sustainable Energy, LLC

This report is available at no cost from the National Renewable Energy Laboratory (NREL) at www.nrel.gov/publications.

Contract No. DE-AC36-08GO28308
Technical Report

NREL/TP-6A40-81244

October 2021

National Renewable Energy Laboratory 15013 Denver West Parkway Golden, CO 80401

303-275-3000 • www.nrel.gov 


\section{NOTICE}

This work was authored by the National Renewable Energy Laboratory, operated by Alliance for Sustainable Energy, LLC, for the U.S. Department of Energy (DOE) under Contract No. DE-AC3608GO28308. Funding provided by the U.S. Department of the Interior, Bureau of Ocean Energy Management (BOEM), Pacific OCS Region, through Interagency Agreement Number M19PG00025 with the U.S. Department of Energy, National Renewable Energy Laboratory. The views expressed herein do not necessarily represent the views of the DOE or the U.S. Government.

This report is available at no cost from the National

Renewable Energy Laboratory (NREL) at

www.nrel.gov/publications.

U.S. Department of Energy (DOE) reports produced

after 1991 and a growing number of pre-1991

documents are available

free via www.OSTI.gov.

Cover Photos by Dennis Schroeder: (clockwise, left to right) NREL 51934, NREL 45897, NREL 42160, NREL 45891, NREL 48097, NREL 46526 .

NREL prints on paper that contains recycled content. 


\section{Acknowledgments}

This study was funded by the U.S. Department of the Interior, Bureau of Ocean Energy Management (BOEM), Pacific OCS Region, through Interagency Agreement Number M19PG00025 with the U.S. Department of Energy, National Renewable Energy Laboratory. We would like to thank the BOEM staff who contributed to the content and review of this report, including: Sara Guiltinan, Necy Sumait, and Whitney Hauer, as well as other bureau team members for their thoughtful reviews, comments, and suggestions. We also would like to thank the members of the Technical Working Group (TWG) who provided ongoing input and review of this technical report. Members of the TWG include:

- Anders Johnson - Bonneville Power Agency

- Travis Douville - Pacific Northwest National Laboratory

- Dhruv Bhatnager - Pacific Northwest National Laboratory

- Andy Lanier - Oregon Department of Land Conservation and Development

- Jason Sierman - Oregon Department of Energy

- Jimmy Lindsay - Portland General Electric

We would also like to thank the NREL staff who helped organize and contribute to TWG meetings: Walt Musial, Chloe Constant, Tiffany Byrne, and Melinda Marquis. Finally, we would like to thank Brady Cowiestoll, Philipp Bieter, and Melinda Marquis for their review of this document. 


\section{List of Acronyms}

BPA

CAISO

dGen

Gas-CC

Gas-CT

LCOE

NREL

NSRDB

PCM

PV

ReEDS

reV

SAM

VRE

WECC

WIND
Bonneville Power Agency

California Independent System Operator

Distributed Generation Market Demand

natural gas combined cycle

natural gas combustion turbine

levelized cost of energy

National Renewable Energy Laboratory

National Solar Resource Database

production cost model

photovoltaic

Regional Energy Deployment System

Renewable Energy Potential

System Advisor Model

variable renewable energy

Western Electricity Coordinating Council

Wind Integration National Dataset 


\section{Executive Summary}

Offshore wind generation could be on the cusp of becoming a major contributor to the electricity system in the United States over the next decade. This is due to both expected system cost reductions and a combination of recent state and federal policy goals. In March 2021, the U.S. set a target to deploy $30 \mathrm{GW}$ of offshore wind by 2030, California directed its Energy Commission to quantify the maximum feasible capacity of offshore wind by June 1, 2022, and eight mid-Atlantic states have committed to building over $35 \mathrm{GW}$ of offshore wind by 2035 and 39 GW by 2040 .

While much of the offshore wind development is focused on fixed-bottom turbines in the relatively shallower waters of the east coast, the coastal Western states, especially Oregon, are home to some of the strongest and most consistent winds in North America (Musial et al. 2019), in the Western Interconnection in particular (Jorgenson et al. 2021). In Oregon, a bill passed in 2021 directs the Oregon Department of Energy to conduct a literature review on the benefits and challenges of integrating up to three GWs of floating offshore wind by $2030 .{ }^{1}$ Furthermore, a 2021 announcement between the State of California and the federal government ${ }^{2}$ suggests $^{2}$ growing momentum for offshore wind along the Pacific Coast.

The objective of our analysis is to build on previous work investigating offshore wind integration in Oregon (Douville et al. 2020) and in the U.S. Northeast (Beiter et al. 2020) by analyzing how future power generation and transmission systems will manage the inclusion of offshore wind. The analysis provides insights to system planners and policymakers so they can address key system constraints and maximize the value of offshore wind to Oregon and the broader power system. Similar to the approach taken in Beiter et al. 2020 and Douville et al. 2020, we utilize a production cost model (PCM) to simulate system dispatch to understand the operational impacts of the integration of offshore wind. While Douville et al. 2020 focused on many levels of offshore wind deployment, we selected a few key levels of offshore wind and varied the grid infrastructure characteristics of the rest of the system. Most notably, we varied the land-based variable renewable energy (VRE) penetration, degree of transmission infrastructure investment, and deployment of energy storage systems at the offshore wind injection points. We also test the robustness of the findings around offshore wind integration by running multiple simulations modeling historical weather conditions from different years.

\section{Scenarios}

In this study, we explored the value and impacts of Oregon offshore wind integration by simulating a diversity of scenarios. There are four categories that determine the overall scenario configuration: the offshore wind penetration (base, mid, and high), the power generation and transmission system in the Western Interconnection (current grid, future grid), whether transcoastal transmission upgrades occur (existing, expanded), and whether energy storage is colocated with the point of interconnection for offshore wind. Finally, we also ran multiple weather years for some scenarios. Table ES-1 lists all category combinations that define the scenarios

\footnotetext{
${ }^{1}$ https://olis.oregonlegislature.gov/liz/2021R1/Measures/Overview/HB3375

2 https://www.gov.ca.gov/2021/05/25/california-announces-historic-agreement-with-federal-partners-to-advanceoffshore-wind-development/
} 
that we modeled using a full-year PCM simulation. In total, 10 scenario combinations were modeled using the 2012 meteorological year ${ }^{3}$, and three combinations were modeled separately with all seven meteorological years (2007-2013).

Table ES- 1. All Scenario Combinations Studied in the PCM

\begin{tabular}{|c|c|c|c|c|c|}
\hline $\begin{array}{l}\text { Scenario } \\
\text { Name }\end{array}$ & $\begin{array}{l}\text { Offshore } \\
\text { Wind } \\
\text { Penetration }\end{array}$ & $\begin{array}{c}\text { WECC } \\
\text { Infrastructure } \\
\text { Year }\end{array}$ & $\begin{array}{c}\text { Trans- } \\
\text { Coastal } \\
\text { Transmission }\end{array}$ & $\begin{array}{l}\text { Co-Located } \\
\text { Storage }\end{array}$ & $\begin{array}{c}\text { Meteorological } \\
\text { Years }\end{array}$ \\
\hline $\begin{array}{l}\text { Base - } \\
\text { Current Grid } \\
\text { (CG) }\end{array}$ & \multirow{2}{*}{$0 \mathrm{GW}$} & Current Grid & \multirow{2}{*}{$\begin{array}{l}\text { Existing } \\
\text { capacity }\end{array}$} & \multirow{2}{*}{ No Storage } & 2012 only \\
\hline $\begin{array}{l}\text { Base - } \\
\text { Future Grid } \\
\text { (FG) }\end{array}$ & & Future Grid & & & $2007-2013$ \\
\hline $\begin{array}{c}\text { Mid Offshore } \\
\text { - CG }\end{array}$ & \multirow{4}{*}{$2.6 \mathrm{GW}$} & \multirow[b]{2}{*}{ Current Grid } & \multirow{4}{*}{$\begin{array}{l}\text { Existing } \\
\text { capacity }\end{array}$} & No Storage & 2012 only \\
\hline $\begin{array}{c}\text { Mid Offshore } \\
\text { - CG - } \\
\text { Storage }\end{array}$ & & & & Storage & 2012 only \\
\hline $\begin{array}{c}\text { Mid Offshore } \\
- \text { FG }\end{array}$ & & \multirow[b]{2}{*}{ Future Grid } & & No Storage & $2007-2013$ \\
\hline $\begin{array}{c}\text { Mid Offshore } \\
\text { - FG - } \\
\text { Storage }\end{array}$ & & & & Storage & 2012 only \\
\hline $\begin{array}{l}\text { High } \\
\text { Offshore - } \\
\text { FG }\end{array}$ & \multirow{4}{*}{$5 \mathrm{GW}$} & \multirow{4}{*}{ Future Grid } & \multirow{2}{*}{$\begin{array}{l}\text { Existing } \\
\text { capacity }\end{array}$} & No Storage & 2012 only \\
\hline $\begin{array}{c}\text { High } \\
\text { Offshore - } \\
\text { FG - Storage }\end{array}$ & & & & Storage & 2012 only \\
\hline $\begin{array}{c}\text { High } \\
\text { Offshore - } \\
\text { FG - } \\
\text { Transmission } \\
\text { (Tx) }\end{array}$ & & & \multirow{2}{*}{$\begin{array}{l}\text { Expanded } \\
\text { transmission }\end{array}$} & No Storage & $2007-2013$ \\
\hline $\begin{array}{l}\text { High } \\
\text { Offshore - } \\
\text { FG - Tx - } \\
\text { Storage }\end{array}$ & & & & Storage & 2012 only \\
\hline
\end{tabular}

Figure ES- 1 shows the locations of the offshore wind study sites and the points of interconnection. We designed the $2.6 \mathrm{GW}$ offshore wind penetration to represent the maximum

\footnotetext{
${ }^{3}$ Brinkman et al. 2021 used the 2012 meteorological year because it was shown to be an average wind and solar potential year across most regions of CONUS.
} 
offshore wind build-out that is possible without large quantities of congestion-related offshore wind curtailment and without large trans-coastal transmission infrastructure upgrades. For a detailed discussion of our design process for these scenarios, see Section 2.5.1. Table ES-2 shows the maximum offshore wind capacities identified to meet this criteria and are used the Mid Offshore scenarios. Due to internal plant losses, we modeled the maximum injected power to be $83.4 \%$ of the maximum nameplate capacity. 


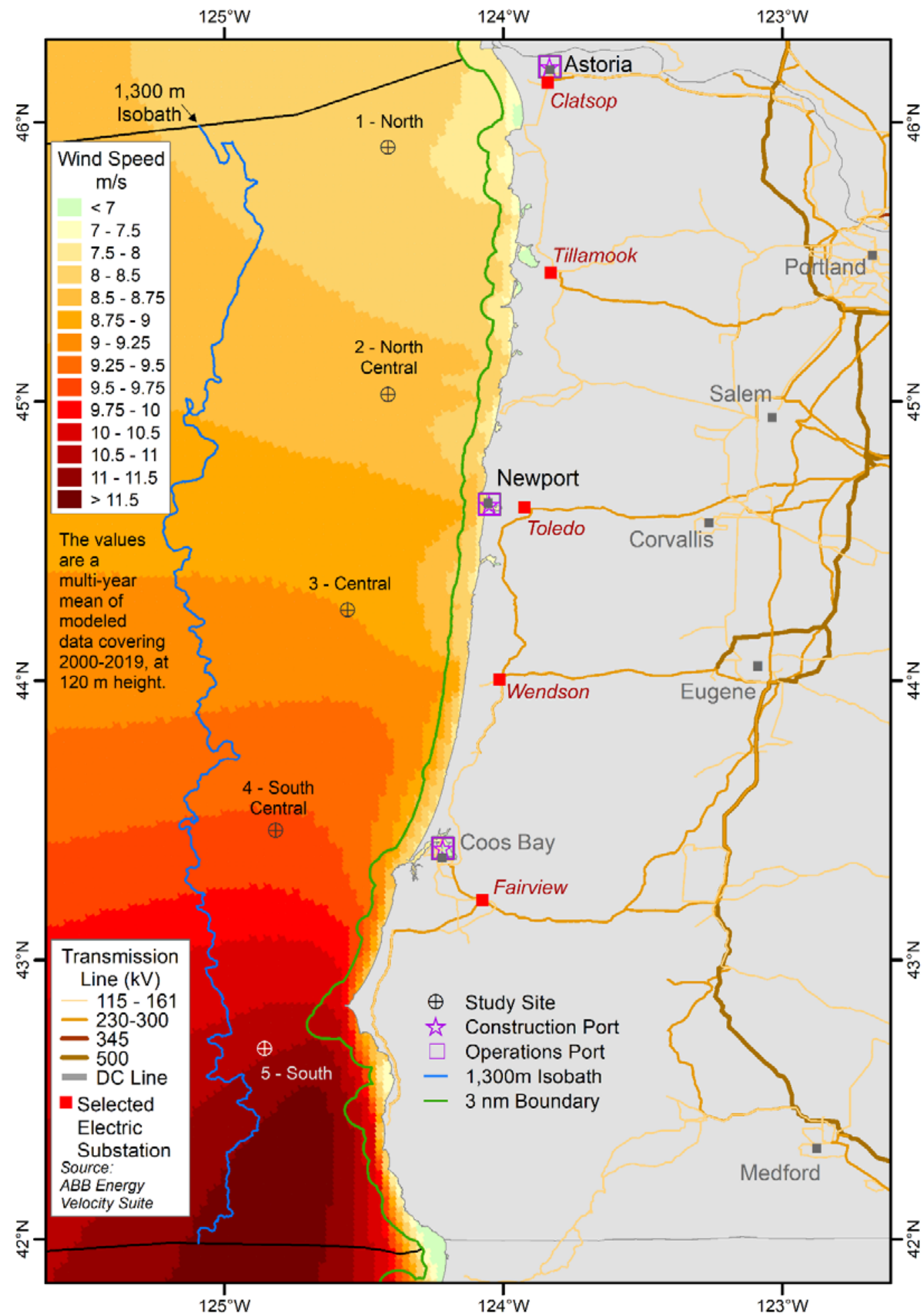

Figure ES- 1. Map of the trans-coastal transmission lines, which connect the offshore wind interconnection points to the 500-kV line connecting Medford, Eugene, and Portland (the I-5 corridor in the Willamette Valley). 
The southerly injection points are connected with higher transmission capacity and can therefore host larger capacities of offshore wind generation. These sites also have the greatest annual wind energy potential due to the strong and consistent wind speeds. The High Offshore wind penetration assumes 1,000 MW are connected to each of the five points of interconnection. In scenarios with upgraded transmission, we increased the capacity of trans-coastal $230-\mathrm{kV}$ line capacities so they could deliver all injected offshore wind generation without overloading.

Table ES- 2. Max Penetration of Offshore Wind That Can Be Accommodated by the Existing Transmission System ${ }^{4}$

\begin{tabular}{|ccc|}
\hline Offshore Wind Injection Point & $\begin{array}{c}\text { Max } \\
\text { Capacity } \\
\text { (MW) }\end{array}$ & $\begin{array}{c}\text { Max } \\
\text { Injected } \\
\text { Offshore } \\
\text { Wind } \\
\text { Power } \\
\text { (MW) }\end{array}$ \\
\hline Clatsop & 361 & 301 \\
\hline Tillamook & 553 & 461 \\
\hline Toledo & 156 & 130 \\
Wendson & 613 & 512 \\
\hline Fairview & 941 & 785 \\
\hline Total & $\mathbf{2 , 6 2 5}$ & $\mathbf{2 , 1 8 9}$ \\
\hline
\end{tabular}

As described in Section 2.3, the future grid infrastructures used in this study came from the National Renewable Energy Laboratory's (NREL's) flagship capacity expansion model, the Regional Energy Deployment System (ReEDS $)^{5}$, which builds both generation and transmission to meet system needs. Figure ES- 2 shows the future grid generation capacity by type for the two grid infrastructure scenarios studied: a contemporary and a future system represented by the ReEDS solutions for current and future, respectively. Across the Western Interconnection and Oregon, thermal generation was retired and land-based wind and solar generation capacity increased greatly between the current and future grid infrastructures. These infrastructures were adapted from those used in Novacheck et al. Forthcoming. Offshore wind or the storage capacity associated with it, which is the focus of this study, is not included in the capacity plots. When we added various amounts of offshore wind and storage, the infrastructure shown here was not changed.

\footnotetext{
${ }^{4}$ Due to internal plant losses, we modeled the maximum injected power (third column) to be $83.4 \%$ of the maximum nameplate capacity (second column).

${ }^{5}$ https://www.nrel.gov/analysis/reeds/
} 

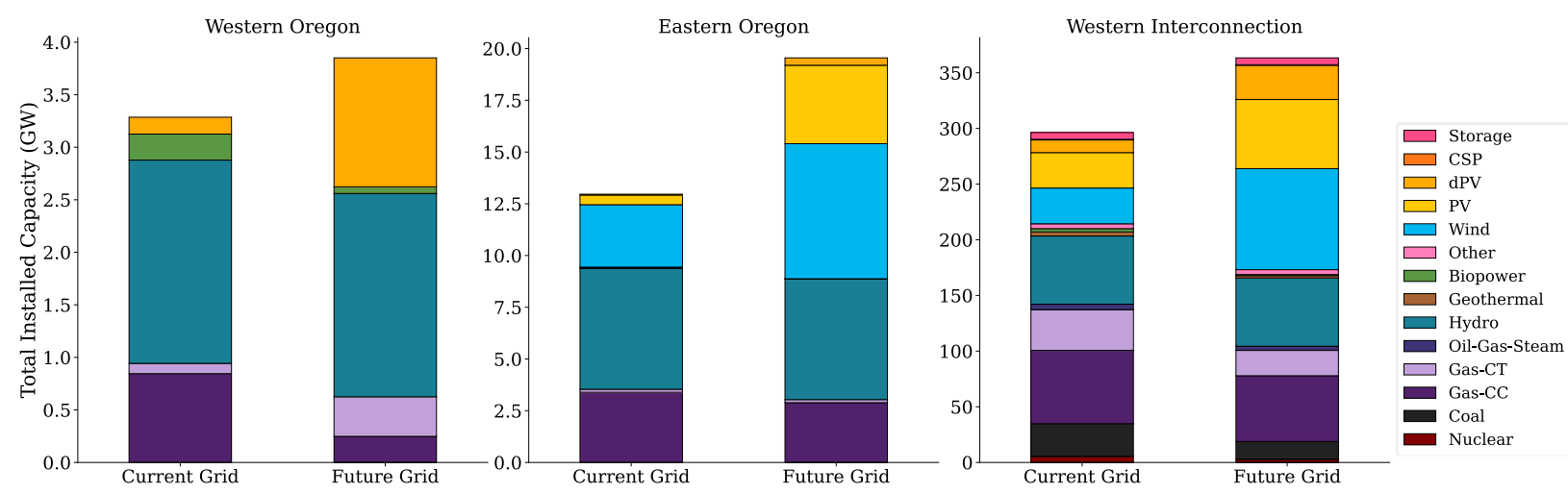

Figure ES- 2. Installed capacity in Western Oregon (left), Eastern Oregon (middle) and the Western Interconnection (right) for the current and future grid infrastructures, exclusive of the offshore wind and storage capacities evaluated in this study.

\section{Results}

This section summarizes our key findings from the system dispatch results. The primary categories of analysis include offshore wind curtailment, the system value of offshore wind, and offshore wind's impact to cross-Cascade transmission flows. More detailed investigation of other aspects of offshore system impact can be found in the main body of the report.

We found that trans-coastal transmission congestion is the key driver of curtailment of offshore wind. Without upgrading the transmission, congestion and its associated curtailment could be avoided by limiting nameplate offshore wind capacity to $2.6 \mathrm{GW}^{6}$ spread across the five main points of interconnection along the Oregon coast. Some targeted upgrades may still be required after more detailed power flow studies are performed. All points of interconnection would require transmission to connect the offshore site to land, and, in some cases, additional landbased transmission would be needed to reach the in-land substation for the point of interconnection. Furthermore, substations and other electrical infrastructure may need to be updated. The design and cost of this grid infrastructure is not considered in this study. As described in greater detail in Section 2.5.1, distributing the offshore wind along the coast in this way maximizes its capacity within the existing transmission infrastructure.

Figure ES- 3 shows the curtailment of offshore wind when the capacity is increased to $5 \mathrm{GW}$.

Without trans-coastal transmission upgrades, curtailment is significant across the sites because of congestion on the lines that connect Clatsop, Tillamook, and Wendson to the broader transmission system in the I-5 corridor. In our storage scenarios, relatively small batteries with power ratings sized at $10 \%$ of the associated nameplate offshore wind capacity were able to reduce curtailment by about $15 \%$ when co-located with the point of offshore wind interconnection. When we expanded trans-coastal transmission to accommodate $5 \mathrm{GW}$ of offshore wind, curtailment dropped to near zero.

While transmission congestion is the most significant driver of offshore wind curtailment in either the current or future power system, oversupply during high land-based VRE periods also

${ }^{6} 2.6 \mathrm{GW}$ of nameplate capacity would inject a maximum of $2.1 \mathrm{GW}$ at any hour given internal plant losses. 
plays a role in offshore wind curtailment. However, this role is relatively small. Curtailment of land-based VRE did increase between the mid and high offshore wind scenarios, but only at a rate of $100 \mathrm{GWh}$ of land-based VRE curtailment for every 1,000 GWh of offshore wind generation. Furthermore, only $15 \%$ of the increase in land-based curtailment comes from VRE in Eastern Oregon. This suggests that operational factors beyond the additional offshore wind injection are responsible for most of the increase in land-based curtailment.

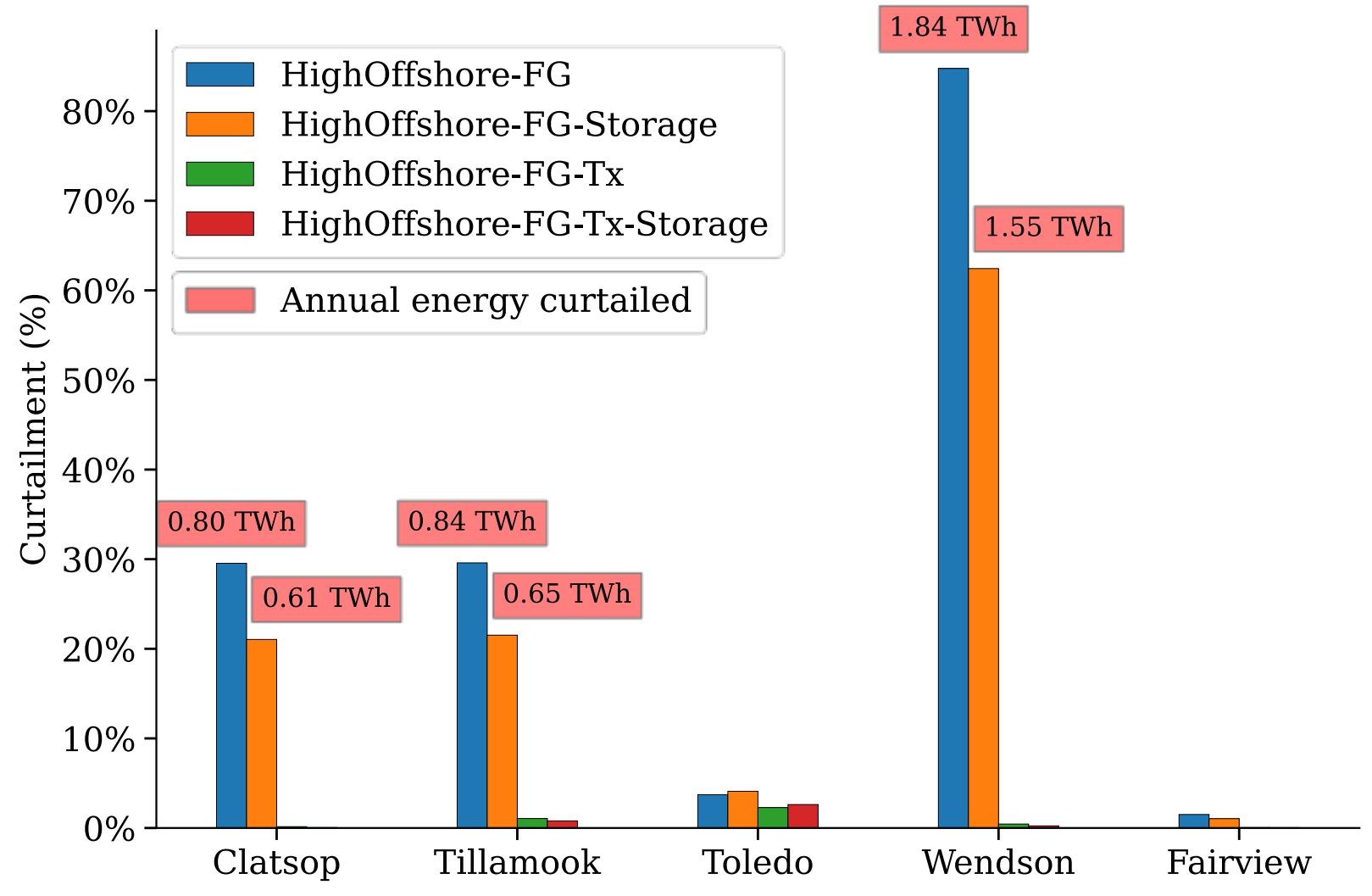

Figure ES- 3. Curtailment of offshore wind at each point of interconnection for the four High Offshore wind penetration scenarios. Red textboxes show the total annual curtailed energy for select bars with large amount of curtailment.

We estimated the total system value of integrating offshore wind by combining value streams from routine operations, complementary capacity, and carbon dioxide $\left(\mathrm{CO}_{2}\right)$ emissions reduction, and comparing this combined value to the Base system, where there is no offshore wind added to the system. Operational value includes the reduction in total system production costs (i.e., fuel costs, variable operation and maintenance, and start and stop costs) derived from displacing thermal generation. The capacity value of offshore wind was estimated by calculating the offshore wind capacity factor during the top 100 net load hours (load minus VRE) in the current and future grid systems. This method assumes a proportion of the added offshore wind capacity would provide the system with firm capacity that would otherwise need to be served by a different resource. In this study, we valued firm capacity using the California Independent System Operator's (CAISO's) assumed cost of new simple cycle gas combustion turbines 
(CAISO 2012) ${ }^{7}$. The value of $\mathrm{CO}_{2}$ emissions reduction was determined using the displaced emissions tied to the integration of offshore wind and the United States' social cost of carbon. ${ }^{8}$ The total value of offshore wind for all 2012 weather year scenarios is plotted in Figure ES- 4. This value is derived from taking the difference from the Base-CG scenario.

Western Interconnection

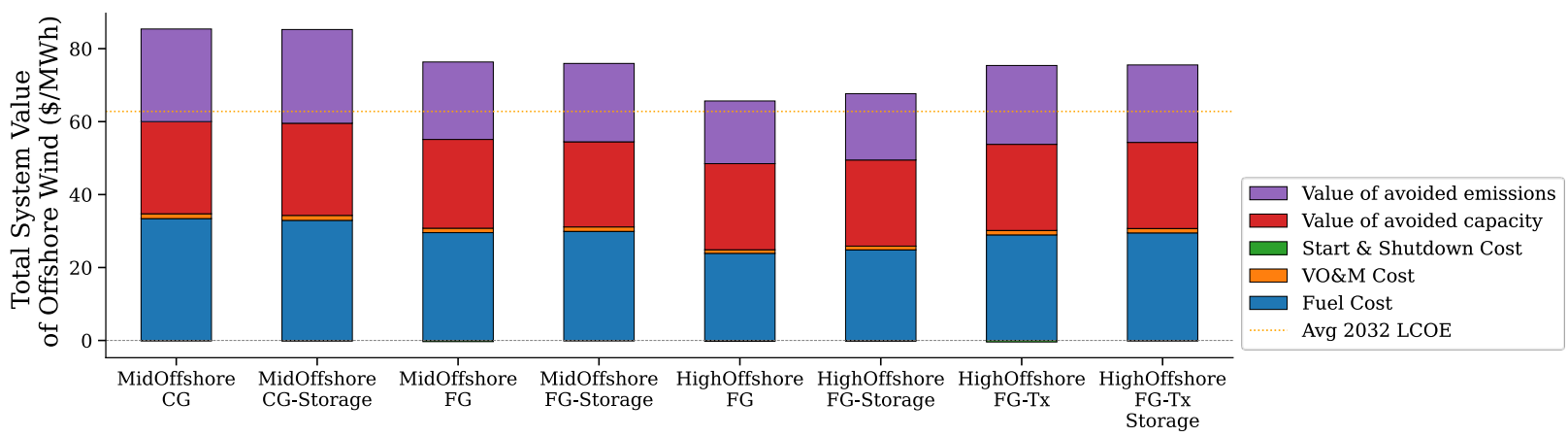

Figure ES- 4. Total system value stacks for all scenarios studied, as compared to the associated 0 GW offshore wind base case, for current scenarios (left) and future scenarios (right), modeled with the 2012 meteorological year.

Using the levelized cost of energy ( $\mathrm{LCOE}, \$ / \mathrm{MWh}$ ) for several years in the future can give a general idea of how system value may compare to cost of those technologies in the future, although real costs may vary considerably. Musial et al., 2021 projected the average $\mathrm{LCOE}^{9}$ for offshore wind in 2032 to be $\$ 63 / \mathrm{MWh}$ and that value is plotted with a dotted yellow line in Figure ES- 4 for reference. The system value offshore wind is larger than the estimated LCOE across all penetration and grid infrastructure scenarios. The LCOE projections for 2022 (\$123/MWh) and 2027 (\$92/MWh), exceed the total system values of offshore wind in every scenario.

The system value of offshore wind is highest in the current grid infrastructure scenarios, exceeding \$85/MWh. As more land-based VRE is added to the system and least efficient gas and coal are retired in the future grid infrastructure scenarios, the value drops to $\$ 65 / \mathrm{MWh}$ to $\$ 75 / \mathrm{MWh}$, depending on the amount of offshore wind curtailment. All three of the offshore wind value streams analyzed - energy, capacity, and emissions - dropped in value from the current to the future grid infrastructure scenarios. However, in the future grid infrastructure scenarios, a higher proportion of the value to the system was derived from offshore wind's capacity value.

\footnotetext{
${ }^{7}$ The policy limitations on new construction of gas resources and the potential higher cost of zero emission firm capacity resources (e.g., battery storage, hydrogen fueled turbines, etc.) may suggest a higher value of displaced firm capacity should be used.

${ }^{8}$ https://www.whitehouse.gov/wpcontent/uploads/2021/02/TechnicalSupportDocument_SocialCostofCarbonMethaneNitrousOxide.pdf

${ }^{9}$ While LCOE is a good proxy for the cost of a given technology, it does not necessarily capture all costs associated with building offshore wind in Oregon. For instance, undersea transmission will require additional investment, and the manufacture of the turbines themselves will likely involve carbon emissions. Furthermore, the comparison with LCOE is not a holistic cost-benefit analysis, as it does not consider alternative generation options.
} 
This signals that, as the system decarbonizes, the capacity value of offshore wind becomes a more significant value stream, even if the absolute value decreases.

Besides offering value to the system, offshore wind has a direct impact on how power moves throughout the Western Interconnection. The impact is especially pronounced on cross-Cascade power flow in Oregon along the defined Western Electricity Coordinating Council's (WECC's) "P05 South of Cascade" interface. This interface is largely responsible for transporting electricity from wind and solar resource-rich regions in Eastern Oregon, Idaho, and Wyoming to the Western Oregon load centers. One of the main questions this study sought to address was the extent to which offshore wind can alleviate flow along this corridor.

Figure ES-5 shows the hourly change in P05 flow between the offshore wind scenarios and scenarios with no offshore wind against the aggregate offshore wind generation in each hour. During hours of average power flows, we found a robust relationship of a 511-537 MW (depending on the scenario) decrease in flow along the P05 interface for every 1,000 MW of offshore wind generation. However, we found little correlation between hours of high P05 flow in the $0 \mathrm{GW}$ offshore wind base case and the hours of offshore wind generation. We found strong offshore wind potential during some hours of high P05 flow in the base case, which in turn reduced the flow along the P05 interface; however, during most hours of high P05 flow there was very little offshore wind generation, and thus P05 flow in those heavy hours was largely unchanged. This suggests offshore wind is not a good substitute for cross-Cascade transmission upgrades that might be needed to address reliability or resource adequacy concerns. However, more research using system reliability- and resilience-focused tools would be needed to more fully investigate this.

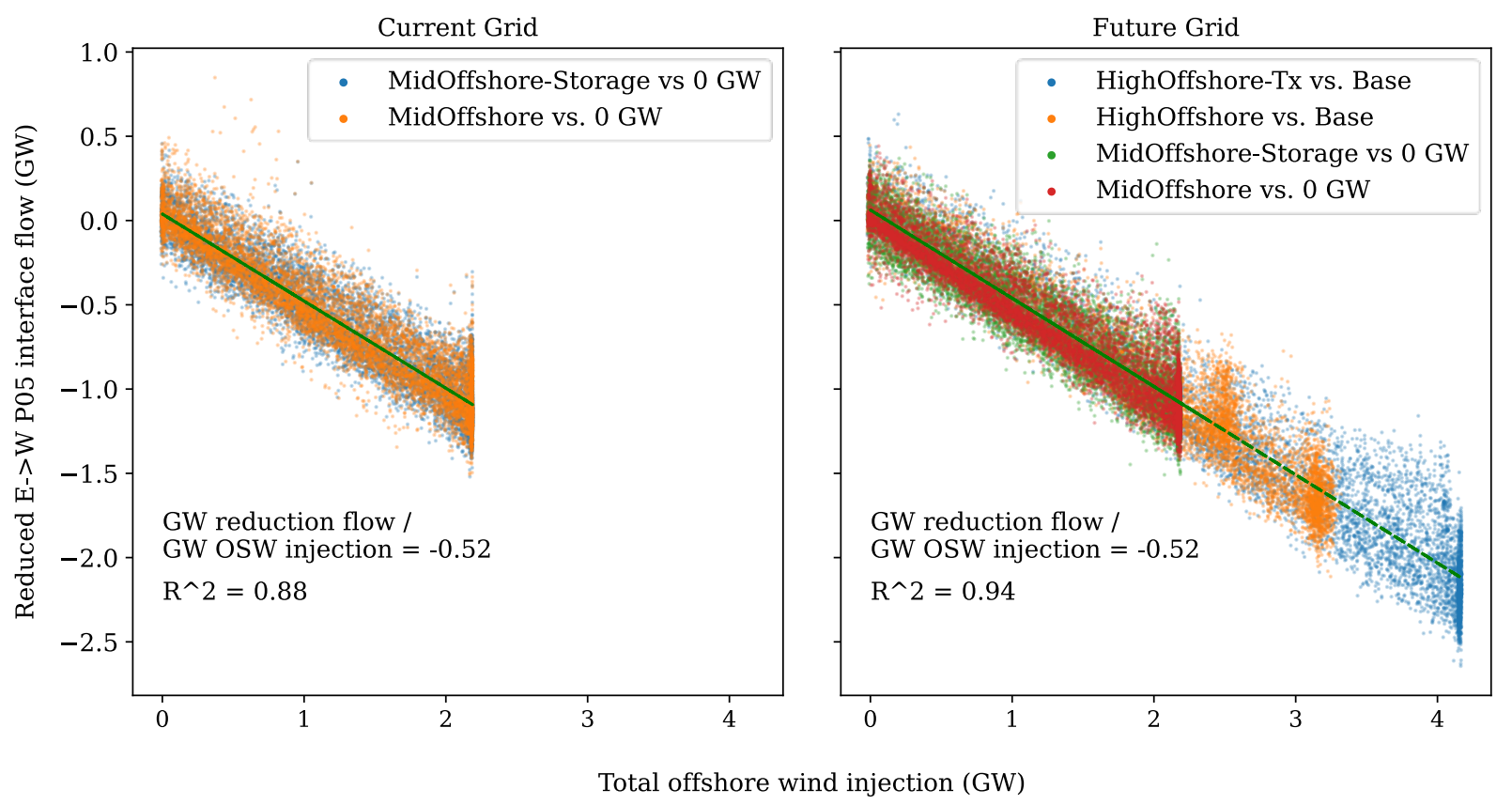

Figure ES-5: Reduced East to West P05 interface flow versus offshore wind injection at every hour of the year, for most scenarios studied in the current (left) and future (right) grid scenarios. The dotted green trendlines are fitted to each scenario. 


\section{Conclusion}

This analysis used high-resolution offshore wind data and a detailed PCM of the Western Interconnection to explore the value and operational impact of integrating offshore wind along Oregon's coastline. Leveraging local technical stakeholder expertise and input, we determined a set of scenarios to explore. These scenarios vary both offshore wind penetrations and the Western Interconnection generation and transmission infrastructure. This allowed us to determine how sensitive our findings were to changes to the rest of the system and to increasing penetrations of offshore wind. From the scenario modeling and analysis, we identified the following key findings:

- Trans-coastal transmission constraints and congestion are the key drivers to curtailment of Oregon offshore wind. Once power can be delivered into the Willamette Valley, there are few system constraints that lead to significant curtailment of offshore wind off the coast of Oregon.

- Approximately $2.6 \mathrm{GW}$ of installed offshore wind capacity can be integrated into Oregon's power system without major upgrades to trans-coastal transmission while avoiding significant curtailment. To reach $2.6 \mathrm{GW}$, the offshore wind capacity is not evenly distributed amongst coastal substations, rather the capacities were chosen based the ratings of the of associated trans-coastal transmission lines while maximizing southern offshore wind due to its superior capacity factor. ${ }^{10}$ Detailed power flow analysis is needed to refine the distribution of offshore wind, the total offshore wind capacity, and identify small upgrades to the trans-coastal system to enable or increase the $2.6 \mathrm{GW}$ finding.

- The range of system value ${ }^{11}$ provided by offshore wind ranges between $\$ 65 / \mathrm{MWh}$ and $\$ 85 / \mathrm{MWh}$ across the various scenarios considered. This range is above $\$ 63 / \mathrm{MWh}$, the average projected $2032 \mathrm{LCOE}$ for Oregon offshore wind reported (Musial et al. 2021). The value of offshore wind decreases slightly in the future grid scenarios as it would displace the use of more efficient gas generation and compete with more land-based VRE than in the current grid scenarios.

- We found that offshore wind heavily influences the flow along cross Cascade transmission. Across all scenarios we found a robust relationship of approximately 500-550 MW decrease in hourly flow along cross Cascade transmission for every 1,000 MW of hourly offshore wind generation. However, we also found there was not a strong relationship between the highest crossCascade transmission flow hours and high offshore wind generation, limiting the extent to which offshore wind can be considered a non-wires alternative to cross cascade transmission.

\footnotetext{
${ }^{10}$ It was assumed that the needed transmission infrastructure to reach coastal substations were a part of the offshore wind project and do not introduce any constraints to delivering offshore wind generation.

${ }^{11}$ The system value of offshore wind includes its operational, capacity, and emissions reduction value. The value excludes the costs to build the offshore wind and connect to onshore substations.
} 
- Depending on the meteorological year, ${ }^{12}$ offshore wind can serve between 84 $88 \%$ and $90-93 \%$ of the hourly coastal load in the Mid Offshore and High Offshore scenarios, respectively. While the capacity credit of offshore wind, when only considering coastal net load, ranges between $34-61 \%$ and $33-62 \%$ for the two scenarios. In other words, depending on the weather year, 880-1,580 MW and 1,650-3,100 MW can be counted on to serve coastal loads for the Mid Offshore and High Offshore scenarios, respectively.

- Offshore wind allows for more optimal daily and hourly scheduling of hydropower, while still complying with various technical and regulatory constraints on the water resource. In addition, based on the limited 7-year data set, we find there is little relationship between the inter-annual variability of offshore wind and water availability for hydro generation, and that water availability has little impact to the total system value of offshore wind.

- Oregon offshore wind has the potential to contribute to the evening net load peak in California (i.e., mitigate duck curve challenges), however transmission congestion between California and Oregon limit this contribution.

- Co-located storage at the point of interconnection for offshore wind reduces curtailment when trans-coastal transmission is not upgraded, providing a nonwires alternative to increase offshore wind capacity beyond 2.6 GW. Analysis of the storage operations suggests greater need to optimize the size and duration of the co-located storage.

${ }^{12}$ We studied the meteorological years of 2007-2013 for arrive at this finding. 


\section{Table of Contents}

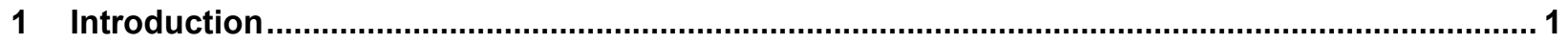

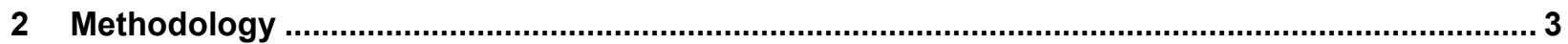

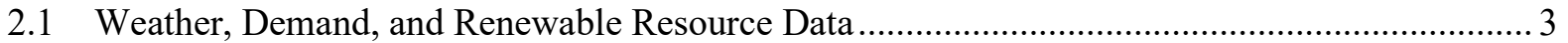

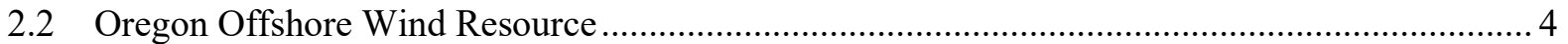

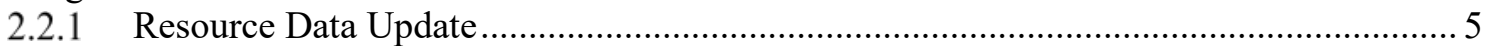

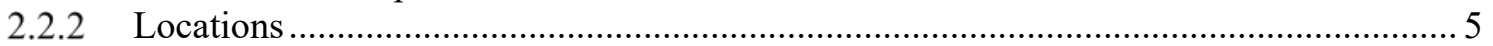

2.2.3 Conversion of Wind Resource Data to Power Profiles ................................................ 7

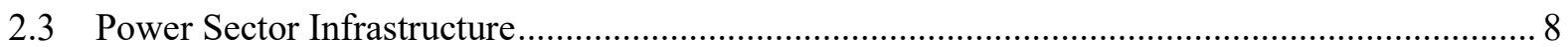

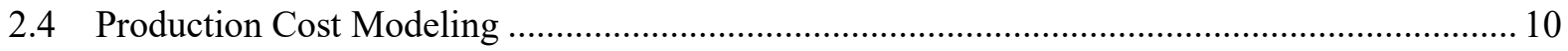

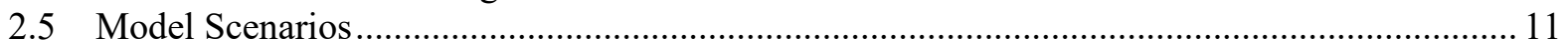

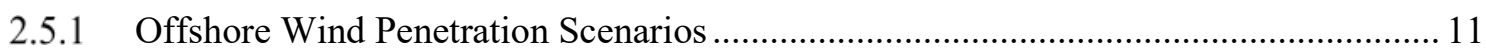

2.5.2 Trans-Coastal Transmission Upgrade Scenarios........................................................... 14

2.5.3 WECC Power Sector Infrastructure Scenarios........................................................ 14

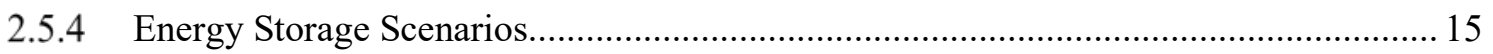

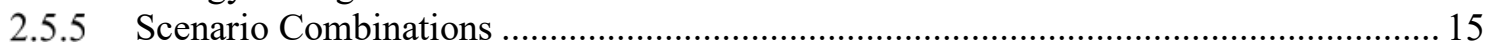

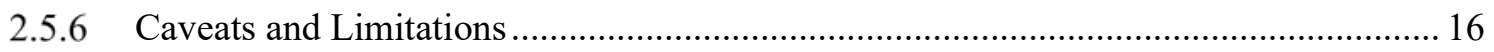

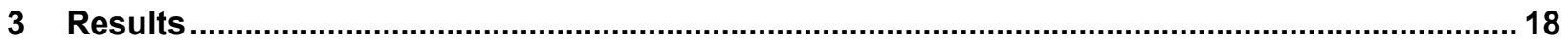

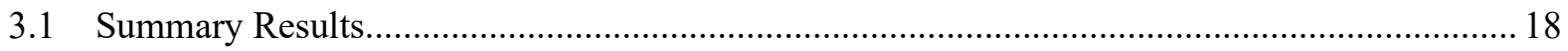

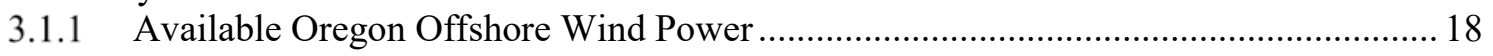

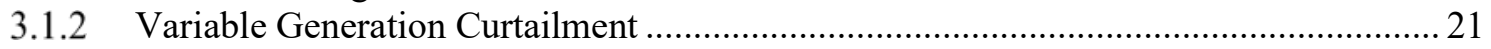

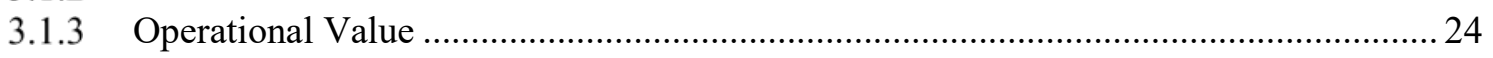

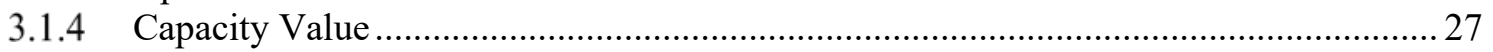

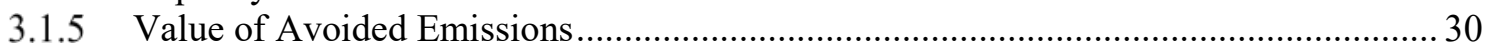

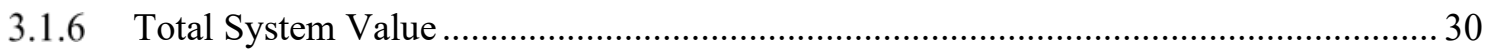

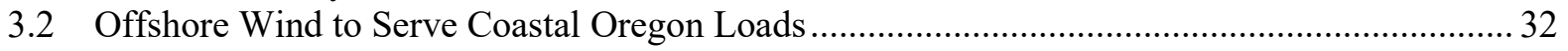

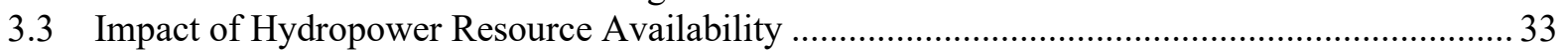

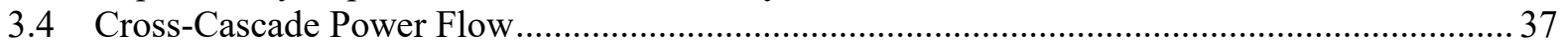

3.5 Opportunities for Offshore Wind to Mitigate Net Load "Duck Curve" Challenges ................... 47

3.6 Impact of Storage Co-Located with Offshore Wind ............................................................. 48

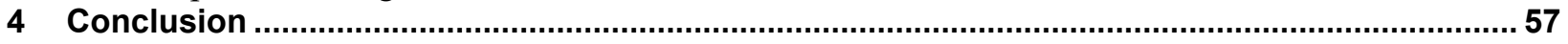

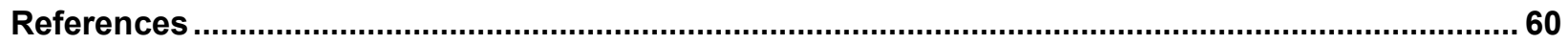




\title{
List of Figures
}

Figure ES- 1. Map of the trans-coastal transmission lines, which connect the offshore wind interconnection points to the $500-\mathrm{kV}$ line connecting Medford, Eugene, and Portland (the I-5 corridor in the Willamette Valley).................................................................................... ix

Figure ES- 2. Installed capacity in Western Oregon (left), Eastern Oregon (middle) and the Western Interconnection (right) for the current and future grid infrastructures, exclusive of the offshore wind and storage capacities evaluated in this study..............................................

Figure ES- 3. Curtailment of offshore wind at each point of interconnection for the four High Offshore wind penetration scenarios. Red textboxes show the total annual curtailed energy for select bars with large amount of curtailment.

Figure ES- 4. Total system value stacks for all scenarios studied, as compared to the associated $0 \mathrm{GW}$

offshore wind base case, for current scenarios (left) and future scenarios (right), modeled with the 2012 meteorological year.

\author{
ix
}

Figure ES-5: Reduced East to West P05 interface flow versus offshore wind injection at every hour of the
year, for most scenarios studied in the current (left) and future (right) grid scenarios. The dotted green and red trendlines are fit to the Mid Offshore-Storage scenario in the current grid and the High Offshore-Tx scenario in the future grid, respectively.

Figure 1. Total U.S. monthly hydro generation for 2007-2013 based on EIA-923 data ........................... 4

Figure 2. The PNW20 100-meter wind speeds for offshore wind (left) and the difference between the PNW20 and WIND Toolkit 100-meter wind speed (right) ............................................... 5

Figure 3. Offshore wind locations used to produce power profiles ....................................................... 7

Figure 4. First step in the reV pipeline. Although the full tool allows for deeper analysis of technical potential and cost estimation, this study only leveraged the reV's plant performance functionality.

Figure 5. Installed capacity in Western Oregon (left), Eastern Oregon (middle) and the Western Interconnection (right) for the model infrastructure years current and future. Offshore wind or storage capacity associated with the offshore wind are not included in these capacity plots. When we added various amounts of offshore wind and storage, the infrastructure shown here

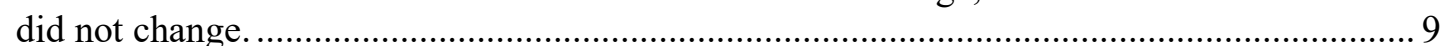

Figure 6. Example unit commitment and economic dispatch result from a PCM simulation ................... 11 Figure 7. Annual energy production and capacity factor of the offshore wind associated with each of the five points of interconnection for the available 20 historical weather years. The green line represents the median year, the blue dot shows the 2012 meteorological year, the main year we ran in our PCM. The edges of the boxes represent the $25^{\text {th }}$ and $75^{\text {th }}$ percentiles, while the ends of the whiskers represent 1.5 times the interquartile range.

Figure 8 . Daily average offshore wind generation. The blue shading shows the gap between the maximum and minimum average hourly values across the 20 -year data set. Similarly, the median profile plots the median average hourly value across the entire data set. ............................ 20

Figure 9. Generation duration curves for the entire 2000-2019 data set (left) and select years (right). The vertical dashed lines highlight the maximum and minimum percentages of time during which the offshore wind operates within $1 \%$ of their maximum output. This corresponds to 827 MW for individual plants and 4,128 MW for all aggregate offshore wind in the High Offshore penetration scenarios..

Figure 10. Total curtailment by variable generation source for the entire Western Interconnection (top) and for Eastern Oregon (bottom) for all scenarios studied in 2012.

Figure 11. Total curtailment by variable generation source for Eastern Oregon (left) and the entire Western Interconnection (right), averaged over all seven meteorological years 2007-2013. The red error bars represent the max and min from the 7-year data set. Western Oregon is not included in these plots because it experiences no curtailment in these three scenarios... 23 
Figure 12. Curtailment of at each of the five offshore wind points of interconnection for the four high offshore wind scenarios

Figure 13. Total generation change for all scenarios studied for 2012, for the entire Western Interconnection.

Figure 14. Total generation change for the entire Western Interconnection, averaged across all seven meteorological years. The 7-year range in reduced gas-CC generation is indicated with the red error bars.

Figure 15. Net change in production cost for the entire Western Interconnection for all offshore wind scenarios, compared to the $0 \mathrm{GW}$ offshore wind base case, run with the 2012 meteorological year. The dollar value is normalized by precurtailment offshore wind generation for each penetration (i.e., 10.6 TWh for the Mid Offshore scenario and 19.5 TWh for the High Offshore scenario).

Figure 16. Operational value (total net change in production cost) for the entire Western Interconnection, averaged across all seven meteorological years, compared to the 0 -GW offshore wind base case. The red error bars represent the maximum and minimum years. The dollar value is normalized by precurtailment offshore wind generation for each penetration (i.e., 10.6 TWh for the Mid Offshore scenario and 19.5 TWh for the High Offshore scenario).....................2

Figure 17. Correlogram for aggregate renewable resources in the Western Interconnection..................... 28

Figure 18. Distribution of estimated capacity credit for each site for the High Offshore, Future Grid scenario. Capacity credit is estimated by taking the average capacity factor of the offshore wind at each point of interconnection during the top 100 net load hours of the year for the Western Interconnection.

Figure 19. Total system value stacks for all scenarios studied, as compared to the associated 0-GW offshore wind base case, for current grid infrastructure scenarios (left) and future grid infrastructure scenarios (right), modeled with the 2012 meteorological year.

Figure 20. Total system value stacks for offshore wind, averaged across all seven meteorological years, compared to the $0-\mathrm{GW}$ offshore wind base case. The red error bars represent the maximum and minimum years. In both cases, the Start \& Shutdown Cost (green) is a small negative system value.

Figure 21. Summary of the available hydropower resource in the Western Interconnection in each meteorological year, as measured by the total annual hydropower generation. The y-axis plots offshore wind availability for context, with total annual generation in (left) and capacity credit (right). 2008 has the lowest deviation from the mean hydropower generation.

Figure 22. Diurnal average hydro generation curves, by season, for the four water years studied in this section. In high water resource years, hydropower contributes to both evening and morning load peaks in winter and spring. By contrast, hydro generators conserve water in low-water

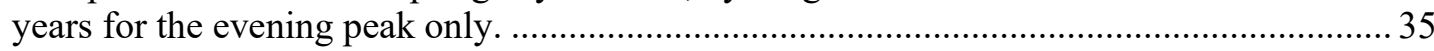

Figure 23. Total annual generation change for the low-, high-, and very high-water years relative to the "normal" water year of 2008

Figure 24. Total curtailment (total generation divided by total resource availability) in the High OffshoreFG-Tx transmission scenario for years with different hydropower resource availability. Eastern Oregon is shown on the left, and the full Western Interconnection is shown on the

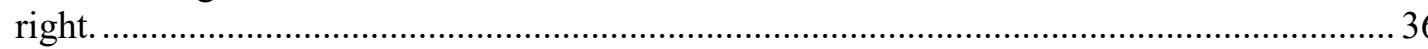

Figure 25. Total system value stacks for offshore wind, averaged across different hydropower resource

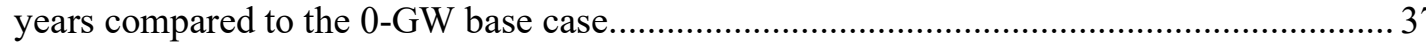

Figure 26. Electrical transmission map of Oregon, including the offshore wind sites and their points of interconnection. The "P05 West of Cascades-South" interface is shown with the yellow arrow.

Figure 27. Reduced East to West P05 interface flow versus offshore wind injection at every hour of the year, for most scenarios studied in the current (left) and future (right) grid scenarios. The 
dotted green and red trendlines are fit to the Mid Offshore-Storage scenario in the current grid and the High Offshore-Tx scenario in the future grid, respectively.

Figure 28. Dispatch stacks for the three-day period surrounding the highest P05 flow reduction day, for Western Oregon (left) and Eastern Oregon (right). P05 hourly flow is shown with the dotted red line. December 22 also corresponds to the second highest offshore wind generation day. No Eastern Oregon curtailment is observed during this period.

Figure 29. Dispatch stacks for the three-day period surrounding the day with the highest curtailment in Eastern Oregon, June 9, for Western Oregon (left) and Eastern Oregon (right). P05 flow is shown with the dotted red line.

Figure 30. Summary of a three-day period with no P05 flow reduction, shown with total generation difference by technology type (left) and time series dispatch stacks (right). The black line on plots on the left is the net generation change relative to the Base-FG scenario...................... 44

Figure 31. Flow duration curve of the P05 interface for all three offshore wind penetration scenarios in future. Data from all seven meteorological years is combined........................................... 45

Figure 32. Offshore wind performance during the 0-GW offshore wind base case P05 summer flow hours (June through October). The set of violin plots breaks every hour of the summer into 1-GW bins. Data from all seven meteorological years is combined.

Figure 33. Offshore wind performance during the 0-GW offshore wind base case P05 winter flow hours (January-May, November-December). The set of violin plots breaks every hour of the winter into 1-GW bins. Data from all seven meteorological years is combined.

Figure 34. Net load plots for example days in CAISO, which illustrate the famous "duck curve" behavior. Net imports from Oregon and offshore wind generation are also plotted. The left plot is a day with high offshore wind resource and noticeable changes in Oregon to California imports, while the right plot is a day with little to no offshore wind.

Figure 35. Duration curves for all hours that represent opportunities where larger storage might further reduce offshore wind curtailment. The orange and blue lines represent hours where curtailment reduction opportunities might be provided by upgrading the storage power and capacity, respectively.

Figure 36. Dispatch stacks for Western Oregon during three-day periods with short-term dips in wind resource.

Figure 37. Dispatch stacks for Western Oregon during a three-day period with multiday wind droughts. 53 Figure 38. Dispatch stack for the three days surrounding the day with the highest change in Clatsop to Driscolt flow due to the addition of energy storage (left), along with the total generation change for these three days (right). Both scenarios include High Offshore penetration and trans-coastal transmission expansion. The difference in Clatsop to Driscolt flow is plotted in the dispatch stacks with the dotted red line along the right axis. Positive values indicate more easterly flow in the energy storage scenario.

Figure 39. Duration curves plotting the difference in flow for all relevant trans-coastal transmission lines, between the two High Offshore future upgraded trans-coastal transmission scenarios with and without storage. In general, a reduction in flow (storage-no storage) across the transcoastal range to the I-5 corridor is indicated by positive values. However, in plots marked by a single asterix, this reduction is indicated by negative values. The Toledo to Wendson line, marked by a double asterix, flows north to south from the Florence node to the Coos Bay node.

Figure 40. Impact of trans-coastal transmission upgrades on energy storage dispatch. The duration curve on the left plots the change in net energy storage generation (dispatch-charging) between the upgraded and existing trans-coastal transmission scenarios. 56 


\section{List of Tables}

Table ES- 1. All Scenario Combinations Studied in the PCM vii

Table ES- 2. Max Penetration of Offshore Wind That Can Be Accommodated by the Existing Transmission System ... $\mathrm{x}$

Table 2. Summer Thermal Limits of the Trans-Coastal Transmission Lines Responsible for Delivery of Offshore Wind Energy

Table 3. Max Penetration of Offshore Wind That Can Be Accommodated by the Existing Transmission System.

Table 4. All Scenario Combinations Studied in the PCM ...................................................................... 16

Table 5. Capacity Value of Offshore Wind for Different Scenarios..................................................... 30

Table 5. Percentages of Hourly Local Coastal Load That Is Servable by the Offshore Wind Associated with Each Point of Interconnection....................................................................................... 33

Table 6. Annual Flow Reduction on the P05 Interface for all Scenarios With Offshore Wind Generation39 Table 7. Additional Curtailment Opportunities for Each Co-Located Offshore Wind Energy Storage Generator, Broken Down by Constraint Type 


\section{Introduction}

Offshore wind generation could be on the cusp of becoming a major contributor to the electricity system in the United States over the next decade. This is due to both expected system cost reductions and a combination of recent state and federal policy goals. In March 2021, the U.S. set a target to deploy $30 \mathrm{GW}$ of offshore wind by 2030. In addition, California directed its Energy Commission to quantify the maximum feasible capacity of offshore wind by June 1 , 2022. Finally, eight mid-Atlantic states have committed to building over $35 \mathrm{GW}$ of offshore wind by 2035 and 39 GW by 2040 .

While much of the offshore wind development is focused on fixed-bottom turbines in the relatively shallower waters of the East Coast, the Pacific states, especially Oregon, are home to some of the strongest and most consistent winds in North America (Musial et al. 2019) and in the Western Interconnection in particular (Jorgenson et al. 2021). In Oregon, a bill passed in 2021 directs the Oregon Department of Energy to conduct a literature review on the benefits and challenges of integrating up to $3 \mathrm{GW}$ of floating offshore wind by $2030 .{ }^{13}$ Furthermore, a 2021 announcement between the State of California and the federal government ${ }^{14}$ suggests growing momentum for offshore wind along the Pacific Coast.

A 2019 study of Oregon offshore wind found that $97 \%$ of the $62 \mathrm{GW}$ of available technical potential for offshore wind development is in water depth greater than 60 meters (Musial et al. 2019). Deeper waters pose significant engineering, construction, and cost challenges for fixedbottom turbines. Therefore, turbines off the Oregon coast must be anchored using costlier floating platform technology. While this type of anchoring can be more costly, Musial et al. estimated that the cost of deploying this nascent floating technology off the coast of Oregon could decrease by $50 \%$ in the coming decade. The study found the levelized cost of energy (LCOE) for the highest quality sites along Oregon's southern coast dropping to \$51/MWh by 2032, roughly equivalent to today's LCOE of a new natural gas combined cycle (gas-CC) (Lazard 2020).

Douville et al. 2020 analyzed the system effects of integrating various levels of offshore wind off the coast of Oregon. The results showed that $2 \mathrm{GW}$ of offshore wind could be integrated into the existing transmission network without significant curtailment, but curtailment quickly increases once $3 \mathrm{GW}$ and more offshore wind is installed. Douville et al. 2020 also provided insights regarding the impact of offshore wind on transmission flow along key transmission corridors in Oregon. For example, Douville et al. 2020 found the utilization of the cross-Cascade transmission corridor to reduce by up to $1.5 \mathrm{GW}$ with increasing offshore wind penetration.

Other studies have investigated offshore wind's unique impact and value proposition to the power system along the East Coast. Using a production cost model (PCM), Beiter et al. 2020 considered the system impacts of integrating a large amount of offshore wind in New York and New England's power system. Mills et al. 2018 used historical wholesale electricity and

\footnotetext{
${ }^{13}$ https://olis.oregonlegislature.gov/liz/2021R1/Measures/Overview/HB3375

${ }^{14} \mathrm{https}$ ://www.gov.ca.gov/2021/05/25/california-announces-historic-agreement-with-federal-partners-to-advanceoffshore-wind-development/
} 
renewable energy credit prices to estimate the market value of offshore wind sites along the Atlantic seaboard.

The objective of our analysis is to build on previous work investigating offshore wind integration in Oregon (Douville et al. 2020) and in the U.S. Northeast (Beiter et al. 2020) by analyzing how future power generation and transmission systems will operate the inclusion of offshore wind. The analysis provides insights to system planners and policymakers so they can address key system constraints and maximize the value offshore wind could bring to Oregon and the broader Western Interconnection. Similar to the approach taken in Beiter et al. 2020 and Douville et al. 2020, we utilized a PCM to simulate system dispatch and analyze the operational impacts of the integration of offshore wind. While Douville et al. 2020 focused on many levels of offshore wind deployment, we selected a few key levels of offshore wind and varied the grid infrastructure characteristics of the rest of the system. Most notably, we varied the land-based variable renewable energy (VRE) penetration, degree of transmission infrastructure investment, and colocating energy storage at the point of interconnection for offshore wind. We also tested the sensitivity of the findings to different weather patterns by modeling multiple historical weather years. 


\section{Methodology}

In this section, we describe the development of future power system scenarios, characterize the offshore wind data applied to those scenarios, and highlight the production cost modeling approaches used to evaluate offshore wind integration. These approaches are common among similar large-scale renewables grid integration studies, such as Brinkman et al. 2021 and Novacheck et al. Forthcoming.

\subsection{Weather, Demand, and Renewable Resource Data}

Operational modeling and assessment of future high-renewable systems require high-resolution temporal and spatial data sets. The offshore wind data comes from a new state-of-the-art 20-year data set called PNW20 that is described below in Section 2.2. Land-based wind profiles leveraged the National Renewable Energy Laboratory (NREL) Wind Integration National Dataset (WIND) Toolkit (Draxl et al. 2015), ${ }^{15}$ which is the flagship wind resource data set for grid integration studies. This data set provides gridded wind resource at $2-\mathrm{km}$ resolution. The original temporal interval is 5 minutes, though only 60 -minute data was used for this project. The data set is seeded with reanalysis data from 2007-2013 to model the weather conditions from those years, and this define the historical meteorological years available in this study.

Solar resource data are available from the NREL National Solar Resource Database (NSRDB) ${ }^{16}$ (Sengupta et al. 2018) from 1998 and are regularly updated with new data. The native resolution of the solar data is $4 \mathrm{~km}$, and the temporal resolution is 30 minutes.

To create hourly generation profiles for new wind and solar plants for the two infrastructure scenarios, we utilized the combination of two NREL tools, the Renewable Energy Potential geospatial platform (reV) (Rossol, Buster, and Bannister 2021; Maclaurin et al 2019) and the NREL System Advisor Model (SAM).${ }^{17} \mathrm{reV}$ determines the location of new variable generation based on the lowest LCOE and transmission, transmission infrastructure, and other geographic information and constraints. SAM then produces generation profiles for the sites chosen by reV using resource data from the WIND Toolkit and NSRDB and system configuration and technology assumptions for the turbines or photovoltaic (PV) systems. Wind turbine assumptions used to generate hourly profiles assumed future technology performance projections as described in the NREL ATB 2019. We assumed PV systems were single-axis tracking and had an inverterloading ratio of 1.3. Distributed PV was modeled using a diversity of tilt angles and orientations.

The regional hourly load profiles for this study are based on the historical electricity demand for each corresponding meteorological year (2007-2013). To scale these profiles to the current and future infrastructure years, we applied load multipliers taken from the U.S. Energy Information Administration Annual Energy Outlook 2018 reference scenario's yearly demand growth projections. This simple scaling method neglects the potentially significant changes to the shape of electricity demand curves that will likely occur due to widespread electric vehicle adoption,

\footnotetext{
15 "Wind Integration National Dataset Toolkit," NREL, https://www.nrel.gov/grid/wind-toolkit.html.

16 "NSRDB: National Solar Radiation Database," NREL, https://nsrdb.nrel.gov.

17 "System Advisor Model (SAM)", NREL, https://sam.nrel.gov.

"Renewable Energy Potential (reV)", NREL, https://www.nrel.gov/gis/renewable-energy-potential.html.
} 
demand response technologies, and behind-the-meter storage. Incorporating these effects requires a bottom-up approach to load shape projections, which is beyond the scope of this study.

For hydropower units that have a reservoir and the flexibility to be dispatched, we defined monthly energy limits based on reported generation from the U.S. Energy Information Administration's Form EIA-923. ${ }^{18}$ These data are specified at the facility level. Figure 1 plots these monthly hydro energy limits. This approach is similar to that taken by O'Connell et al. 2019 and is described in further detail in Novacheck et al. Forthcoming. Other constraints on hydropower units, such as minimum generation levels, ramp rates, and identifying run-of-river units, are based on data collected for Brinkman et al. 2021.

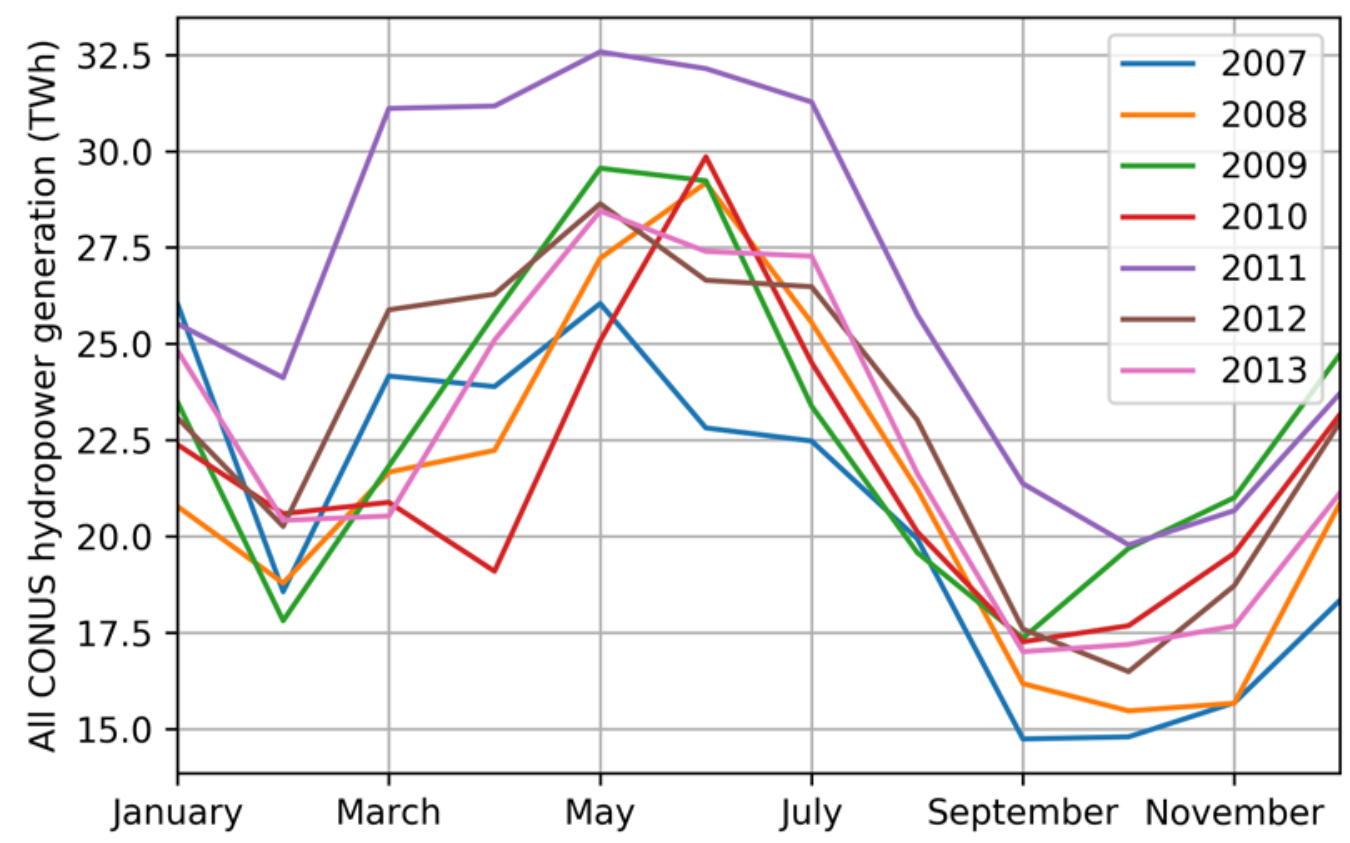

Figure 1. Total U.S. monthly hydro generation for 2007-2013 based on EIA-923 data

Taken together, these data comprise our own historical, high temporal, and spatial resolution data set of weather, electricity demand, hydropower potential, wind resource, and solar resource covering 2007-2013. Combining our data set with the assumed wind and solar generator locations for the current and future infrastructure years allows us to assess how much energy larger amounts of VRE capacity would produce if the same weather were to occur in the future.

\subsection{Oregon Offshore Wind Resource}

In this section, we explain the specifics of the Oregon offshore wind data, site selection, and the process to convert weather data into generation profiles for 2000-2019.

\footnotetext{
18 "Form EIA-923 Detailed Data with Previous Form Data (EIA-906/920)," EIA, October 29, 2020, https://www.eia.gov/electricity/data/eia923/.
} 


\subsubsection{Resource Data Update}

The offshore wind resource used in our PCM is taken from a 20-year wind resource data set, called the PNW20 released in 2021, produced using the Weather and Research Forecasting model. ${ }^{19}$ These data replace NREL's previous WIND Toolkit for offshore waters and cover the period 2000 through 2019 and use updates to the Weather and Research Forecasting modeling for California offshore wind modeling described in Optis et al. 2020. Figure 2 shows an increase in the 100-meter wind speeds throughout the Pacific Northwest over the existing WIND Toolkit data.
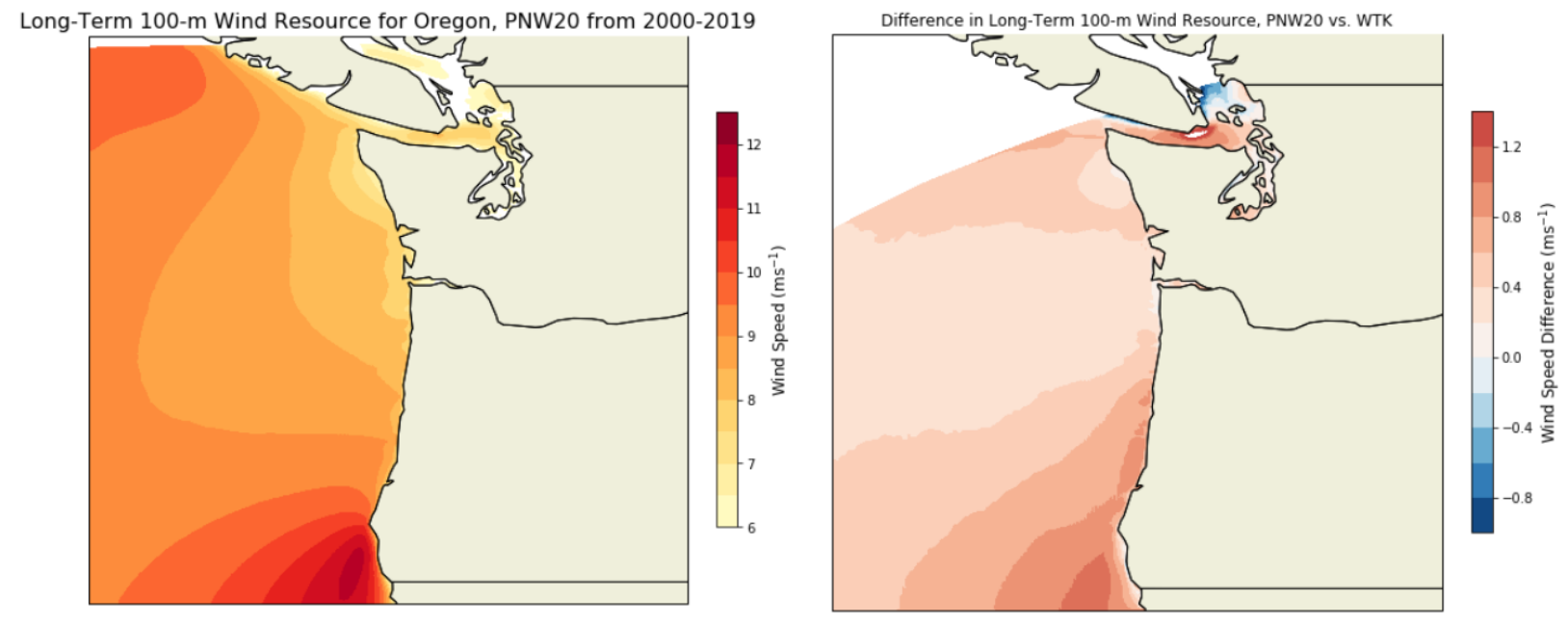

Figure 2. The PNW20 100-meter wind speeds for offshore wind (left) and the difference between the PNW20 and WIND Toolkit 100-meter wind speed (right)

While the full 20-year range is analyzed below, our available historical data for all other model inputs (i.e., land-based wind generation, solar generation, and regional load) only covers 20072013. We ran PCM analyses with synchronous data for all of these years, with some analysis focused specifically on 2012 .

\subsubsection{Locations}

A previous NREL study (Musial et al. 2019) identified technically viable locations for large wind projects off the Oregon coast. These locations, chosen with the input of the Pacific Ocean Energy Trust and the Trust's geographic information system subcontractor Parametrix, were based on the following criteria: water depth less than $1,000 \mathrm{~m}$, average wind speeds greater than $7 \mathrm{~m} / \mathrm{s}$, distances greater than $10 \mathrm{~nm}$ offshore to mitigate possible detrimental visual impacts to coastal communities, avoidances of overlap with subsea communication and data cables (North American Submarine Cable Association 2019), and overlap with the WindFloat Pacific Project site (west of Coos Bay, Oregon), which was proposed in 2014 as part of the DOE's advanced wind energy technology demonstration projects. Figure 3 shows the five selected study sites along with their points of interconnection. We assume the submarine transmission infrastructure to connect the offshore wind site to the land-based substations are direct radial connections and

\footnotetext{
${ }^{19}$ https://www.nrel.gov/news/program/2021/offshore-wind-data-release-propels-wind-prospecting.html
} 
sized such that the maximum output, after losses, from each site can be delivered to the onshore network. In other words, these radial connections would not introduce additional constraints to what is already modeled. The submarine transmission infrastructure will need additional investment and design, but such granular detail is outside the scope of this system-wide grid integration report and would be more appropriately captured in a developer's feasibility study.

The site selection described above is only based on technical feasibility and does not imply that the sites have been deemed suitable for development. Before any offshore sites could be developed, a comprehensive stakeholder engagement process would need to be conducted. The engagement process would need to address: proximity to installation and service ports, proximity to land-based substations for electrical grid interconnection, bathymetry, slope, critical habitat and habitat conservation areas, marine protected areas, areas of cultural significance, and fishing activity, to name a few critical considerations. While Musial et al. 2019 incorporated some of these considerations, they did not significantly drive the site selections.

For the purpose of this integration study, the offshore wind sites are only used to generate realistic wind power profiles for use in the PCM. Ideal locations for offshore wind development may be outside of the sites shown in Figure 3. The site 1-North is connected to the Clatsop substation, 2-North Central to the Tillamook substation, 3-Central to the Toledo substation, 4South Central to the Wendson substation, and 5-South to the Fairview substation. The five substations identified were chosen as viable $230-\mathrm{kV}$ substations close to the coastline. Members of our technical working group, including experts from the Bonneville Power Agency (BPA), the Oregon Department of Energy, Pacific Northwest National Laboratory, the Bureau of Ocean Energy Management, PGE, and others assisted in the selection of substations. For the remainder of the document, we refer to the five study sites for offshore wind based on their point of interconnection, from north to south as follows: Clatsop, Tillamook, Toledo, Wendson, and Fairview. As mentioned above, we have not considered the design or costs of connecting these offshore sites to the coastal substations using submarine infrastructure. 


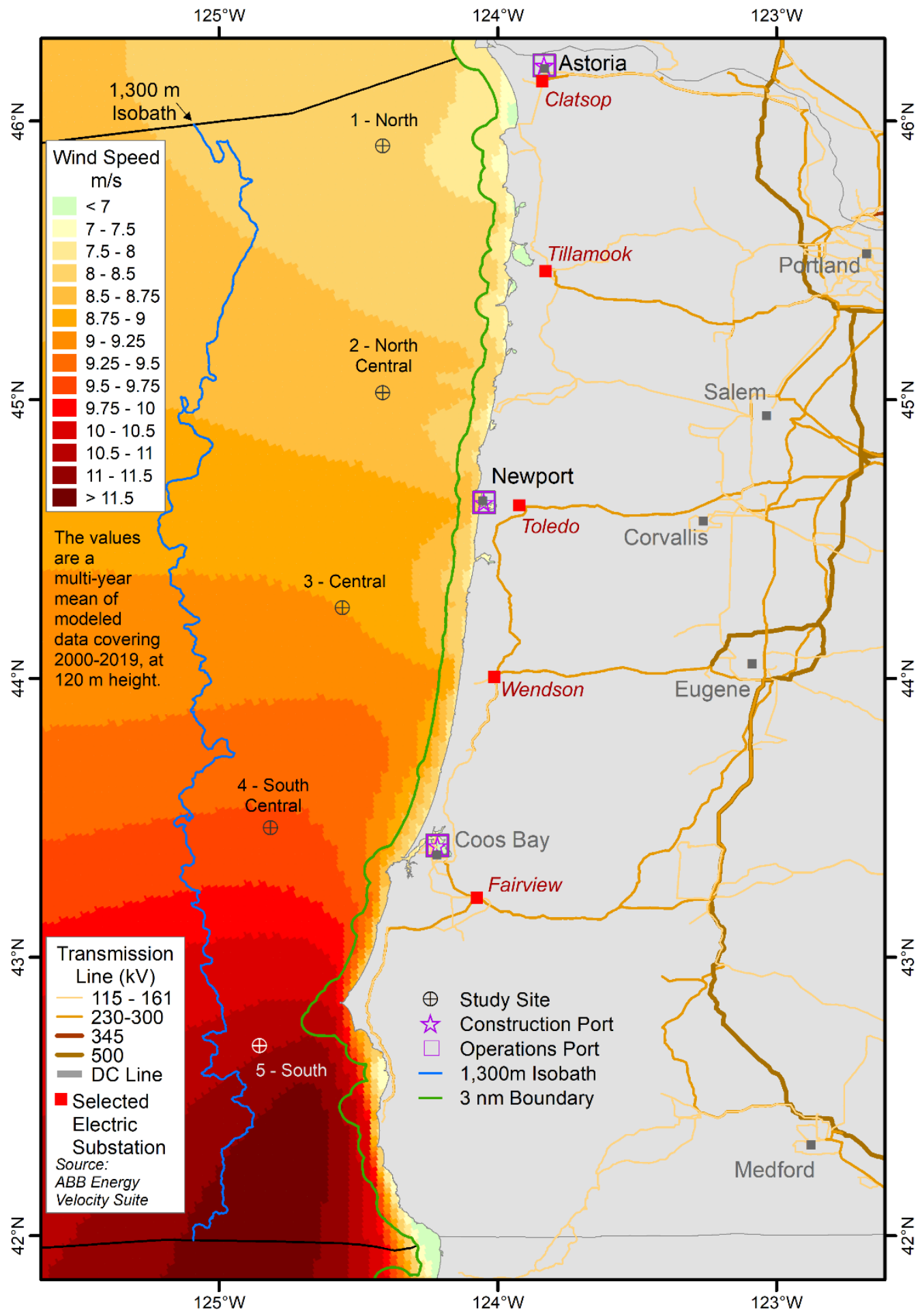

Figure 3. Offshore wind locations used to produce power profiles

\subsubsection{Conversion of Wind Resource Data to Power Profiles}

NREL's tool for estimating electrical power output from weather data and renewable plant assumptions is SAM. To estimate representative wind power profiles in the areas shown in 
Figure 3, we utilized the reV tool. As shown in Figure 4, one of reV's core features is the application of SAM's techno-economic algorithm to gridded layers (i.e., spatially continuous layers) of renewable resource data. We set the SAM wind plant system specifications to match the NREL 12-MW reference turbine and calculated hourly generation potential for each $2 \mathrm{~km} \mathrm{x} 2$ $\mathrm{km}$ grid cell. According to Musial et al. 2019, this sized turbine is expected to be available in 2027. This turbine choice was suggested by offshore wind technology experts at NREL. Due to internal losses, the maximum output at each site is limited to $83.4 \%$ of nameplate capacity. Internal losses are due to wake losses, turbine availability and performance losses, electrical losses in collector lines, transformers, and other equipment, and environmental losses, ${ }^{20}$ but it does not factor in losses associated with transporting the offshore wind energy to the coastal substation.

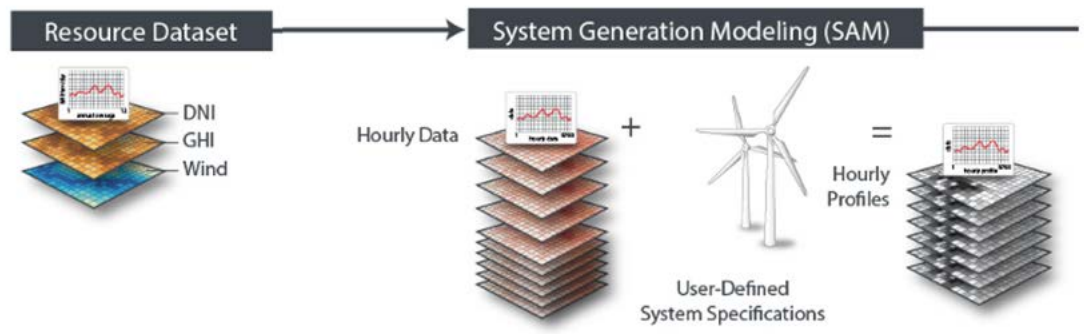

Figure 4. First step in the reV pipeline. Although the full tool allows for deeper analysis of technical potential and cost estimation, this study only leveraged the reV's plant performance functionality.

Musial et al. 2019 limited their study to a maximum of $5 \mathrm{GW}$ of total offshore wind capacity along the Oregon coast, 1,000 MW at each of the five sites. We used this value for our maximum offshore wind build out scenario as well.

\subsection{Power Sector Infrastructure}

To assess the impact of offshore wind deployment into systems with different levels of VRE, we leveraged power sector infrastructures with varying penetrations of wind and solar generation.

These scenarios, which have been utilized across several production cost studies, were developed using the NREL's primary capacity expansion tool, ReEDS. ReEDS simulates electricity sector investment decisions based on system constraints and demands for energy and ancillary services (Brown et al. 2020). The model determines co-optimized generation and transmission expansion to determine the least-cost system needed to satisfy regional demand requirements and maintain grid system adequacy. Specifically, ReEDS identifies the type and location of thermal and renewable resource deployment, as well as a transmission infrastructure expansion to accommodate those installations. Behind-the-meter, distributed PV capacity was included in the infrastructure with NREL's Distributed Generation Market Demand (dGen) model. It simulates customer adoption of distributed energy resources for residential, commercial, and industrial entities. ${ }^{21}$ For more information on how the ReEDS and dGen models were used to produce a

\footnotetext{
${ }^{20}$ For more information about these internal plant losses, consult the SAM help from within the software or on the online forum at https://sam.nrel.gov/forum.html.

21 “Distributed Generation Market Demand Model.” NREL, https:/www.nrel.gov/analysis/dgen/.
} 
PCM for the Eastern, Western, and Texas Interconnections, see Novacheck et al. Forthcoming. For this study, we reduced the PCM used in Novacheck et al. Forthcoming to just the Western Interconnection. ${ }^{22}$

For this study, we focused on two power system infrastructures for the Western Interconnection - a system that represents the infrastructure expected in current, and a future system with a larger penetration of VRE nominally representing the year future. ${ }^{23}$ Figure 5 shows the resulting generation types in the two infrastructure scenarios. The future system experiences significant growth in eastern Oregon of utility scale PV, distributed PV, and landbased wind over the current system. For the purposes of this study, "Eastern Oregon" refers to the portion of the state east of the Cascade mountain range. As penetration increases in eastern areas far from the load centers of Portland and Seattle, the existing cross-Cascade transmission infrastructure may become stressed. One of the research topics this study aims to address is the extent to which offshore wind deployment in western Oregon can alleviate this stress.
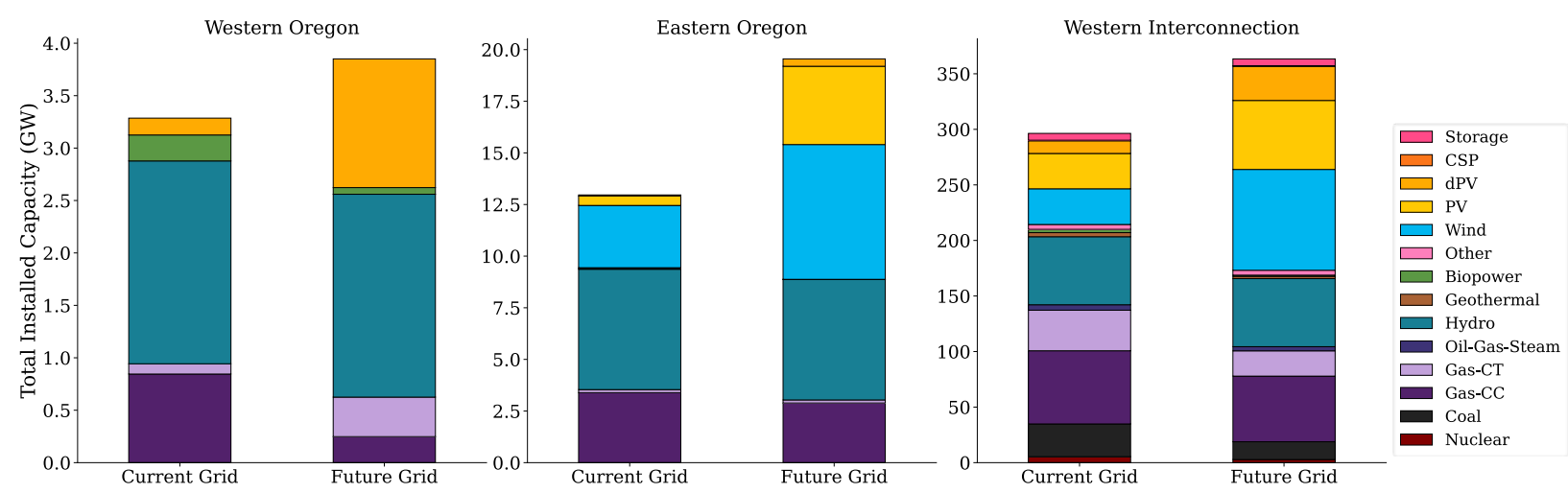

Figure 5. Installed capacity in Western Oregon (left), Eastern Oregon (middle) and the Western Interconnection (right) for the model infrastructure years current and future. Offshore wind or storage capacity associated with the offshore wind are not included in these capacity plots. When we added various amounts of offshore wind and storage, the infrastructure shown here did not change.

As part of the co-optimization of generation and transmission, ReEDS also builds new transmission between its zones. The new transmission capacity is translated to the nodal PCM by adding new transmission lines connecting substations that represent the expanded pathways built out by ReEDS. Table 1 lists the new capacity between power sector zones. The new transmission is including in the modeling of the future system and does influence the results, and we did not attempt to isolate the value or the reliance the future system has to these new lines. The capacity of key trans-coastal transmission corridors rated at $230 \mathrm{kV}$ and above were updated based on the advice of the transmission engineering department of the BPA. Due to line sag from solar heating and other factors, line flow limits are generally lower in the summer. As advised by BPA, we defined separate limits for summer (June through September) and winter. Even with

\footnotetext{
22 The future generation infrastructure are based on policies as of 2019. The clean electricity penetration of the future system falls below what is needed to achieve the carbon pollution-free power sector by 2035 goal set by President Biden and may not be consistent with recent legislation in Oregon (i.e., HB 2021).

${ }^{23}$ The resulting clean electricity penetrations of the current and future were developed before the announcement of targets set forth by the Biden administration and are lower than those targets.
} 
these specific updates, our study still involves abstractions typical of transmission representation in PCMs. Our results do not fully capture real operating conditions due to topology approximations (we largely ignore low voltage lines) and limitations of representing commercial constraints. These limitations include the availability of short- or long-term transmission products, regional transmission organizations, and the existence of power delivery contracts between transmission operators, generators, and load-serving entities.

Table 1. Expanded ReEDS Transmission Capacity Between FERC Order 1000 Regions From 2024 to 2036.

\begin{tabular}{|lll|}
\hline Zone From & Zone To & $\mathbf{2 0 3 6}$ \\
\hline CAISO & West Connect & $422 \mathrm{MW} \mathrm{(9 \% )}$ \\
\hline Columbia Grid & Canada & $523 \mathrm{MW} \mathrm{(349 \% )}$ \\
\hline Columbia Grid & Northern Tier & $1,027 \mathrm{MW}(14 \%)$ \\
\hline Columbia Grid & West Connect & $12 \mathrm{MW} \mathrm{(24 \% )}$ \\
\hline West Connect & Mountain West & $0 \mathrm{MW} \mathrm{(0 \% )}$ \\
\hline West Connect & Northern Tier & $929 \mathrm{MW} \mathrm{(91 \% )}$ \\
\hline West Connect & SPP & $340 \mathrm{MW} \mathrm{(110 \% )}$ \\
\hline
\end{tabular}

\subsection{Production Cost Modeling}

To examine the system value and operational changes of integrating offshore wind along the Oregon coast, we used a detailed database of the Western Interconnection generation and transmission system described in the above section and performed production cost modeling. We simulated system operations using a commercial software from Energy Exemplar called the PLEXOS Integrated Energy Model (PLEXOS). ${ }^{24}$ As a unit commitment and economic dispatch simulation model, PLEXOS optimizes operation of the generation mix to minimize overall production cost while observing various constraints such as generator minimum operating levels, ramp rates, reserve requirements, transmission thermal and interface flow limits, and more. Full details on assumptions and set up of the nodal Western Interconnection PCM can be found in Brinkman et al. 2021. Figure 6 shows an example result from a PCM simulation demonstrating the hourly unit commitment and economic dispatch of different generation technologies and fuel types to serve system load. This simulation assumes all dispatchable generators and storage controllers have perfect 24-hour foresight with 4-hour resolution, including perfect wind, solar, and load forecasts.

24 “PLEXOS Market Simulation Software,” Energy Exemplar, https://energyexemplar.com/solutions/plexos/. 


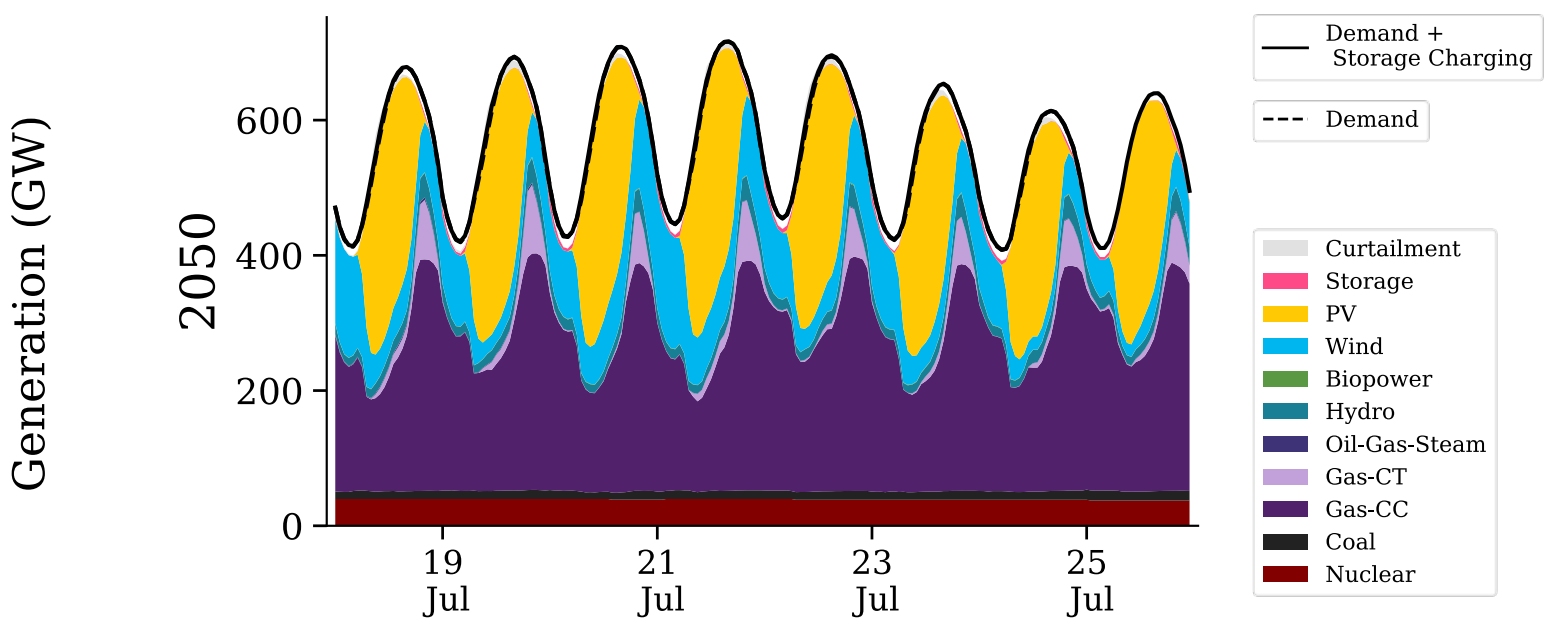

Figure 6. Example unit commitment and economic dispatch result from a PCM simulation

We ran the PCM for a full year of system operations for the seven weather years of 2007-2013 with different power system infrastructure scenarios, described in the next section. Applying the synchronous time-series wind, solar, load, and hydro data to a future system infrastructure allows investigation of that system's possible reaction to consistent historical weather. By running all seven historical weather years, we allow for greater confidence in the results, especially in the face of annual changes in the hydro availability (i.e., wet and dry years).

\subsection{Model Scenarios}

Our design of the PCM scenarios were overseen and approved by a diverse stakeholder group comprised of technical experts from Pacific Northwest National Laboratory, BPA, the Oregon Department of Energy, the Bureau of Ocean Energy Management, and the Pacific Ocean Energy Trust. Throughout the course of several meetings, the following modeling levers were identified as most relevant:

- Total offshore wind penetration, between 0 and $5 \mathrm{GW}$

- Trans-coastal transmission expansion. "Trans-coastal transmission" refers to the corridors that connect the sparsely populated coast to the I-5 corridor in the Willamette Valley across the Coastal Range.

- Model infrastructure year (current, 2024 and future, 2036). As discussed earlier, future includes significant deployment of solar PV and land-based wind in eastern Oregon and beyond.

- Addition of energy on the coast at the same interconnection point as the offshore wind

- Historical meteorological years (2007-2013)

\subsubsection{Offshore Wind Penetration Scenarios}

In their recent analysis, Douville et al. 2020 studied the impact of all offshore wind penetration levels from 0 to $5 \mathrm{GW}$, with an increment of $1 \mathrm{GW}$. Rather than reproduce the same offshore wind penetration scenarios, we focused on three levels: a reference case $(0 \mathrm{GW})$, a highpenetration case $(5 \mathrm{GW})$, and a case that assumed the maximum offshore wind capacity that could be integrated with the current trans-coastal transmission infrastructure $(2.6 \mathrm{GW})$. 
As described in Section 2.2.3, Musial et al. 2019 published a study focused on the cost feasibility of wind energy off the coast of Oregon, with an update in 2021 (Musial et al. 2021). This study estimated the maximum technical potential of offshore wind-respecting the aforementioned considerations of important nonpower uses along the coast - to be just about 1,080 MW at each site. These results informed our High Offshore scenario, which places 1,000 MW at each site. As neither the previous study nor this one represents a comprehensive assessment of the development potential of the entire Oregon coast, more than $5 \mathrm{GW}$ of floating offshore wind may be possible in the region.

We designed the Mid Offshore scenario with the maximum possible penetration of offshore wind without trans-coastal transmission infrastructure upgrades by performing test runs of the PCM. We started by scaling the maximum power output of offshore wind at each of the five points of interconnection to match the summer trans-coastal line limit for the associated evacuation line. The summer limits were verified in consultation with BPA; however, there is uncertainty regarding the exact limits on these lines. The assumed limits are shown in Table 2. The lines can also be found on the map in Figure 3. 
Table 2. Summer Thermal Limits of the Trans-Coastal Transmission Lines Responsible for Delivery of Offshore Wind Energy

\begin{tabular}{|c|c|}
\hline 230-kV Line & $\begin{array}{c}\text { Summer Thermal Rating } \\
\text { (MW) }\end{array}$ \\
\hline Clatsop to I-5 Corridor & 255 \\
\hline Tillamook to I-5 Corridor & 284 \\
\hline Toledo to I-5 Corridor & 426 \\
\hline Wendson to Toledo & 195 \\
\hline Wendson to I-5 Corridor & 335 \\
\hline Fairview to I-5 Corridor & 785 \\
\hline
\end{tabular}

Then, we ran the full-year model and checked for congestion of the trans-coastal lines. If a particular line did not exhibit congestion during the entire year, we increased the capacity of its associated offshore wind generation by the available capacity in its highest utilization hour (i.e., the maximum flow subtracted from the line limit). If a line did exhibit congestion, we first checked that the congestion occurred at the same time as curtailment of its associated offshore wind generation. We then reduced the offshore generation capacity to eliminate the congestion. We repeated this process several times until the trans-coastal transmission was fully utilized with minimal congestion and with no study site experiencing more than $1 \%$ annual curtailment.

As shown in Figure 3, the Toledo and Wendson substations are directly connected by a NorthSouth $230-\mathrm{kV}$ transmission line which has a summer rating of $195 \mathrm{MW}$. There are different hours of the year when generation from both points of interconnection flow through this relatively small line. This can result in congestion and curtailment of both sites. To avoid curtailment and maximize the total offshore wind capacity farther south (where the wind resources is better) we sized the Toledo generator so that it would only serve local load at the town of Newport and surrounding area and not export significant power to the I-5 corridor. The offshore study site connected to the Wendson substation, which has a higher average capacity factor, could then take full advantage of both trans-coastal transmission lines leaving Wendson and Toledo.

Table 3 shows the offshore wind capacities at each study site used in the Mid Offshore scenarios. The southerly injection points are connected with higher trans-coastal transmission capacity and are closer to the higher average wind speeds (Figure 3). 
Table 3. Max Penetration of Offshore Wind That Can Be Accommodated by the Existing Transmission System

\begin{tabular}{|ccc|}
\hline $\begin{array}{c}\text { Offshore Wind Point of } \\
\text { Interconnection }\end{array}$ & $\begin{array}{c}\text { Max } \\
\text { Capacity } \\
\text { (MW) }\end{array}$ & $\begin{array}{c}\text { Max } \\
\text { Injected } \\
\text { Power } \\
\text { (MW) }\end{array}$ \\
\hline 1-Clatsop & 361 & 301 \\
2-Tillamook & 553 & 461 \\
3-Toledo & 156 & 130 \\
4-Wendson & 613 & 512 \\
5-Fairview & 941 & 785 \\
Total & 2625 & 2189 \\
\hline
\end{tabular}

\subsubsection{Trans-Coastal Transmission Upgrade Scenarios}

To study the possibility of integrating more than $2.6 \mathrm{GW}$ offshore wind without causing congestion, we modeled scenarios with increased rating of the trans-coastal transmission lines shown in Table 3. We set the thermal limit of all five corridors in all months of the year to 834 MW, to match the maximum injected offshore wind power at each point of interconnection. Furthermore, we reduce the reactance of each line from their assumed values between $0.03-0.08$ per unit ${ }^{25}$ to 0.005 per unit for each corridor. As this is not a detailed power flow or transmission expansion study, we do not model changes in voltage, substation upgrades or other infrastructure that may be required to achieve these upgrades in practice. We also do not capture the cost of these upgrades, or the fact that BPA may decide to increase the rating of these lines beyond the bare minimum required to export $5 \mathrm{GW}$ of offshore wind power.

\subsubsection{WECC Power Sector Infrastructure Scenarios}

As stated in Section 2.3, we explored how the rest of the Western Interconnection power sector infrastructure would impact the value and system operations with greater penetrations of offshore wind. Figure 5 shows the installed capacity by generator type in Western Oregon, Eastern Oregon, and the rest of the Western Interconnection for our two infrastructure scenarios we consider: current and future. Interregional transmission is also expanded between the current and future systems. In current, $21 \%$ of annual load is served by wind and solar generation. The VRE penetration increases to $46 \%$ of annual load in the future infrastructure scenario.

Between current and future, much of the remaining coal fleet is retired across the interconnection. In Oregon, a portion of the gas-CC is also retired, while some natural gas combustion turbine (gas-CT) capacity is built in Western Oregon to provide peaking capacity. ${ }^{26}$ Distributed PV expands by about 1,000 MW between current and future in Western Oregon. This capacity is mostly located in the urban I-5 corridor.

\footnotetext{
${ }^{25}$ This model utilizes the standard base unit of 100 MVA.

${ }^{26}$ The future generation infrastructure is based on policies as of 2019 . The clean electricity penetration of the future system falls below what is needed to achieve the carbon pollution-free power sector by 2035 goal set by President Biden and may not be consistent with recent legislation in Oregon (i.e., HB 2021).
} 


\subsubsection{Energy Storage Scenarios}

Energy storage technologies offer many values to power systems. In addition to helping fill in supply gaps characteristic of intermittent, weather-based generation, when strategically located storage can also add resilience and help optimize transmission infrastructure and interconnections by mitigating transmission constraints. While several different technologies such as compressed air energy storage, flywheels, and pumped storage can achieve the same functionality, battery energy storage that can be located nearly anywhere are becoming particularly ubiquitous in power system plans with high renewable energy penetrations. While the storage parameters modeled in this study are based on long duration Li-ion batteries, the technology representation and results in our production cost model are general enough to apply to other types of energy storage.

In order to study the value of storage in co-located with offshore wind in Oregon, we designed several storage scenarios. We added five storage projects, one at each offshore wind interconnection point, setting the technical parameters as follows:

- Round-trip efficiency: $85 \%$

- Maximum power: $10 \%$ installed capacity of associated offshore wind generation. Our motivation for capping their power capacity at this level was to limit their benefits to the offshore wind points of interconnection only, rather than allowing them to provide additional benefits elsewhere in the power system.

- Installed capacity: We assumed the storage to have 24-hour storage capability ${ }^{27}$.

- Initial volume: As is typical in our PCMs, we set the storage to be $50 \%$ full at the start of the simulation.

- Foresight: In order to properly value holding energy in storage, the simulation includes a look-ahead period beyond the single day optimization horizon. The look-ahead period is 24hour, but with a reduced temporal resolution of 4-hours.

\subsubsection{Scenario Combinations}

Table 4 lists all combinations of the scenarios that were modeled using a full year PCM simulation. In total, 10 combinations were modeled using the 2012 meteorological year only, while three combinations were modeled with all seven years of meteorological inputs. We chose 2012 for much of our analysis because previous studies (Brinkman et al. 2021 and Bloom et al. 2021 ) identified it as the most "typical" year across all inputs, such as load, wind, solar, and water availability.

\footnotetext{
${ }^{27}$ Batteries with a duration of 24 hours are not readily available, and more conventional 4-6-hour duration batteries would likely lead to different results. The intent of the assumption was to use a duration that was rarely binding, but not considered long-duration or seasonal storage.
} 
Table 4. All Scenario Combinations Studied in the PCM

\begin{tabular}{|c|c|c|c|c|c|}
\hline $\begin{array}{l}\text { Scenario } \\
\text { Name }\end{array}$ & $\begin{array}{c}\text { Offshore } \\
\text { Wind } \\
\text { Penetration }\end{array}$ & $\begin{array}{c}\text { WECC } \\
\text { Infrastructure } \\
\text { Year }\end{array}$ & $\begin{array}{c}\text { Trans- } \\
\text { Coastal } \\
\text { Transmission }\end{array}$ & $\begin{array}{c}\text { Co-Located } \\
\text { Storage }\end{array}$ & $\begin{array}{c}\text { Meteorologica } \\
\text { Years }\end{array}$ \\
\hline Base - CG & \multirow{2}{*}{$0 \mathrm{GW}$} & Current Grid & \multirow{2}{*}{$\begin{array}{l}\text { Existing } \\
\text { capacity }\end{array}$} & \multirow{2}{*}{ No Storage } & 2012 only \\
\hline Base - FG & & Future Grid & & & 2007-2013 \\
\hline $\begin{array}{c}\text { Mid Offshore } \\
\text { - CG }\end{array}$ & \multirow{4}{*}{$2.6 \mathrm{GW}$} & \multirow[b]{2}{*}{ Current Grid } & \multirow{4}{*}{$\begin{array}{l}\text { Existing } \\
\text { capacity }\end{array}$} & No Storage & 2012 only \\
\hline $\begin{array}{c}\text { Mid Offshore } \\
\text { - CG - } \\
\text { Storage }\end{array}$ & & & & Storage & 2012 only \\
\hline $\begin{array}{c}\text { Mid Offshore } \\
\text { - FG }\end{array}$ & & \multirow[b]{2}{*}{ Future Grid } & & No Storage & $2007-2013$ \\
\hline $\begin{array}{c}\text { Mid Offshore } \\
\text { - FG - } \\
\text { Storage }\end{array}$ & & & & Storage & 2012 only \\
\hline $\begin{array}{l}\text { High } \\
\text { Offshore - } \\
\text { FG }\end{array}$ & \multirow{4}{*}{$5 \mathrm{GW}$} & \multirow{4}{*}{ Future Grid } & \multirow{2}{*}{$\begin{array}{l}\text { Existing } \\
\text { capacity }\end{array}$} & No Storage & 2012 only \\
\hline $\begin{array}{c}\text { High } \\
\text { Offshore - } \\
\text { FG - Storage }\end{array}$ & & & & Storage & 2012 only \\
\hline $\begin{array}{l}\text { High } \\
\text { Offshore - } \\
\text { FG - Tx }\end{array}$ & & & \multirow{2}{*}{$\begin{array}{l}\text { Expanded } \\
\text { transmission }\end{array}$} & No Storage & $2007-2013$ \\
\hline $\begin{array}{l}\text { High } \\
\text { Offshore - } \\
\text { FG - Tx - } \\
\text { Storage }\end{array}$ & & & & Storage & 2012 only \\
\hline
\end{tabular}

\subsubsection{Caveats and Limitations}

- The infrastructure plans have low deployment of storage, especially relative to newer versions of the Standard Scenarios. ${ }^{28}$ This report used assumptions from the 2018 Standard Scenarios. The cost of storage was revised down in the 2019 Standard Scenarios resulting in greater deployment of storage.

- We ignore changes in the demand side that would impact the shape of the demand profile, like electrification and demand response.

\footnotetext{
${ }^{28} \mathrm{https}$ //www.nrel.gov/analysis/standard-scenarios.html
} 
- Because we only look at historical weather data, we do not capture any impacts of a further changing climate.

- Frequently production cost modeling includes forecast errors for wind and solar generation. However, we chose not to include forecast errors for the production cost modeling for this study. While NREL publishes high resolution wind and solar data for 2007-2013, at the time the modeling was completed the forecast data had only been robustly generated for 2012 land-based wind and solar data, and not for offshore wind.

- Operating reserves were modeled at an aggregated level for all regions. However, our analysis does not focus on reserve shortages.

- In the PCM, we do not consider the design of the submarine infrastructure to connect the offshore wind generators to their land-based point of interconnection. We assume the design does not introduce new operational constraints that would result in curtailment of the available resource.

- LCOE comparisons include costs of submarine infrastructure and some land-based upgrades to reach the points of interconnection, but they are not specific to the unique attributes of each substation identified as a point of interconnection. This may over or underestimate the costs of achieving the modeled system. 


\section{Results}

In this section, we present the key results and analysis of the Oregon offshore wind generation data and results from our PCM simulations. We first provide a set of summary results, followed by a deeper examination of transmission and power flow impacts, and finally describe an initial investigation of co-locating energy storage at the five offshore wind points of interconnection.

\subsection{Summary Results}

This section summarizes the offshore wind resource and the system impact of integrating offshore wind off the coast of Oregon. We discuss the characteristics of the offshore wind resource, curtailment of offshore wind and other variable generation sources, which types of generation are displaced due to the integration of offshore wind, and the capacity credit of offshore wind. Finally, we will present how these impacts translate into a quantifiable value of the integration of offshore wind.

\subsubsection{Available Oregon Offshore Wind Power}

Due to limitations in available model input data other than the offshore wind resource, we only ran annual PCMs for 2007-2013, with a focus on the 2012 meteorological data. This section places 2012 in the context of the full PNW20 20-year offshore wind resource data set. The results show that 2012 data are relatively representative of wind patterns off the coast of Oregon in other years. Further research would perform more in-depth analyses on the effect of interannual variability of the offshore wind resource on system operation. 


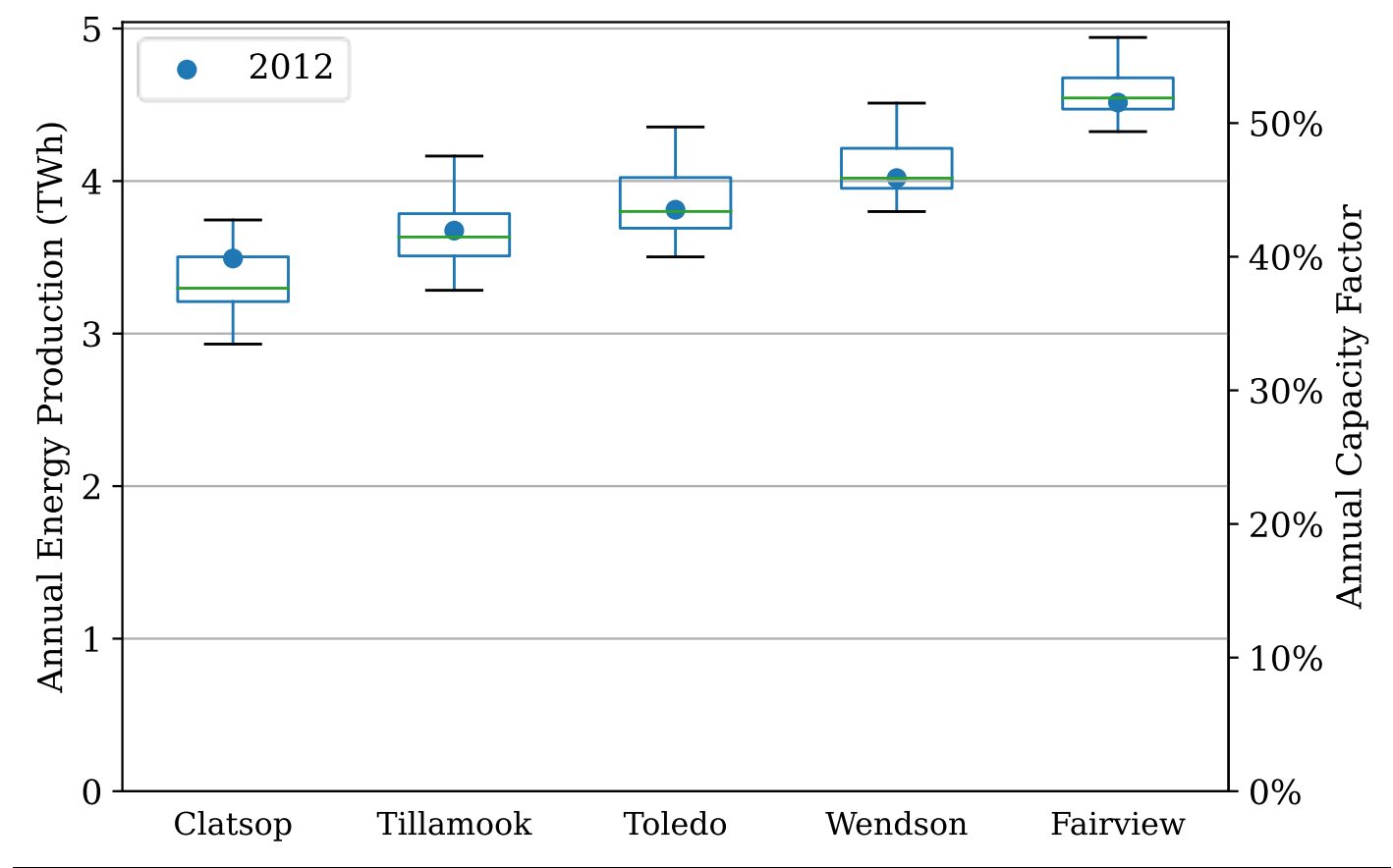

Figure 7. Annual energy production and capacity factor of the offshore wind associated with each of the five points of interconnection for the available 20 historical weather years. The green line represents the median year, the blue dot shows the $\mathbf{2 0 1 2}$ meteorological year, the main year we ran in our PCM. The edges of the boxes represent the $25^{\text {th }}$ and $75^{\text {th }}$ percentiles, while the ends of the whiskers represent 1.5 times the interquartile range.

The distribution of annual energy production for the five chosen study sites are shown in Figure 7. As expected from the resource map in Figure 3, there is a strong North-to-South gradient in available offshore wind resource; the southernmost site (Fairview) has a median output 37\% higher than the northernmost site (Clatsop). The varying quality in wind resource, along with existing trans-coastal transmission infrastructure, was an important factor in designing our intermediate offshore wind penetration scenarios.

The blue dot in Figure 7 represents the annual energy production and capacity factors for 2012 meteorological year. This year falls between the $25^{\text {th }}$ and $75^{\text {th }}$ percentile of years for all sites. Furthermore, the total annual energy production for $2012(19.50 \mathrm{TWh})$ is within $0.06 \%$ of the overall mean (19.49 TWh). We therefore treated 2012 as a representative offshore wind weather year and based our scenario designs on initial results from this year.

Figure 8 plots average daily profiles for each site, across the entire 20 -year weather data set. Our focus year 2012 sits relatively close to the median hourly average profile, though it is slightly above the median from early morning to midafternoon, particularly at the northernmost site. The evening hours in 2012 are generally near the middle of the data set, with the exception of Fairview, the site with the highest consistent wind speeds. The hourly range in diurnal average is roughly $100 \mathrm{MW}$ per site, or $500 \mathrm{MW}$ for all aggregate offshore wind in the High Offshore penetration scenarios. 
Diurnal average offshore wind generation
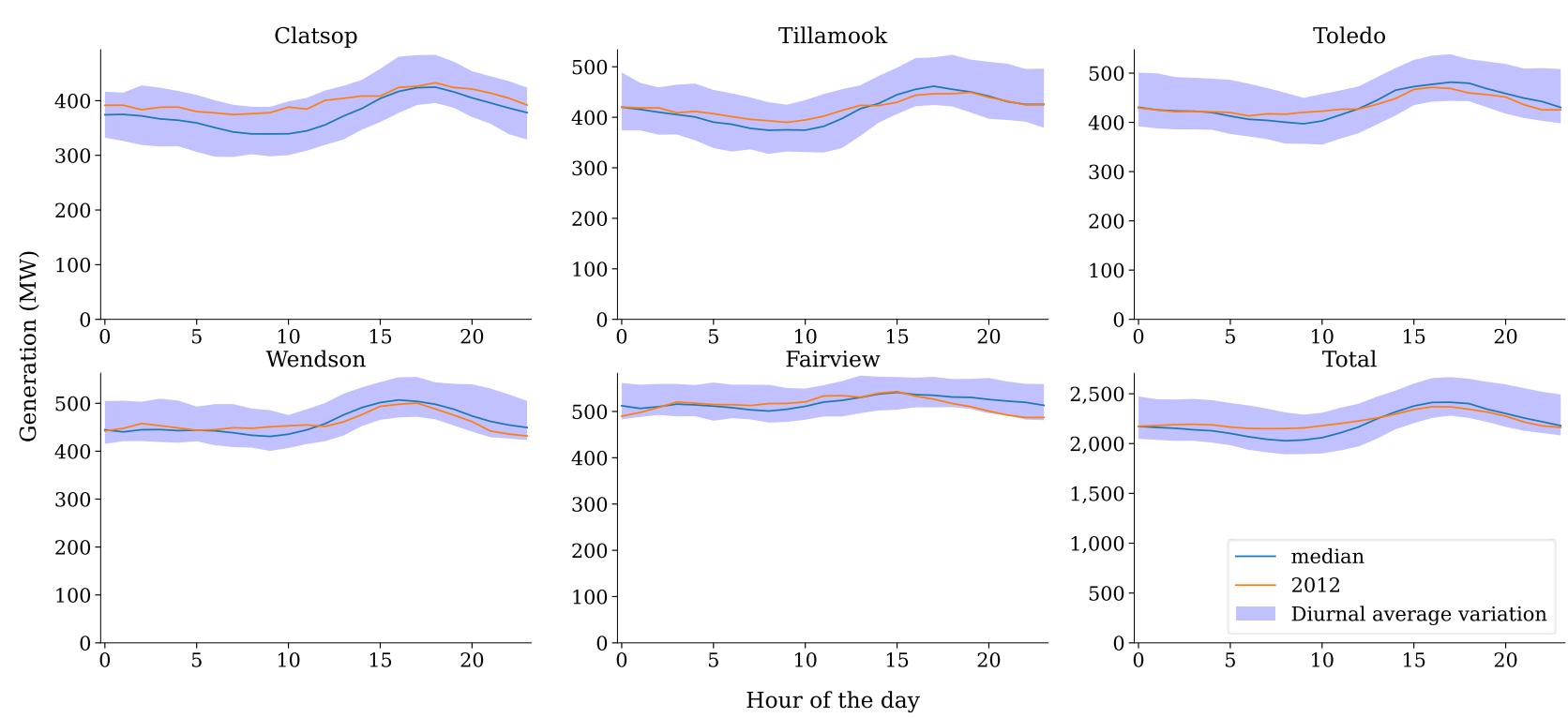

Figure 8. Daily average offshore wind generation. The blue shading shows the gap between the maximum and minimum average hourly values across the $\mathbf{2 0}$-year data set. Similarly, the median profile plots the median average hourly value across the entire data set.

Despite the large variation in wind resource and annual energy production, all offshore wind still operates at or near their maximum some hours of the year. The northern site of Clatsop has the lowest offshore wind capacity factor on the Oregon coast, but it still operates near its maximum output of $834 \mathrm{MW}$ almost $20 \%$ of hours in the 20 -year dataset (see the leftmost dashed line in Figure 9 (left)). By contrast, the site with the highest capacity factor and most consistent wind resource, Port Orford, operates near its maximum for almost $40 \%$ of all hours.

Figure 9 (right) shows the generation duration curve for all aggregated offshore wind in $5 \mathrm{GW}$ penetration scenarios for our model year (2012 meteorological year), and the years with the lowest and highest total energy production (2019 and 2006, respectively). Even in years with relatively poorer wind resource like 2019 , all offshore wind operates near its max during $7 \%$ of hours. This value is $14 \%$ for the year with the highest offshore wind energy production, and $12 \%$ for the 2012 meteorological year. Finally, at least some offshore wind power is operating most of the time in our dataset; aggregate offshore wind produces less than $1 \%$ of its maximum output during only $2 \%$ of hours. 


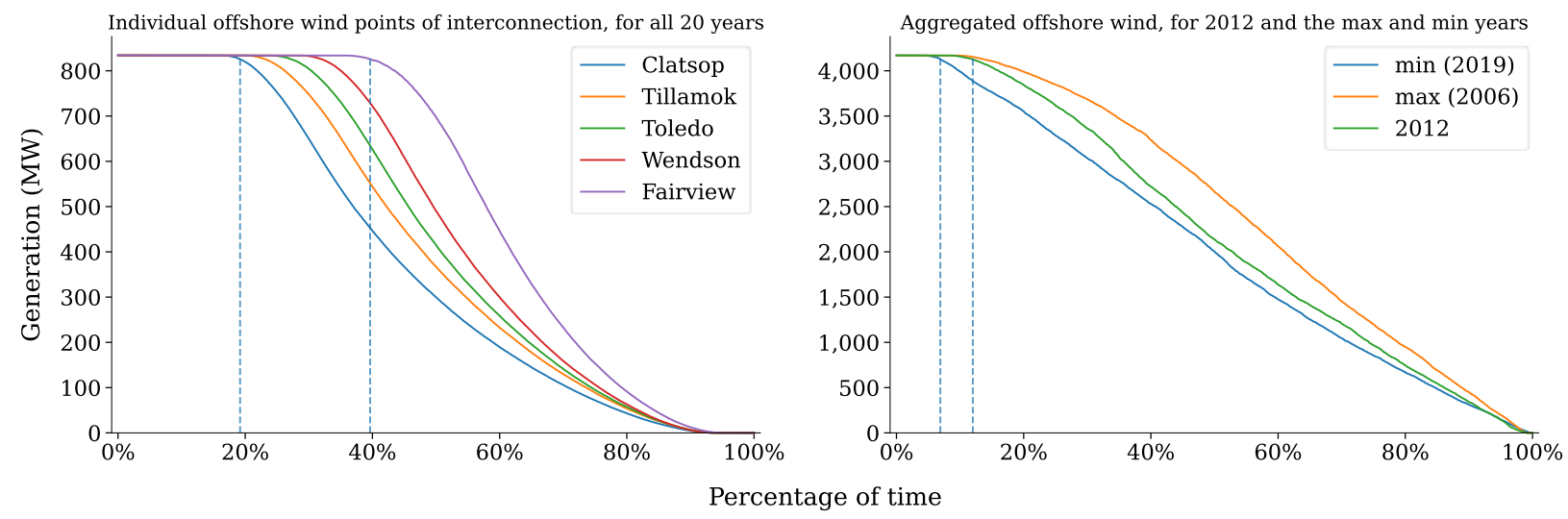

Figure 9. Generation duration curves for the entire 2000-2019 data set (left) and select years (right). The vertical dashed lines highlight the maximum and minimum percentages of time during which the offshore wind operates within $1 \%$ of their maximum output. This corresponds to 827 MW for individual plants and 4,128 MW for all aggregate offshore wind in the High Offshore penetration scenarios.

\subsubsection{Variable Generation Curtailment}

Figure 10 plots total curtailment for all scenarios studied for the entire Western Interconnection and Eastern Oregon, where all land-based wind and utility-scale PV exists in Oregon. In the 0GW offshore wind scenarios, interconnection-wide curtailment increases from $1.3 \%$ in current to $3.2 \%$ in future as the higher penetrations of solar PV and land-based wind result in higher curtailment of both resources. Adding offshore wind in Oregon to the current system does not result in meaningful change in system wide curtailment, including nearly no curtailment of the offshore wind available generation. As described in Section 1.4.1, the nameplate capacity at each offshore wind location in the Mid Offshore scenario was sized to avoid curtailment due to congestion on the trans-coastal transmission system. The near-zero curtailment of offshore wind in both current and future in the $2.6 \mathrm{GW}$ scenario suggests that there are no other system constraints that lead to offshore wind curtailment. The same is true for the higher offshore wind penetration of $5 \mathrm{GW}$ : there is little to no offshore wind curtailment once the trans-coastal range transmission is suitably upgraded to avoid congestion of offshore wind with $1 \mathrm{GW}$ installed at each site.

Western Interconnection

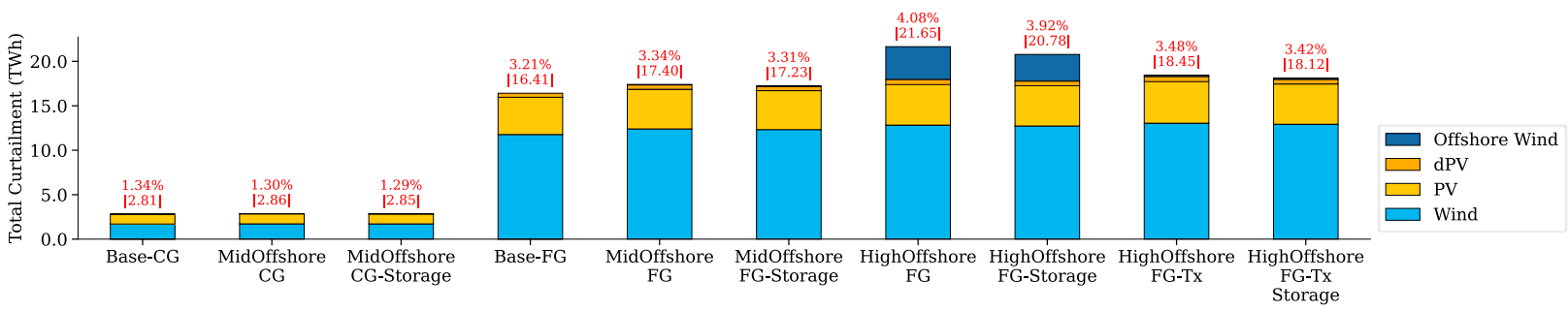




\section{Eastern Oregon}

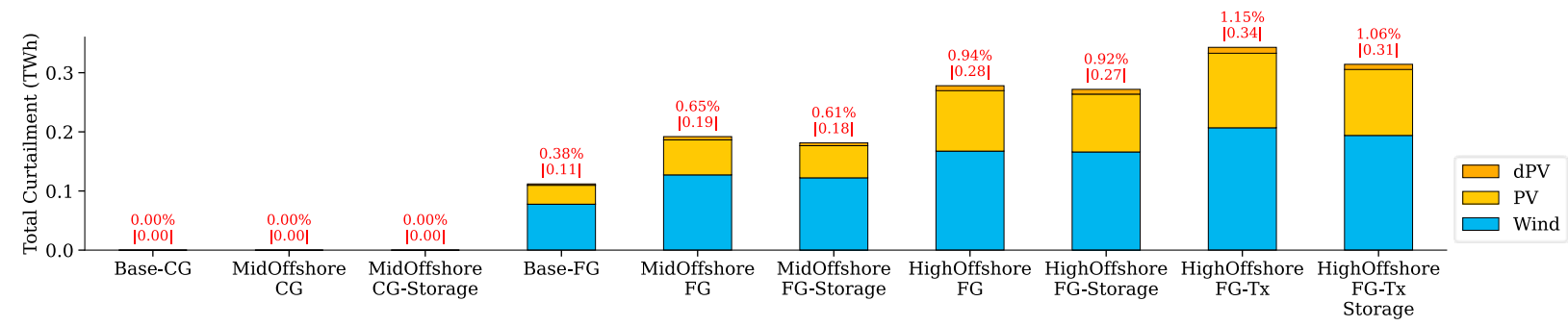

Figure 10. Total curtailment by variable generation source ${ }^{29}$ for the entire Western Interconnection (top) and for Eastern Oregon (bottom) for all scenarios studied in 2012.

To capture variation associated with different weather conditions, we ran the PCM simulation for select scenarios across all seven meteorological years in our data set, 2007-2013. The average annual curtailment results for these seven years are shown in Figure 11. This provides further evidence that 2012 is a relatively typical year, as total curtailment falls both above and below the 7 -year average, depending on the scenario and region. The black error bars in Figure 11 represent the minimum and maximum curtailment years. With a relatively high standard deviation of about $10 \mathrm{TWh}$, total annual curtailment in the entire Western Interconnection appears to be sensitive to the input meteorological year. In Eastern Oregon, where offshore wind has a significant impact on annual curtailment, standard deviation grows from 0.05 , to 0.09 , to 1.4 TWh as offshore wind penetration increases from 0 , to 2.6 , to $5 \mathrm{GW}$, respectively.

\footnotetext{
${ }^{29}$ The exact proportion of PV, distributed PV, and land-based wind curtailment is not necessarily a meaningful result, as the PCM may arbitrarily choose any of these three to curtail if individual sites are not transmissionconstrained.
} 
Eastern Oregon

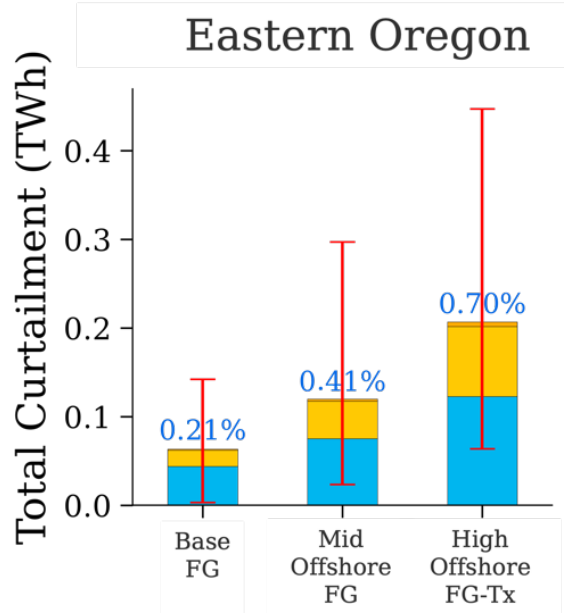

Western Interconnection

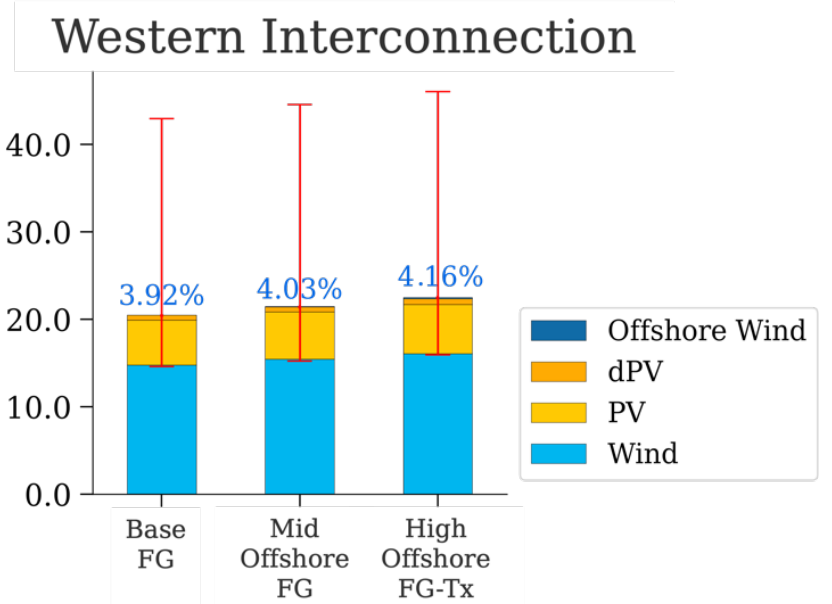

Figure 11. Total curtailment by variable generation source for Eastern Oregon (left) and the entire Western Interconnection (right), averaged over all seven meteorological years 2007-2013. The red error bars represent the max and $\mathrm{min}$ from the 7-year data set. Western Oregon is not included in these plots because it experiences no curtailment in these three scenarios.

Increasing offshore wind penetration in the Future Grid scenario from Mid to High offshore with trans-coastal transmission upgrades does lead to an uptick in land-based wind curtailment across the Western Interconnection, 15\% of which occurs in Eastern Oregon (Figure 10, bottom). The increase in land-based wind curtailment is small relative to the total offshore wind generation. In the High Offshore-FG-Tx scenario, Oregon offshore wind injects nearly 19.5 TWh of energy, which leads a 2-TWh increase of total variable generation curtailment. Co-locating energy storage with Oregon offshore wind reduces the Eastern Oregon land-based variable generation a small amount.

While the uptick in land-based curtailment with increasing offshore wind injection is unsurprising, this pattern might not continue to be the case as PV penetration increases and renewable energy and energy storage is allowed to provide operating reserves (Frew et al. 2021). 


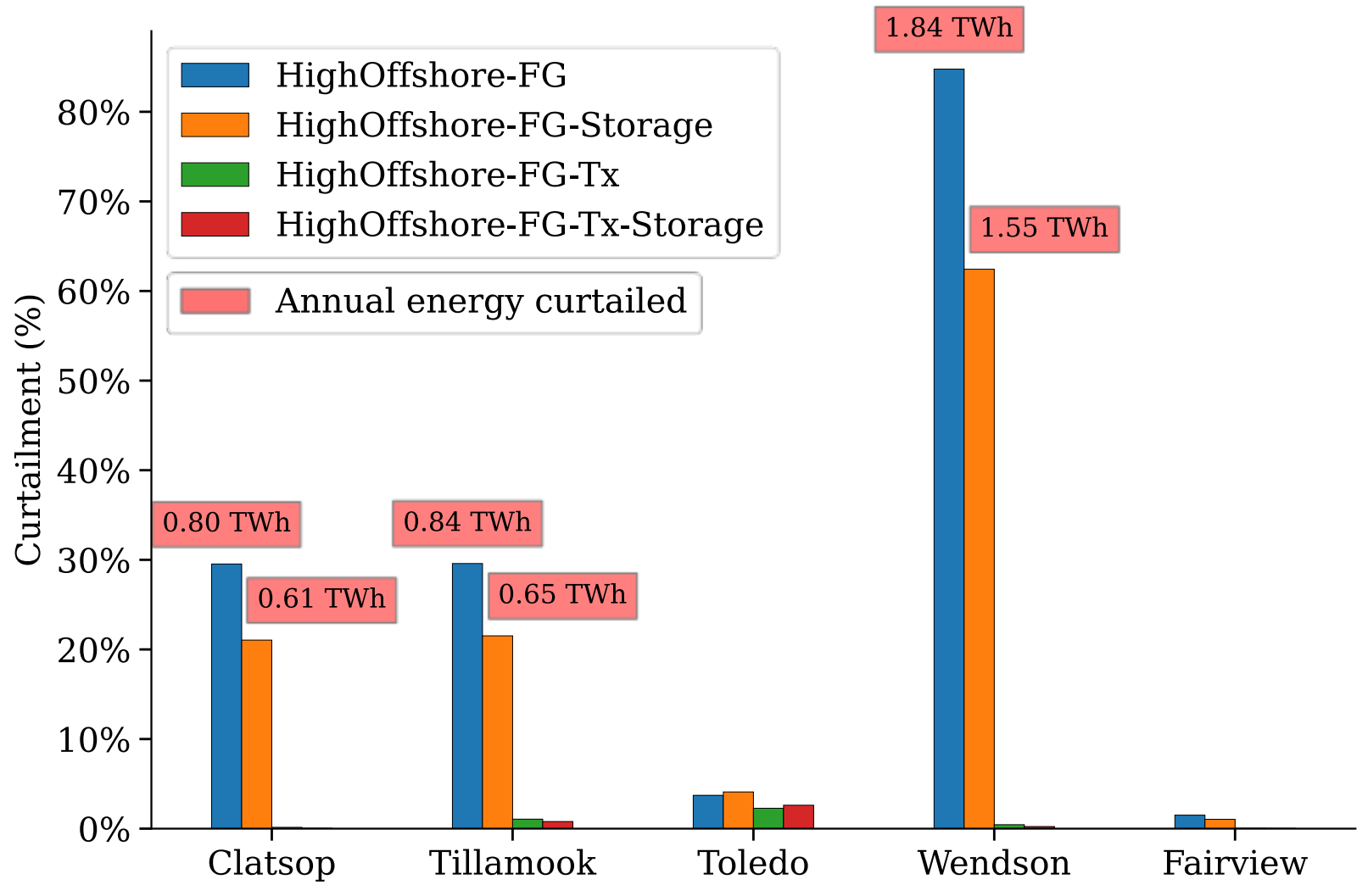

Figure 12. Curtailment of at each of the five offshore wind points of interconnection for the four high offshore wind scenarios

As shown in Figure 10, significant offshore wind curtailment only occurs in the High Offshore scenarios without trans-coastal transmission expansion. Figure 12 plots the curtailment from the High Offshore scenarios, broken down by each individual site. While storage alone reduces offshore wind curtailment by about $15 \%$, upgraded trans-coastal transmission brings it down below $1 \%$. More than $80 \%$ of the generation potential from the Wendson site is curtailed without trans-coastal transmission upgrades or the support of co-located energy storage. As illustrated in Figure 3, Wendson shares existing trans-coastal transmission pathways with the Toledo site.

\subsubsection{Operational Value}

Offshore wind provides operational value to the Oregon and Western Interconnection systems by displacing generation with higher marginal costs, such as coal and gas. We equate production cost change between scenarios with and without offshore wind capacity as the operational value of offshore wind. As seen in Figure 13, Oregon offshore wind largely displaces gas-CC generation in both the current and future systems. Roughly $15 \%-20 \%$ of the reduced gas generation comes from Eastern Oregon. In the future system, there is some displacement of landbased wind and solar PV as the system is at times oversaturated with zero marginal cost variable renewable generation. Given offshore wind's proximity to the Portland load center, the model choses to curtail other variable generation resources in those instances. Note that hydro 
generation is unimpacted on an annual basis. However, the dispatch of the hydro does change shape at locations that have the flexibility to allocate stored water to different days or hours.

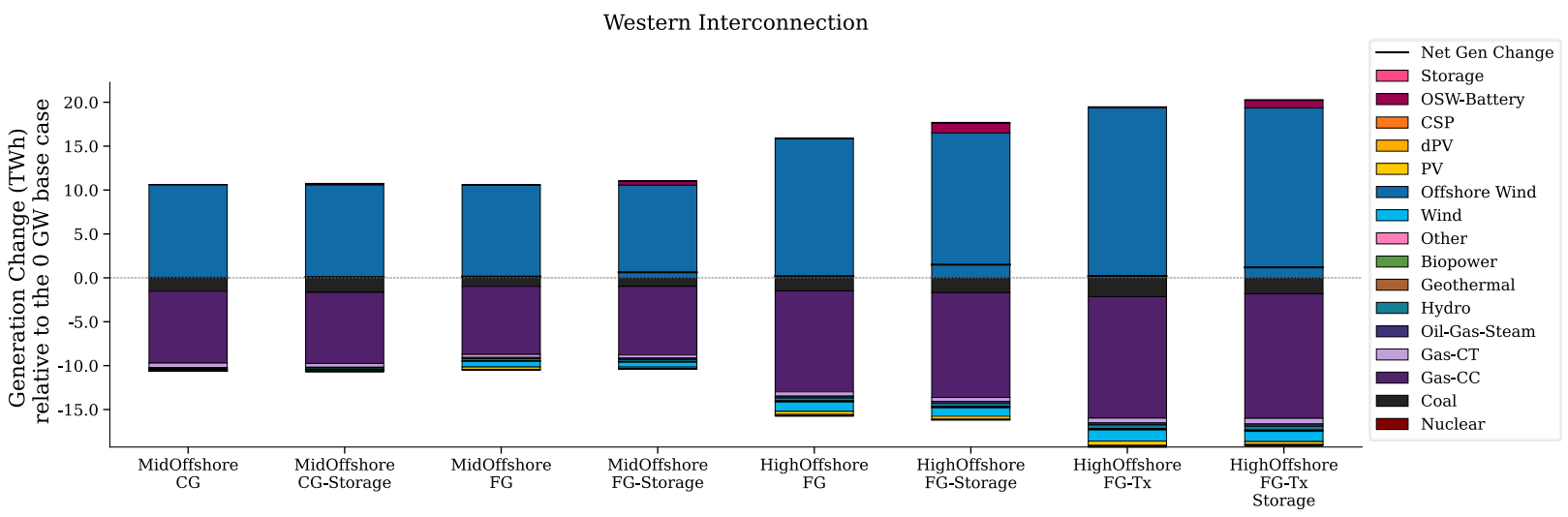

Figure 13. Total generation change for all scenarios studied for 2012, for the entire Western Interconnection

As shown in Figure 14, the 2012 results are consistent with the 7-year meteorological average. Reduced gas-CC generation in 2012 is $0.4 \%$ lower than average in the Mid Offshore scenario, and $0.8 \%$ lower than average in the High Offshore scenario with expanded trans-coastal transmission. The 7-year range in gas-CC generation, indicated by the red error bars in Figure 14, exhibit little variability. The Mid Offshore and High Offshore wind penetration scenarios have standard deviations of 0.62 and $1.3 \mathrm{TWh}$, respectively.

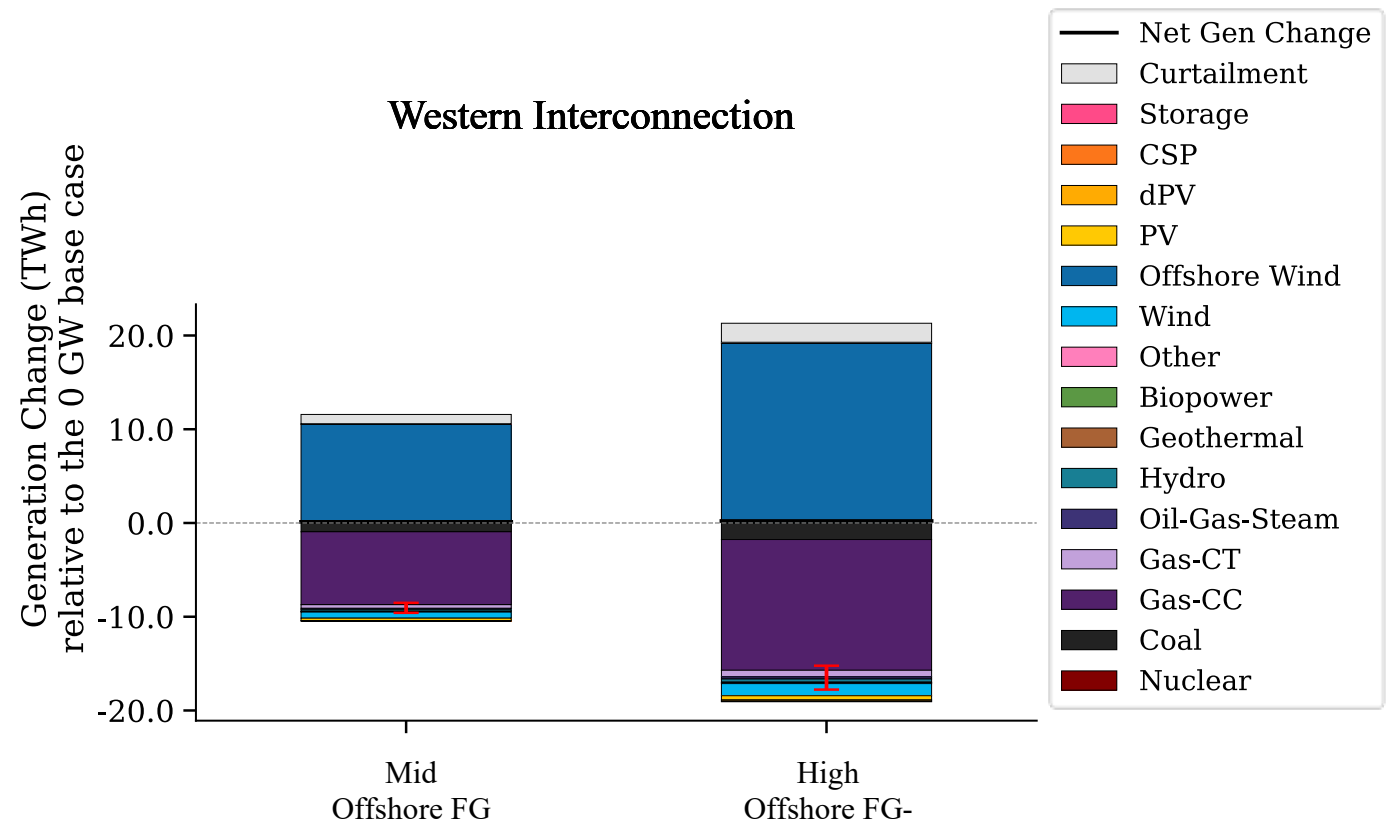

Figure 14. Total generation change for the entire Western Interconnection, averaged across all seven meteorological years. The 7-year range in reduced gas-CC generation is indicated with the red error bars. 
The displaced thermal generation leads directly to operational value of offshore wind because of its impact to total production cost (i.e., change in total fuel, variable maintenance and operations, start and shutdown costs) in the entire Western Interconnection. ${ }^{30}$ Figure 15 plots this production cost change, normalized by the available precurtailment offshore wind generation to convert dollars to dollars per MWh. Almost all of the production cost savings come from avoided fuel cost, though offshore wind does increase the cost of thermal start and shutdowns by a small amount.

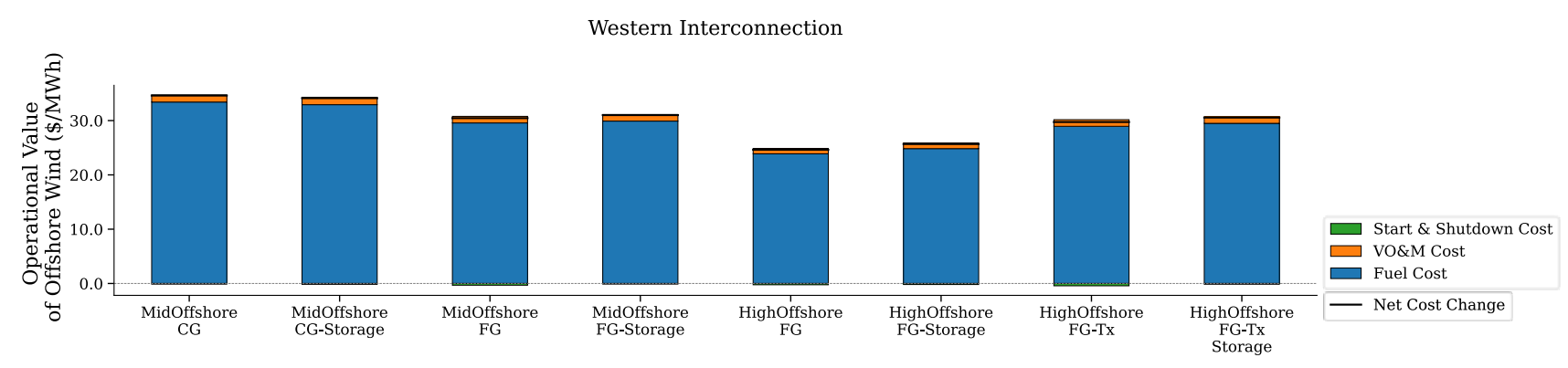

Figure 15. Net change in production cost for the entire Western Interconnection for all offshore wind scenarios, compared to the $0 \mathrm{GW}$ offshore wind base case, run with the 2012 meteorological year. The dollar value is normalized by precurtailment offshore wind generation for each penetration (i.e., 10.6 TWh for the Mid Offshore scenario and 19.5 TWh for the High Offshore scenario).

Offshore wind's operational value is directly correlated to how much of the offshore wind is curtailed. In the High Offshore scenarios without trans-coastal transmission upgrades, operational value decreases to $\$ 25 / \mathrm{MWh}$ compared to $\$ 30 / \mathrm{MWh}$ in the scenarios without curtailment. Figure 16 shows the average operational value across all seven meterological years for the two offshore wind penetration scenarios. At \$31/MWh and \$30/MWh for the Mid Offshore and High Offshore scenarios, respectively, the average values are similar to the 2012 values. The variability in operational value is $\$ 4 / \mathrm{MWh}$ in both penetration scenarios.

\footnotetext{
${ }^{30}$ Much of thermal generation displacement and therefore production cost savings occur outside of Oregon; therefore, it is imperative to capture the operational value to the full interconnection rather than just Oregon.
} 


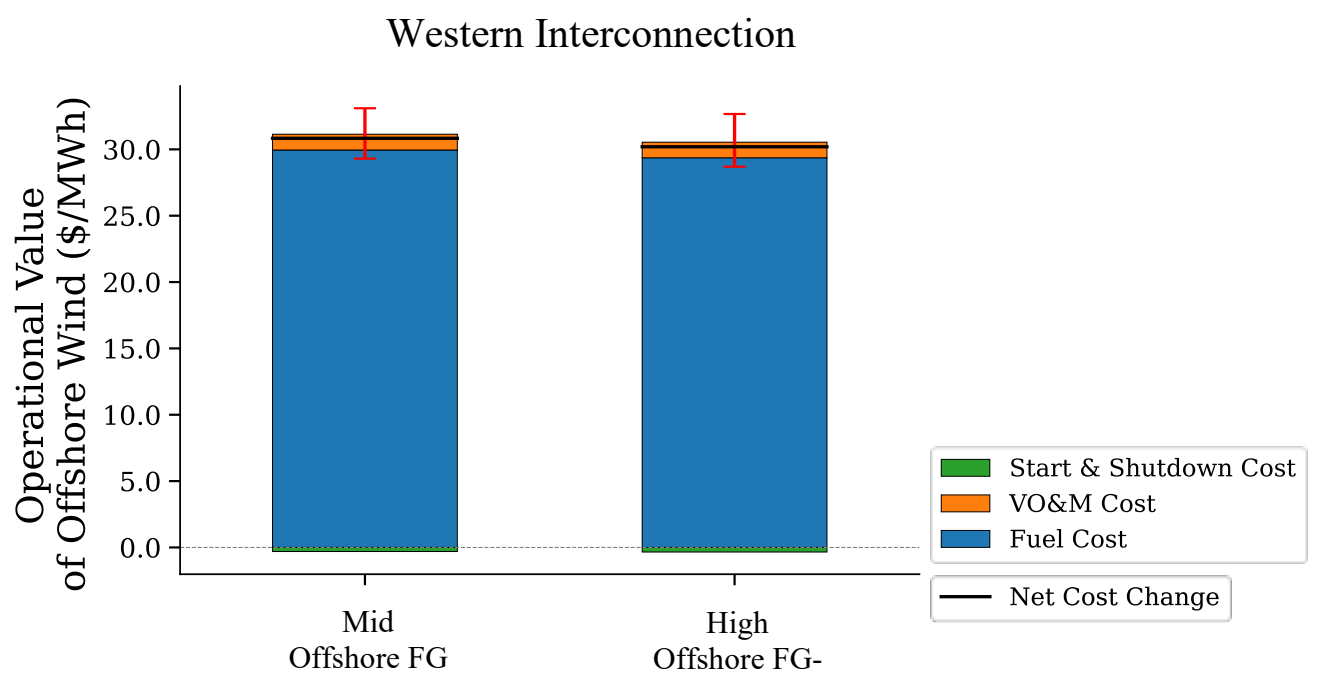

Figure 16. Operational value (total net change in production cost) for the entire Western Interconnection, averaged across all seven meteorological years, compared to the $\mathbf{0}-\mathbf{G W}$ offshore wind base case. The red error bars represent the maximum and minimum years. The dollar value is normalized by precurtailment offshore wind generation for each penetration (i.e., 10.6 TWh for the Mid Offshore scenario and 19.5 TWh for the High Offshore scenario).

\subsubsection{Capacity Value}

With increasing penetrations of VRE, it is increasingly necessary to know how the generation profile correlates with other renewable resources, load, and net load. How well it correlates and, most importantly, contributes during periods of high net load defines the value of reduced need for fully available capacity (i.e., offshore wind's capacity value). To determine the displacement value for fully available capacity, we compare to the cost of building a new gas-CT. We choose to compare against natural gas power plants as they are often used to provide new firm capacity, and will likely continue to some extent in the near future

Figure 17 shows the correlogram of Oregon offshore wind and the load, net load, land-based wind, and solar PV for the Western Interconnection in future. Net load in the figure is the load minus the land-based wind and solar PV. This plot only considers the weather years between 2007 and 2013, due to lack of available land-based wind data during the full 20-year period of offshore wind data. 


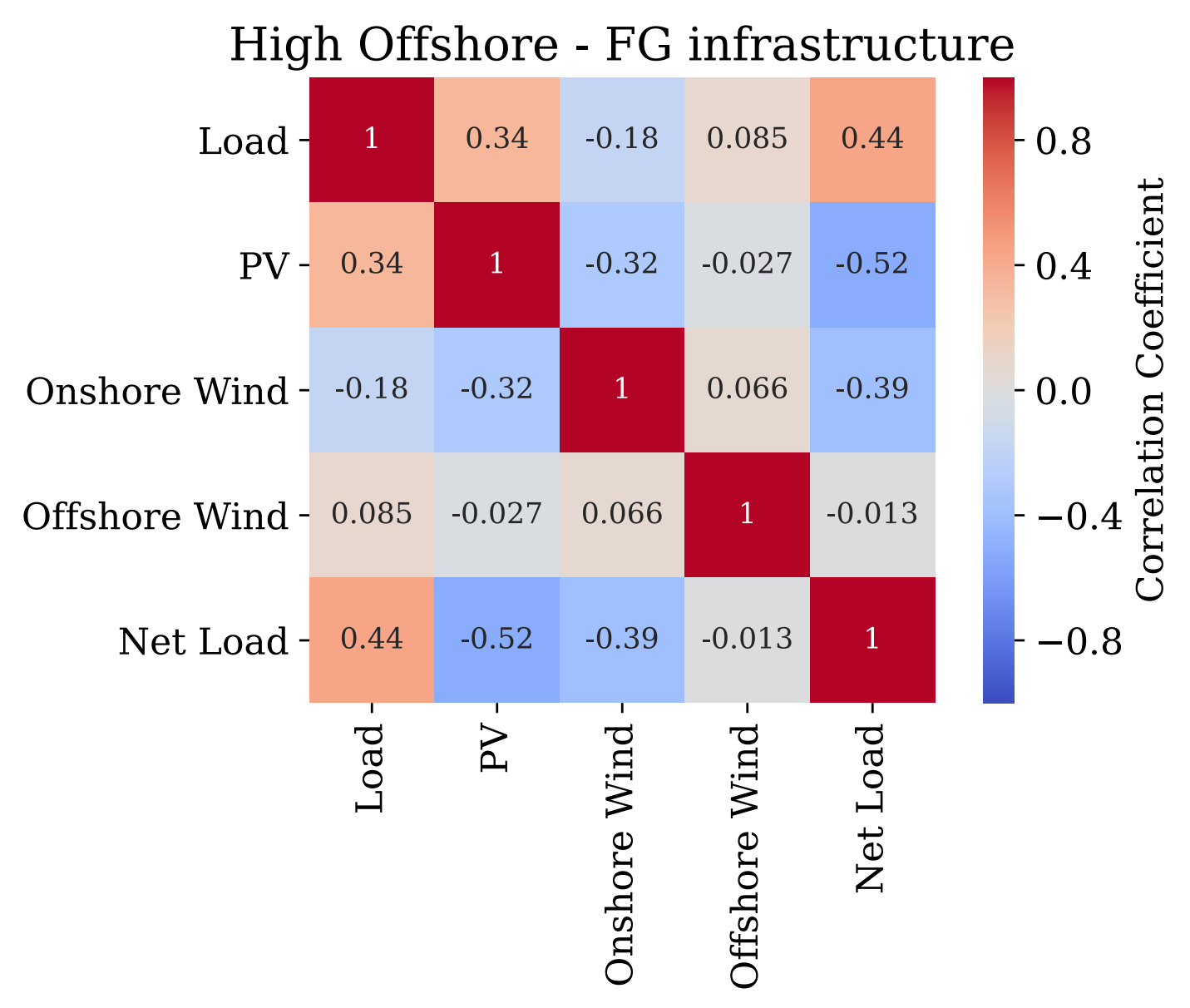

Figure 17. Correlogram for aggregate renewable resources in the Western Interconnection

Solar PV is somewhat correlated with load, but the penetration of solar PV in the Western Interconnection is high enough that PV is anti-correlated with net load. For that reason, the next unit of PV does not contribute to reducing high system net loads. Land-based wind is also anticorrelated with net load. Offshore wind, on the other hand, is not strongly correlated with net load in either direction.

Figure 18 shows the estimated capacity credit of the Oregon offshore wind. The capacity credit is estimated by determining the aggregate capacity factor for each offshore wind site during the top 100 historical net load hours in the Western Interconnection for each weather year between 2007 and 2013. We use Western Interconnection net load, rather than a more local region, to consider the entire power system as a whole. However, transmission limitations might restrict the ability of offshore wind to to provide capacity value to distant areas of the Western Interconnection. 
HighOffshore, FutureGrid

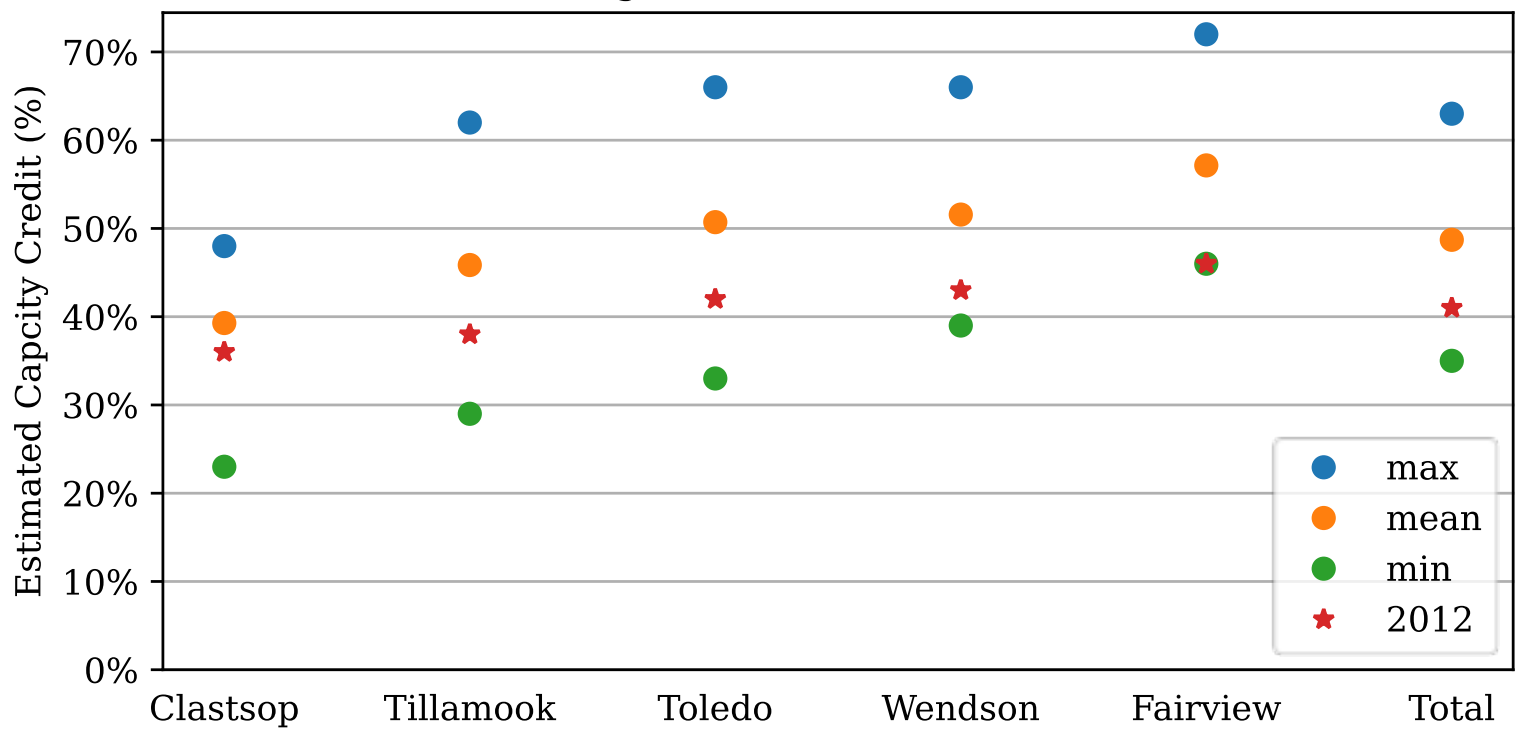

Figure 18. Distribution of estimated capacity credit for each site for the High Offshore, Future Grid scenario. Capacity credit is estimated by taking the average capacity factor of the offshore wind at each point of interconnection during the top 100 net load hours of the year for the Western Interconnection.

Capacity credit increases the further south the offshore wind is located. In the Future Grid with 5 $\mathrm{GW}$ of offshore wind capacity, the total resource ranges from a minimum capacity credit of $35 \%$ of nameplate capacity to a maximum of $63 \%$. These estimates are lower but consistent with a more robust statistical assesement published in Joregenson et al. 2021, which suggested an average capacity credit of Oregon offshore wind in today's system between $48 \%$ and $60 \%$, with portions of Southern Oregon wind reaching capacity credits betweeen $60 \%$ and $75 \%$. For reference, Joregenson et al. 2021 found the average land-based wind capacity credit, assuming today's turbine technology, to be $16 \%$ and the top $75^{\text {th }}$ percentile capacity credit to be $20 \%$. A key difference between our work and Jorgenson et al. is that Jorgenson et al. focused on capacity credit in today's system, while our estimates are forward-looking. Other forward-looking studies, such as Mills and Wiser 2012, have predicted that renewable energy capacity credit will decrease as renewable energy penetration increases, because each wind and solar unit will tend to produce at similar times as some existing units.

Using the estimated capacity credit, we can calculate the capacity value of offshore wind for different penetrations and power sector infrastructures. Table 5 shows the yearly average capacity factor, capacity credit, and capacity value for both offshore wind penetrations and infrastructures. To get the dollar value of capacity for offshore wind, we multiply the capacity credit by an assumed value of new firm capacity, $\$ 190 / \mathrm{kW}$, and normalize by the total generation potential for each site (Denholm et al. 2016). We value firm capacity using CAISO's 2012 published cost of new gas combustion turbines. (CAISO 2012) There is no levelized or time dimension element to this proxy value, so it assumes offshore wind has the same asset life as the avoided capacity resource (here, gas-CT). This value could increase in the future, but likely will not decrease. 
As shown in Table 6, average capacity factor, capacity credit, and capacity values are all higher in the lower offshore wind penetration case. A larger proportion of the aggregate Oregon offshore wind capacity is sited in the southern region of the coast in the Mid Offshore scenario. The capacity value of Oregon offshore wind decreases some in the future scenarios as the penetration of other variable renewables increases. This suggests that offshore is slightly less available during peak net load hours in a higher renewables penetration future. The High Offshore wind penetration also reduces the capacity credit of offshore wind compared to the Mid Offshore scenario in future.

Table 5. Capacity Value of Offshore Wind for Different Scenarios

Note: The uncertainty shows the range across the seven meteorological years studied.

\begin{tabular}{|l|c|c|c|}
\hline & Mid Offshore, current grid & Mid Offshore, future grid & $\begin{array}{c}\text { High } \\
\text { Offshore, } \\
\text { future grid }\end{array}$ \\
\hline $\begin{array}{l}\text { Yearly Average } \\
\text { Capacity Factor }\end{array}$ & $46.0 \pm 2.5 \%$ & $46.0 \pm 2.5 \%$ & $44.3 \pm$ \\
\hline Capacity Credit & $55.0 \pm 10.5 \%$ & $52.7 \pm 12.5 \%$ & $2.5 \%$ \\
\hline Capacity Value & $25.87 \pm 4.94 \$ / \mathrm{MWh}$ & $24.80 \pm 5.88 \$ / \mathrm{MWh}$ & $23.61 \pm$ \\
& & & 6.82 \\
& & & \\
& & & \\
\hline
\end{tabular}

\subsubsection{Value of Avoided Emissions}

Our PCM does not include a carbon tax when making dispatch decisions, and externalities from carbon emissions do not factor into our optimization. We estimated the $\mathrm{CO}_{2}$ emissions reduction social benefit offshore wind provides by calculating the total $\mathrm{CO}_{2}$ emissions reductions in offshore wind scenarios and applying the social cost of carbon to determine a value to the displaced emissions. The total fuel reduction between each scenario in the simulation and the 0 $\mathrm{GW}$ offshore wind base case was multiplied by its associated $\mathrm{CO}_{2}$ emissions rate. We then applied the most recent estimate for the social cost of carbon issued by the U.S. Interagency Working Group on Social Cost of Greenhouse Gases, \$51/ton $\mathrm{CO}_{2} \cdot{ }^{31}$ The results are correlated with displaced thermal generation and therefore the operational value of offshore wind. For that reason, the final value of displaced $\mathrm{CO}_{2}$ emissions are shown in the next section, which summarizes the total system value of offshore wind.

\subsubsection{Total System Value}

We estimated the total system value of integrating offshore wind by adding together operational and capacity value with the emissions cost. These values are plotted for the 2012 meteorological year in Figure 19 and averaged across all seven meteorological years 2007-2013 in Figure 20.

The estimated average LCOE for offshore wind in 2032, $\$ 63 / \mathrm{MWh}$, is plotted with a dotted yellow line (Musial et al. 2021). While this grid integration study ignores the subsea export lines required to deliver offshore wind power to shore, the LCOE value does include the cost of this

\footnotetext{
${ }^{31}$ https://www.whitehouse.gov/wpcontent/uploads/2021/02/TechnicalSupportDocument_SocialCostofCarbonMethaneNitrousOxide.pdf.
} 
and other required infrastructure. The total value of offshore wind is higher than its assumed LCOE in all scenarios, though the margin is significantly higher in the current grid infrastructure. The margin is also comparatively slimmer in the high curtailment scenarios, i.e., High Offshore in the future grid without trans-coastal transmission expansion). Both higher system-wide VRE penetration, as well as offshore wind curtailment, reduces the total value offshore wind provides to the Western Interconnection. The future grid scenarios see a lower fuel cost reduction compared to those for the current grid, but they also have a comparatively higher value of avoided capacity. As the system decarbonizes, capacity value becomes more important.

Western Interconnection

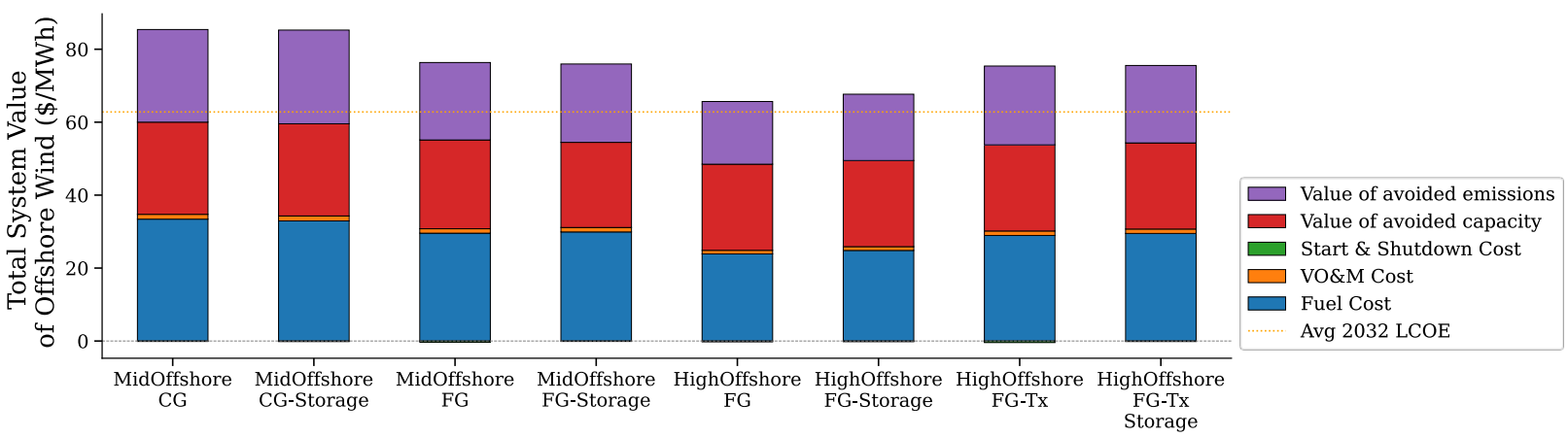

Figure 19. Total system value stacks for all scenarios studied, as compared to the associated 0 GW offshore wind base case, for current grid infrastructure scenarios (left) and future grid infrastructure scenarios (right), modeled with the $\mathbf{2 0 1 2}$ meteorological year.

The 7-year average of offshore wind total system value plotted in Figure 20 is slightly higher than the 2012 value. This reflects the fact that the 2012 capacity value of offshore wind is below average (Figure 18). The variability across the seven meteorological years is relatively tight, at \$11/MWh and \$10/MWh for the 2.6- and High Offshore wind penetration scenarios, respectively. 


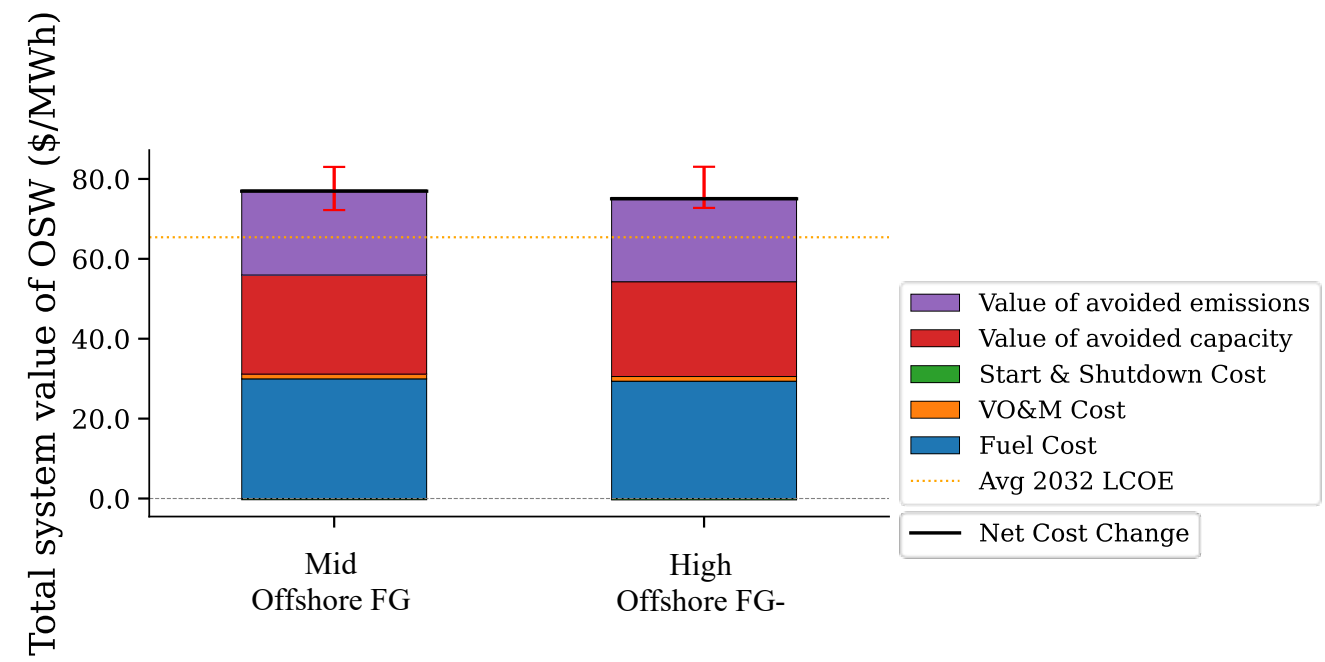

Figure 20. Total system value stacks for offshore wind, averaged across all seven meteorological years, compared to the $\mathbf{0 - G W}$ offshore wind base case. The red error bars represent the maximum and minimum years. In both cases, the Start \& Shutdown Cost (green) is a small negative system value.

\subsection{Offshore Wind to Serve Coastal Oregon Loads}

As described in Douville et al. 2020, the Oregon coast is a remote area that contains very few electric generators. Most of the electricity consumed in this region is produced east of the Coastal and Cascade ranges, largely in the Columbia River valley. Offshore wind presents an opportunity to directly serve these local loads. Douville et al. found that offshore wind could serve roughly $1 \mathrm{GW}$ of coastal loads. We supplement this result by comparing the availability of the offshore wind power to coastal loads on an hourly basis in Table 5. In Table 5, coastal loads were assigned to points of interconnection based on transmission connectivity and proximity.

The results for future load are shown in Table 5. Offshore wind is able to serve large portions of the hourly load associated with each point of interconnection in the High Offshore scenario. As illustrated in Figure ES- 1, these groups of coastal nodes are electrically isolated from each other. For offshore wind generation from any injection substation to be available to serve all coastal loads, coastal transmission upgrades (different from trans-coastal transmission) would need to be upgraded. Otherwise, generation would need to be wheeled via the trans-coastal corridors away from the coastal system and back. The total row compares total coastal load with total offshore wind generation. Aggregating data across the entire coast neglects these transmission limitations, so the total servable load values are strictly higher than those for any one site. The ranges in Table 5 represent the maximum and minimum values across the 7-year meteorological data set.

Table 5 also reports approximations of the capacity credits of offshore wind associated with each point of interconnection, which determines the portion of the offshore wind nameplate capacity that could be counted on during hours of high net load. This method, upon which we elaborate in Section 3.1.4., involves calculating the capacity factor of each generator during the top 100 peak load hours of each coastal load for each meteorological year in the 7-year data set. Table 5 reports the maximum and minimum across these years. Despite the fact that offshore wind at the northernmost points of interconnection, Clatsop and Tillamook, serve a significant majority of 
their local load, their lower capacity credit indicates they are less available during periods of peak load than offshore wind at the other three points of interconnection. In the High Offshore case, when 1,000 GW is connected to each coastal substation, capacity credit increases monotonically as we consider more southerly locations.

Table 5. Percentages of Hourly Local Coastal Load That Is Servable by the Offshore Wind Associated with Each Point of Interconnection. ${ }^{32}$

Note: The results assume loads from the future grid scenarios.

\begin{tabular}{|c|cc|cc|cc|}
\hline \multirow{2}{*}{$\begin{array}{c}\text { Point of } \\
\text { Interconnection }\end{array}$} & \multicolumn{2}{|c|}{ Load } & \multicolumn{2}{c|}{ Mid Offshore } & \multicolumn{2}{c|}{ High Offshore } \\
\cline { 2 - 7 } & $\begin{array}{c}\text { Annual } \\
\text { Total } \\
\text { (TWh) }\end{array}$ & $\begin{array}{c}\text { Annual } \\
\text { Peak (MW) }\end{array}$ & Servable Load & Capacity Credit & Servable Load & $\begin{array}{c}\text { Capacity } \\
\text { Credit }\end{array}$ \\
\hline Clatsop & $0.41-0.41$ & $63-70$ & $74-80 \%$ & $30-58 \%$ & $82-87 \%$ & $30-58 \%$ \\
Tillamook & $1.36-1.37$ & $262-316$ & $67-75 \%$ & $34-64 \%$ & $74-82 \%$ & $34-64 \%$ \\
Toledo & $0.96-0.98$ & $237-286$ & $43-51 \%$ & $34-61 \%$ & $75-83 \%$ & $34-61 \%$ \\
Wendson & $0.34-0.35$ & $76-93$ & $82-86 \%$ & $35-55 \%$ & $84-88 \%$ & $35-55 \%$ \\
Fairview & $1.03-1.03$ & $201-239$ & $80-84 \%$ & $39-58 \%$ & $80-85 \%$ & $39-58 \%$ \\
Total & $4.11-4.13$ & $833-1004$ & $84-89 \%$ & $34-61 \%$ & $90-94 \%$ & $33-62 \%$ \\
\hline
\end{tabular}

\subsection{Impact of Hydropower Resource Availability}

While the previous section shows averages, maxima, and minima for summary results across the seven meteorological years, in this section we focus specifically on the relationships between hydropower resource availability and a few key PCM metrics. We characterize a meteorological year as "wet" or "dry" based on the total electricity produced by hydropower throughout the Western Interconnection in our High Offshore-FG-Tx transmission expansion scenario in that particular year. This metric, along with offshore wind availability and offshore wind capacity credit, is plotted in Figure 21. The interannual variability of offshore wind and Western Interconnection hydropower is similar, whereas the interannual variability of the offshore wind capacity credit is larger than the change in hydropower potential. Using our limited 7-year data set, there appears to be little to no relationship between Western Interconnection hydropower potential and offshore wind generation potential or offshore wind capacity credit.

\footnotetext{
${ }^{32}$ For the purposes of this table, Toledo and Wendson are considered to be isolated from each other, but in reality excess offshore wind generation from each substation could serve the other's load. The Toledo and Wendson substations are more strongly connected compared to the other substations that are largely electrically isolated from each other.
} 

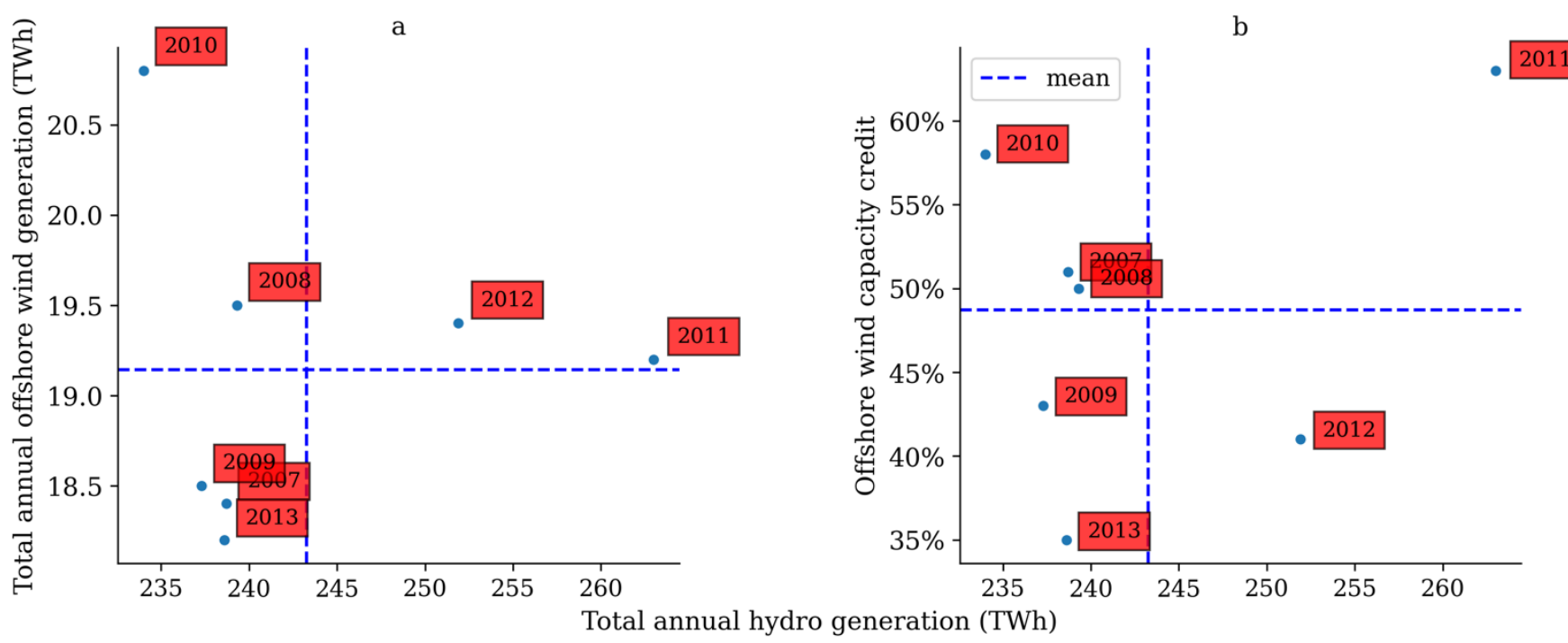

Figure 21. Summary of the available hydropower resource in the Western Interconnection in each meteorological year, as measured by the total annual hydropower generation. The y-axis plots offshore wind availability for context, with total annual generation in (left) and capacity credit (right). 2008 has the lowest deviation from the mean hydropower generation.

Based on historical operations, we assume 1,084 of the 1,629 hydropower units in our Western Interconnection model are dispatchable. In other words, they are able to store water behind dams and optimize how much water to use each day and hour of the year under various operational and regulatory constraints. These units are given different monthly energy limits for each meteorological year based on historical output from the Energy Information Administration, and they are responsible for the variation in the $x$-axis of Figure 21. The remaining 545 nondispatchable hydropower units are given fixed profiles and contribute a total of $78 \mathrm{TWh}$ in every year (roughly $32 \%$ of the total hydro generation). Due to data availability, we do not alter the total annual or monthly generation of these units. Therefore, Figure 21 may not reflect historical hydro generation, and actual variability between years may be somewhat larger. Because 2008 has the lowest deviation from the mean hydropower generation, we take it to represent a "normal" water year. We then take 2010, 2012, and 2011 to be low-, high-, and very high-water years, respectively. For the remainder of this section, we compare these three years to 2008. We do not include 2007, 2009, and 2013, as they are within $0.1 \%$ of 2008.

As shown in Figure 22, the level of water resource availability has a significant impact on diurnal hydropower dispatch patterns in Eastern Oregon during the winter and spring. In high water resource years, hydro generators significantly increase dispatch during both evening and morning load peaks. However, in lower water resource years, hydro generators conserve water for the larger evening peaks only. 


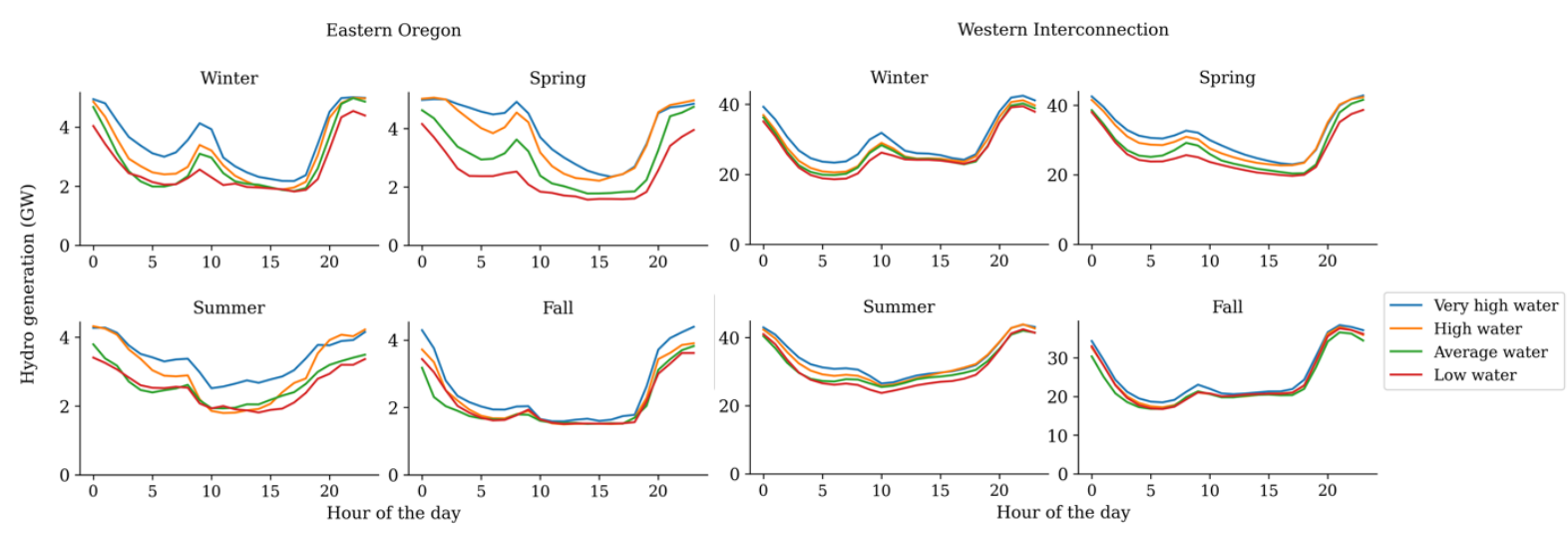

Figure 22. Diurnal average hydro generation curves, by season, for the four water years studied in this section. In high water resource years, hydropower contributes to both evening and morning load peaks in winter and spring. By contrast, hydro generators conserve water in low-water years for the evening peak only.

As shown in Figure 23 (left), increased hydropower generation in Eastern Oregon tends to displace gas-CC generation. This displacement is not one-for-one, however, as Eastern Oregon generates more overall electricity in the higher-water years and exports it to other regions. While this hydrological pattern is still visible when considering the entire Western Interconnection (Figure 23, right), meteorological differences in other VRE profiles and total availability also leads to changes in the total Western Interconnection generation by type. For instance, the lowwater year also has $18 \mathrm{TWh}$ less land-based wind generation than the normal-water year, and this difference dominates the total generation difference stack in Figure 23 (right).

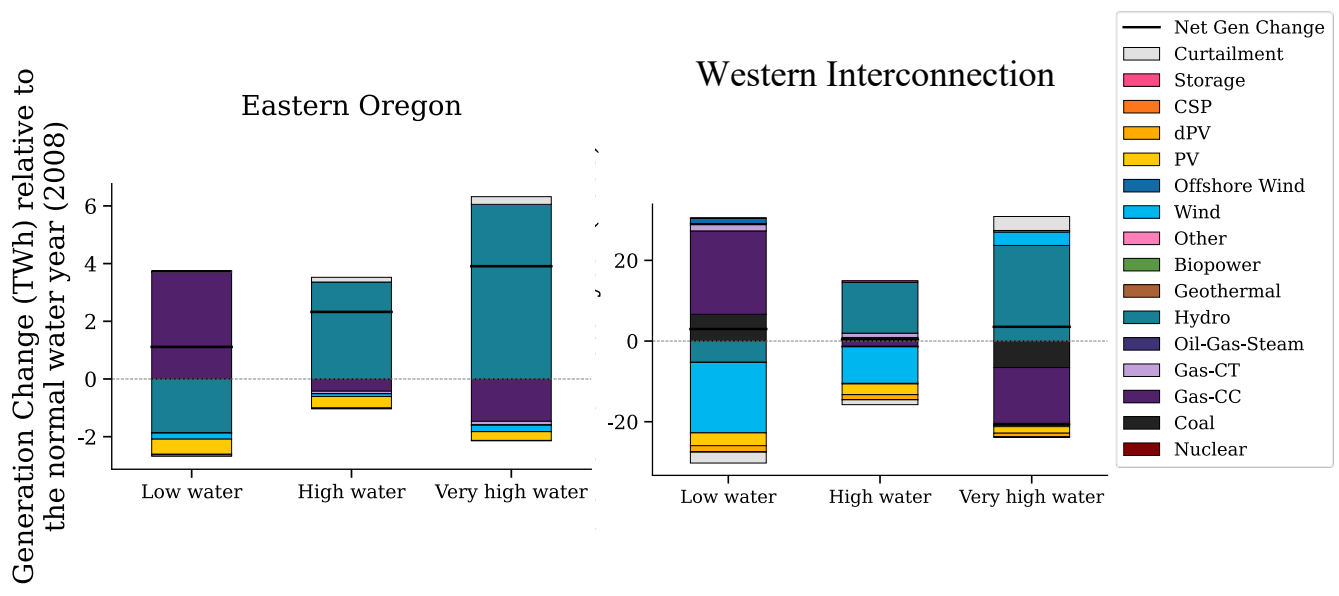

Figure 23. Total annual generation change for the low-, high-, and very high-water years relative to the "normal" water year of $2008^{33}$

Figure 24 plots the impact of water resources on total annual curtailment in Eastern Oregon (left) and the entire Western Interconnection (right). Despite an increase in total hydro generation from

\footnotetext{
33 The net generation increases in the Western Interconnection for both the low- and very high-water years (indicated by the solid black lines in the figure). The increase is due to higher loads in those years relative to 2008, the normal-water year. The load increase is less than $1 \%$ of the total annual generation of about $1,100 \mathrm{TWh}$.
} 
the normal- to high-water year of only $5 \%$, total curtailment in Eastern Oregon roughly doubles. Further, hydro generation increases by $10 \%$ between the normal- and very high-water year, but curtailment triples. A portion of the additional curtailment is due to changes in land-based wind and solar PV profiles and the interannual variability of the total resource in these other meteorological years. By contrast, the total annual offshore wind resource has little impact on curtailment. As shown in Figure 21 (left), the three aforementioned water years have roughly the same total offshore wind resource (each within $5 \%$ of their average).

The relationship between hydropower resource and total curtailment is different when considering the entire Western Interconnection. As shown in Figure 24 (right), both the low- and very high-water years still correspond to proportionately less and more total curtailment. However, we make the unintuitive observation that while total hydropower generation increases by $5 \%$ in the high-water year (2012) compared to the normal-water year (2008), total curtailment decreases by $6 \%$. This is likely due to the fact that hydro has an outsized impact in Eastern Oregon, compared to the full Western Interconnection, so its proportional impact on curtailment is no longer clear. Instead, the difference in land-based wind availability between these meteorological years has a dominating impact on curtailment. The low (2010) and high water (2012) years have both lower land-based wind availability and lower curtailment than the normal (2008) and very high water (2011) years. Specifically, 2010 and 2012 have 19.8 GWh and 9.1 GWh less wind resource availability than 2008, and 2011 has 5.2 GWh more. Solar resource availability is more constant across these four meteorological years, so it has a smaller impact on curtailment.

Eastern Oregon
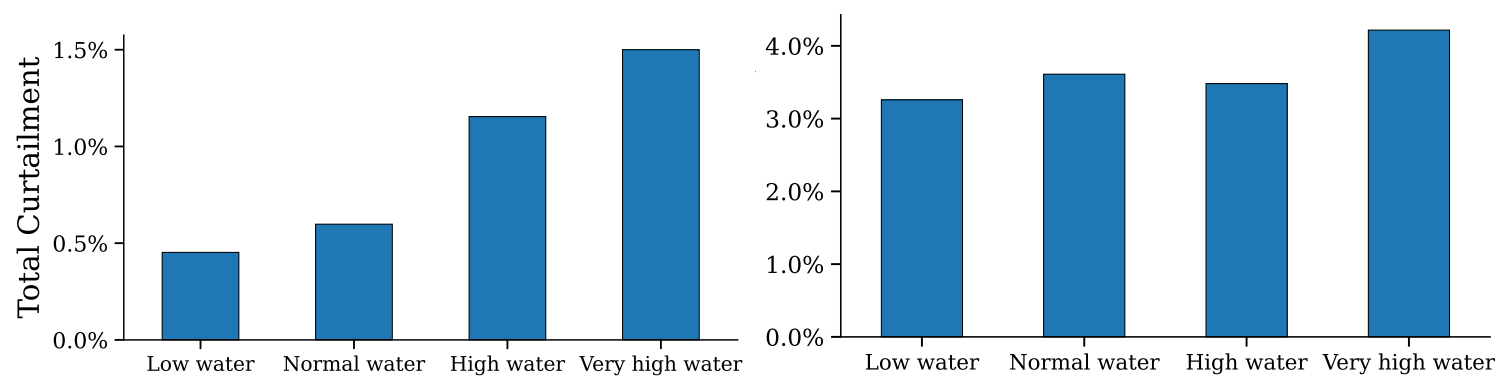

Figure 24. Total curtailment (total generation divided by total resource availability) in the High Offshore-FG-Tx transmission scenario for years with different hydropower resource availability. Eastern Oregon is shown on the left, and the full Western Interconnection is shown on the right.

Annual hydrological conditions also impact the total value that offshore wind provides to the system. Figure 25 plots the total system value, which includes operational cost savings, capacity value, and value of avoided emissions, for the four water years analyzed in this section. As annual hydropower generation increases, it displaces gas generation (see Figure 23) and reduces fuel costs slightly. There is, therefore, less opportunity for offshore wind to displace gas, and its operational value is slightly reduced. This reduction is shown by the fuel cost and value of avoided emissions bars in Figure 25.

Still, the difference in offshore wind's operational value between meteorological years is small, and the variation in total system value is much more dominated by the value of avoided thermal 
capacity (shown by the red stacks in Figure 25). This difference is less impacted by the amount of hydropower generation, and more by the correlation of offshore wind and net load. As shown in Figure 21, the capacity credit of offshore wind in the high-water year of 2012 happens to be well below average, so its total system value stack is noticeably lower. The normal-water year of 2008 is very close to average, and the low- and very high-water years of 2010 and 2011 are well above average.

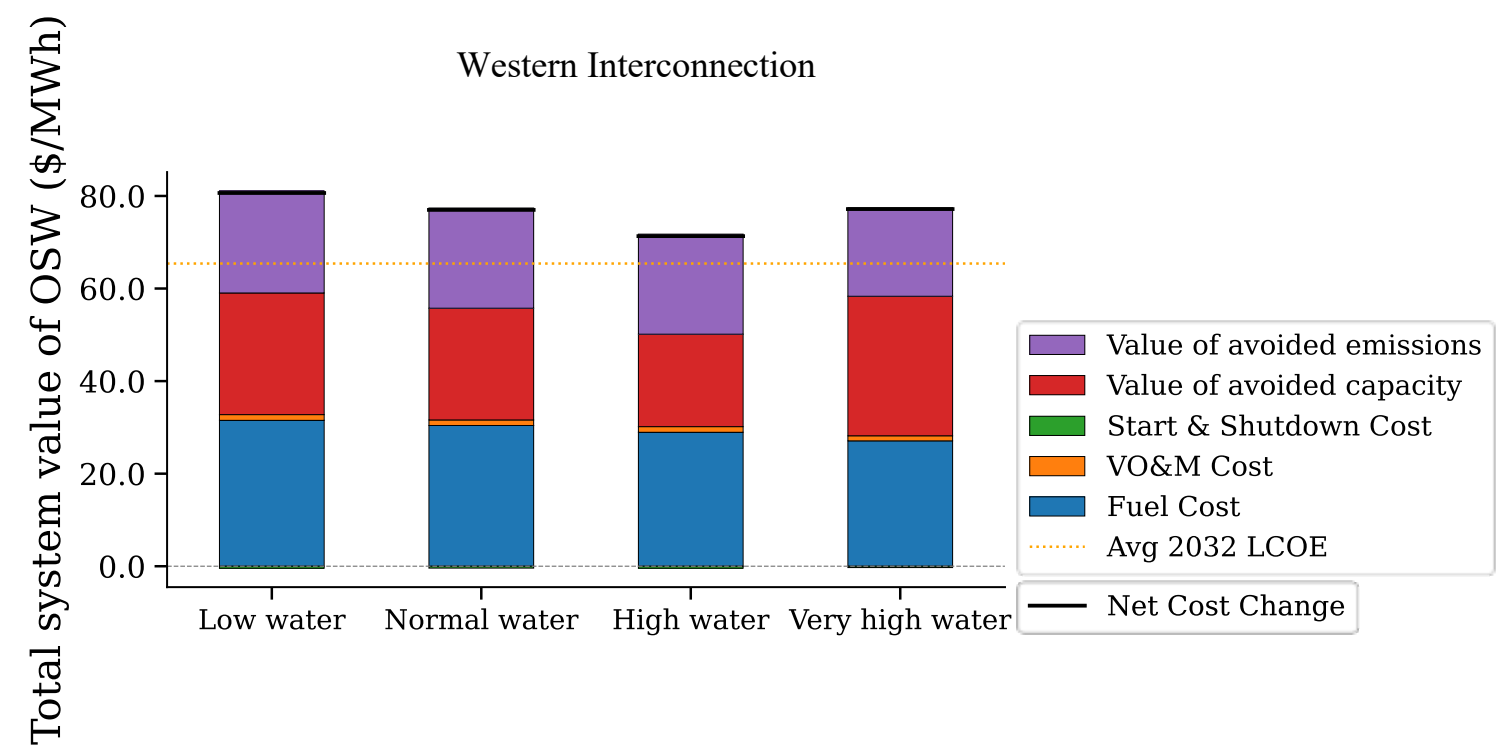

Figure 25. Total system value stacks for offshore wind, averaged across different hydropower resource years compared to the $0-\mathrm{GW}$ base case.

\subsection{Cross-Cascade Power Flow}

This section describes the extent to which offshore wind generation could alleviate transmission flows between the land-based renewable resource rich regions east of the Cascade Range and load centers in the Willamette Valley and Puget Sound. We find that offshore wind does generally reduce on power flow across the Cascades, but it is unlikely to significantly relieve the reliance on cross-Cascade transmission during peak load hours in Portland and the rest of the Willamette Valley.

As shown in Figure 5, the rural expanse east of the Cascade Range could see significant growth of wind and solar energy, and that growth is reflected in the future infrastructure scenario. This area, marked by large-scale VRE buildout, encompasses Eastern Oregon, and parts of Eastern Washington, Idaho, and Wyoming. Since much of the electrical load in the Pacific Northwest is located west of the Cascade Range in the I-5 corridor, cross-Cascade transmission and the possible need for greater expansion has long been a topic of great interest. The portion of this transmission corridor within Oregon, illustrated in Figure 26, is grouped into an interface called "P05 West of Cascades-South." The existing thermal power flow limits for the P05 interfaces are 5,738 MW in summer (June through September) and 7,605 in winter. The increase in variable renewable generation east of the Cascades may lead to congestion or require transmission upgrades on this interface. This section explores the relationship between Oregon offshore wind and power flow across the Cascades along the P05 interface. 


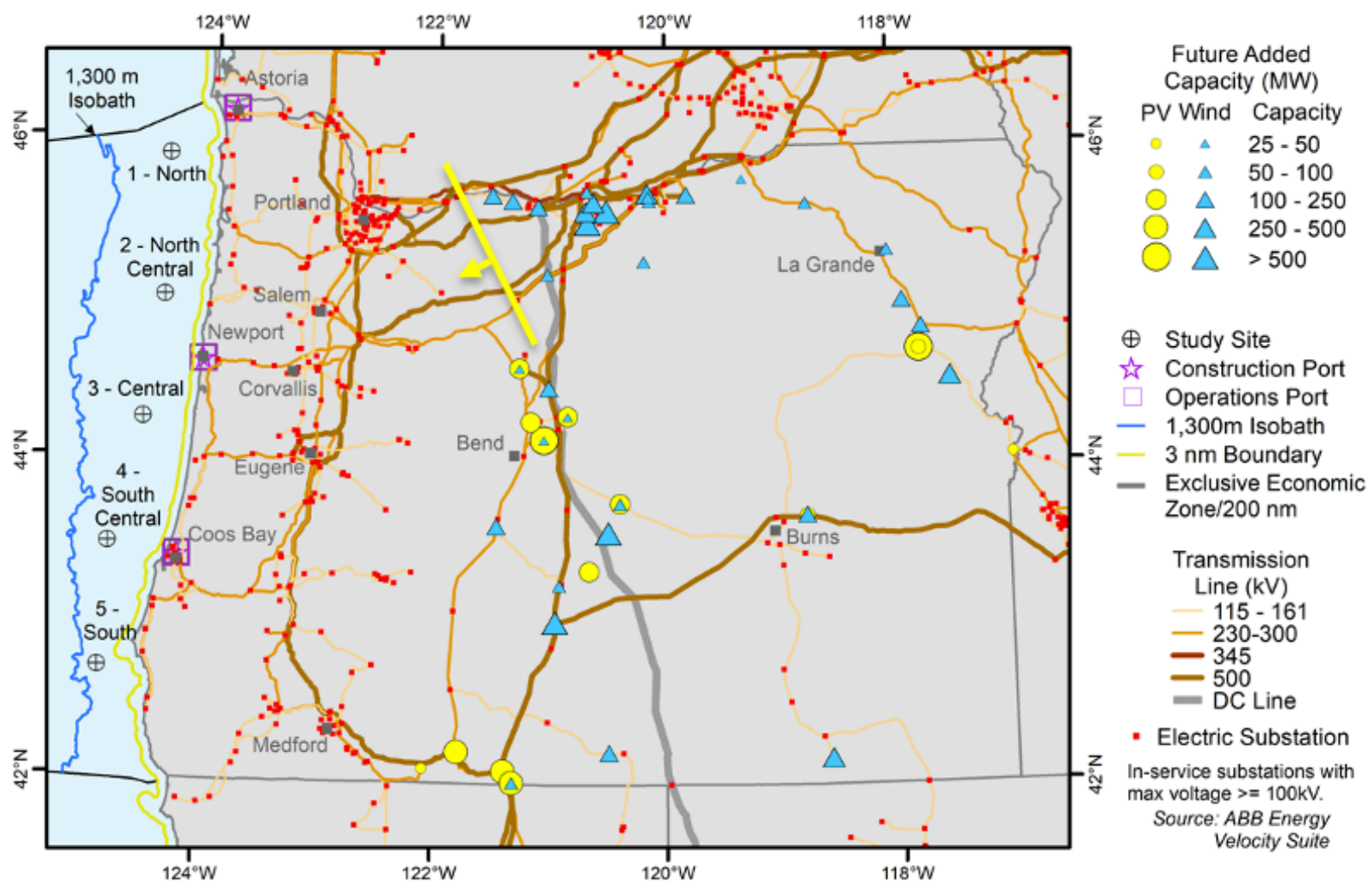

Figure 26. Electrical transmission map of Oregon, including the offshore wind sites and their points of interconnection. The "P05 West of Cascades-South" interface is shown with the yellow arrow.

Table 6. summarizes the annual flow reduction on the P05 interface associated with each of the offshore wind generation scenarios. Column 2 reports post-curtailment offshore wind generation data. In column 3, total P05 flow is compared between the given scenario and its associated no offshore wind base case (i.e., either 0-GW current or 0-GW future). As shown in the fourth column, the ratio of P05 flow reduction to offshore wind injection is roughly -0.49 across all scenarios. This suggests that regardless of the level of offshore wind penetration or other infrastructure developments (co-located storage or adjacent transmission upgrades), every 1,000 MW of injected offshore wind power is associated with 511-537 MW reduced East to West flow in the P05 interface. 
Table 6. Annual Flow Reduction on the P05 Interface for all Scenarios With Offshore Wind Generation

\begin{tabular}{|l|l|l|l|}
\hline Scenario & $\begin{array}{l}\text { Annual Offshore } \\
\text { Wind Generation } \\
\text { (TWh) }\end{array}$ & $\begin{array}{l}\text { Total Annual P05 } \\
\text { Flow Reduction } \\
\text { Relative to 0-GW } \\
\text { Scenarios }\end{array}$ & $\begin{array}{l}\text { Normalized Flow } \\
\text { Reduction (P05 Flow } \\
\text { Reduction/Offshore } \\
\text { Wind Injection) }\end{array}$ \\
\hline Mid Offshore-CG & $10.6 \mathrm{TWh}$ & $-5.1 \mathrm{TWh}$ & -0.48 \\
\hline $\begin{array}{l}\text { MidOfffshore-CG- } \\
\text { Storage }\end{array}$ & $10.6 \mathrm{TWh}$ & $-5.1 \mathrm{TWh}$ & -0.48 \\
\hline $\begin{array}{l}\text { Mid Offshore-FG } \\
\text { 10.6 TWh }\end{array}$ & $-5.2 \mathrm{TWh}$ & -0.50 \\
\hline $\begin{array}{l}\text { High Offshore-FG } \\
\text { 15.8 TWh }\end{array}$ & $-7.9 \mathrm{TWh}$ & -0.49 \\
\hline $\begin{array}{l}\text { High Offshore-FG- } \\
\text { Storage }\end{array}$ & $16.2 \mathrm{TWh}$ & $-8.1 \mathrm{TWh}$ & -0.50 \\
\hline $\begin{array}{l}\text { High Offshore-Tx } \\
19.4 \mathrm{TWh}\end{array}$ & $-9.6 \mathrm{TWh}$ & -0.50 \\
\hline $\begin{array}{l}\text { High Offshore-Tx- } \\
\text { Storage }\end{array}$ & $19.4 \mathrm{TWh}$ & $-9.6 \mathrm{TWh}$ & -0.50 \\
\hline
\end{tabular}

This pattern remains consistent when we compare offshore wind injection and P05 flow reduction at every hour of the year. Figure 27. Reduced East to West P05 interface flow versus offshore wind injection at every hour of the year, for most scenarios studied in the current (left) and future (right) grid scenarios. The dotted green and red trendlines are fit to the Mid OffshoreStorage scenario in the current grid and the High Offshore-Tx scenario in the future grid, respectively. plots the P05 flow reduction against the concurrent instantaneous offshore wind injection at every hour of the year. The slope of the linear fit in both current and future is -0.52 , consistent with the total annual results. Any injection of offshore wind reduces the flow, and thus reliance on, the P05 interface. 


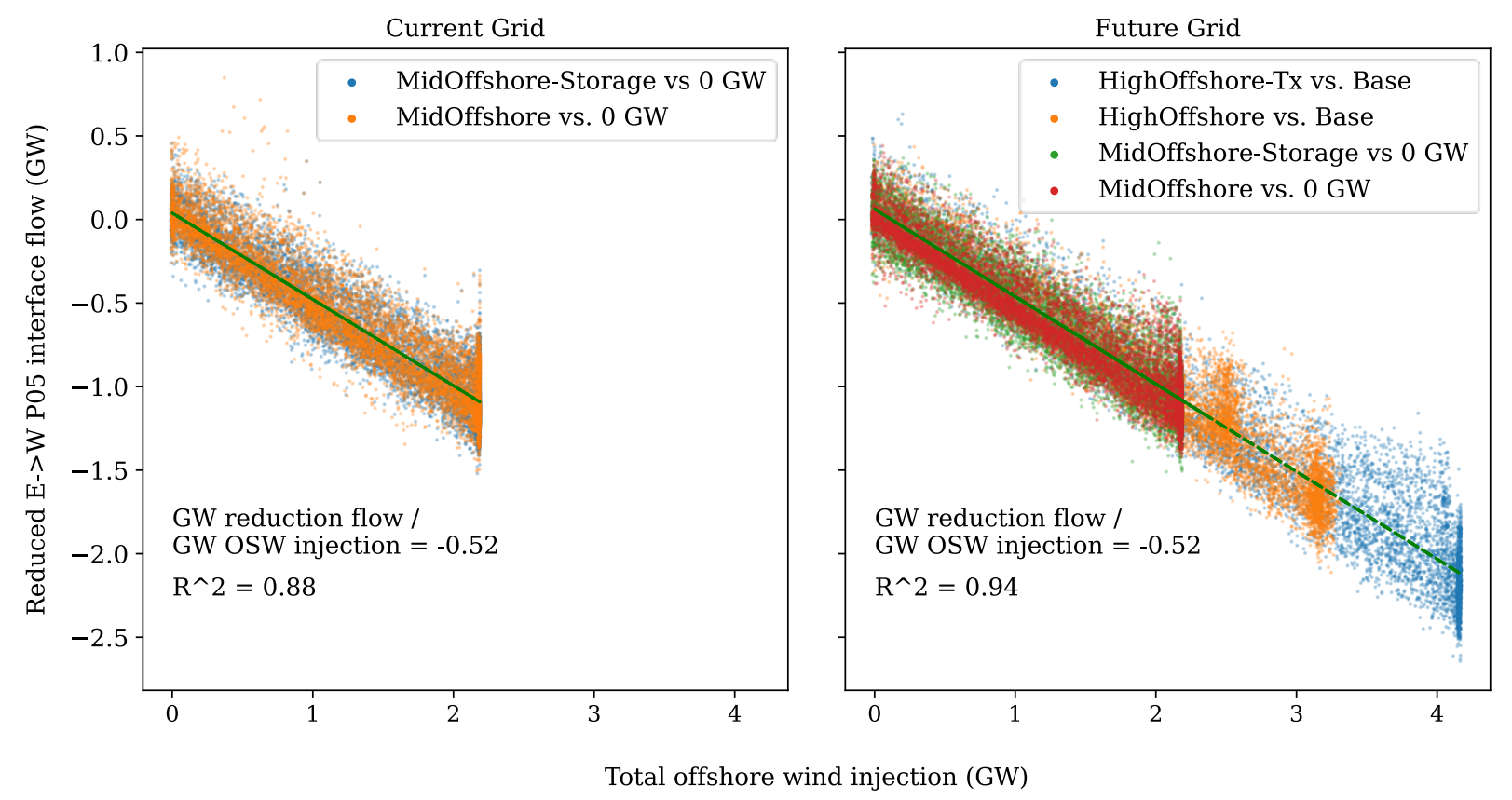

Figure 27. Reduced East to West P05 interface flow versus offshore wind injection at every hour of the year, for most scenarios studied in the current (left) and future (right) grid scenarios. The dotted green trendlines are fitted to each scenario.

While reducing reliance on the P05 transmission corridor would benefit Oregon's grid, some of this benefit could be eroded if it corresponds to increased renewable energy curtailment elsewhere in the system, such as Eastern Oregon. In Figure 28 and Figure 29, we examine two 3day periods of offshore wind-related P05 flow reduction: the first is associated with no increase in Eastern Oregon curtailment, while the second period has the highest Eastern Oregon curtailment in the record. This curtailment is exacerbated by, but not solely due to, offshore wind.

We observe the highest reduction in P05 flow on December 22, and the system dispatches surrounding this day are shown in Figure 28. The single-day average flow of the P05 interface reduces from $4.9 \mathrm{GW}$ in the 0 -GW offshore wind base case to $2.6 \mathrm{GW}$ in the High Offshore-Tx scenario, a reduction of 44\%. Unsurprisingly, December 22 also corresponds to the second highest offshore wind generation day in the simulation. 

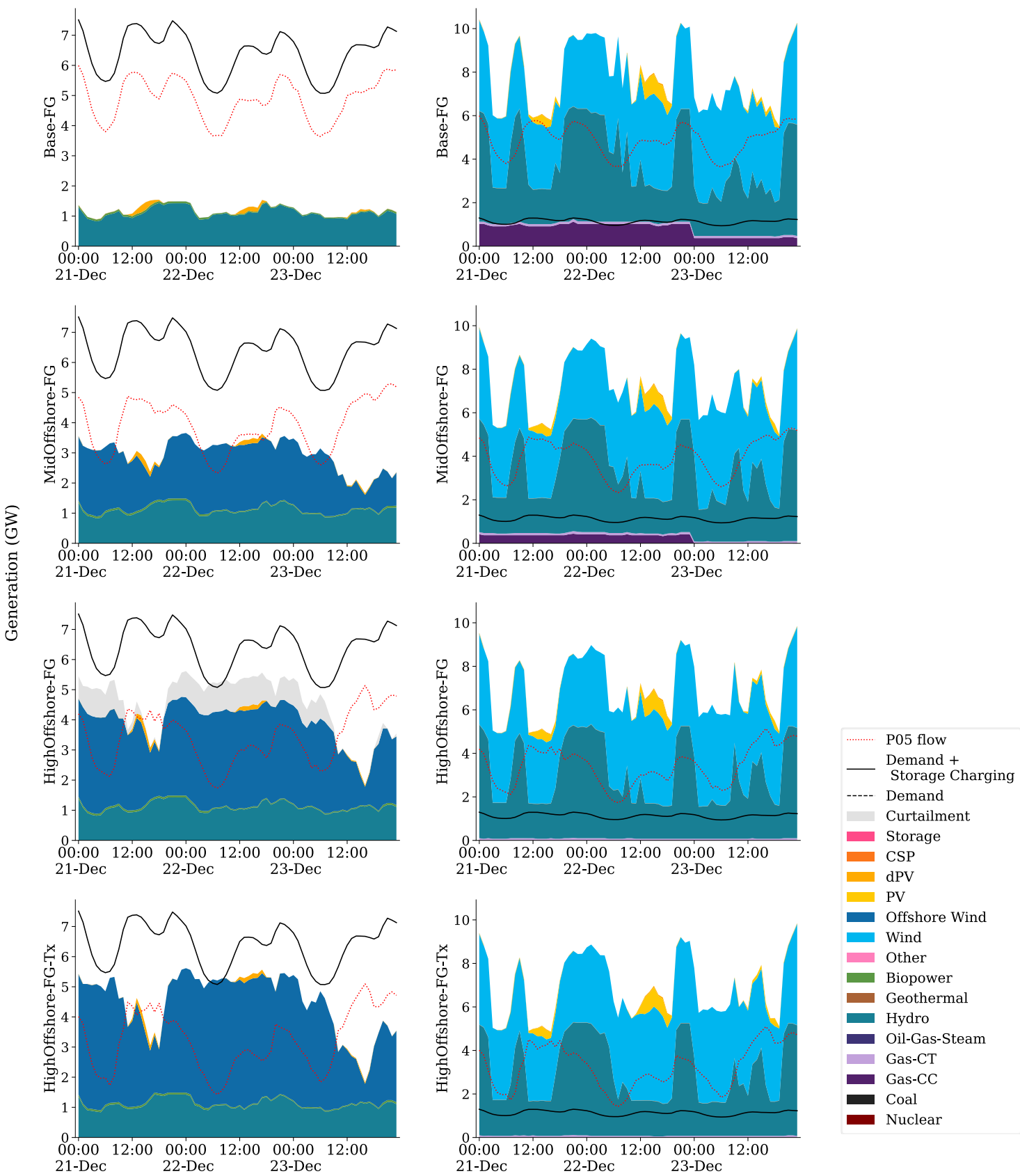

Figure 28. Dispatch stacks for the three-day period surrounding the highest P05 flow reduction day, for Western Oregon (left) and Eastern Oregon (right). P05 hourly flow is shown with the dotted red line. December 22 also corresponds to the second highest offshore wind generation day. No Eastern Oregon curtailment is observed during this period.

Despite high levels on December 22 of both offshore wind generation (average single-day capacity factor in the High Offshore-FG-Tx scenario of 53\%) and land-based wind generation in Eastern Oregon (average single-day capacity factor of 56\%), the system requires no curtailment of land-based wind or solar PV in Eastern Oregon. The only offshore wind curtailment occurs in 
the High Offshore-FG scenario without trans-coastal transmission upgrades and is entirely due to trans-coastal transmission congestion. Only gas generation (both gas-CT and gas-CC) is displaced by offshore wind. In part, this is due to the fact that utility-scale solar PV and distributed PV operate at very low levels (both with average single capacity factors of $3 \%$ ) during this winter period.

In contrast, Figure 29 plots the system dispatch for a period that sees both high offshore wind generation and high curtailment in Eastern Oregon. Land-based wind and solar PV in Eastern Oregon during this time period is curtailed by $22 \mathrm{GWh}(6 \%)$ in the $0-\mathrm{GW}$ offshore wind base case. Spring is generally marked by oversupply from wind and hydropower and lower loads and is a normal time to see increased land-based VRE curtailment, irrespective of offshore wind. In the scenario with the highest offshore wind generation-High Offshore-FG-Tx-Eastern Oregon VRE curtailment rises to $31 \mathrm{GWh}(9 \%)$. However, not every MWh of offshore wind is counteracted by a MWh of VRE curtailment elsewhere in the system. The additional land-based VRE curtailment in Eastern Oregon only corresponds to $7 \%$ of the offshore wind injected during the three-day period. Curtailment throughout the Western Interconnection increases more significantly during this three-day period; the additional interconnection-wide land-based VRE curtailment corresponds to $47 \%$ of the offshore wind generation. We chose this period intentionally to demonstrate operational tradeoffs during an especially high oversupply period in Eastern Oregon. This high level of land-based curtailment corresponding to high offshore wind injection is not common the rest of the year. 


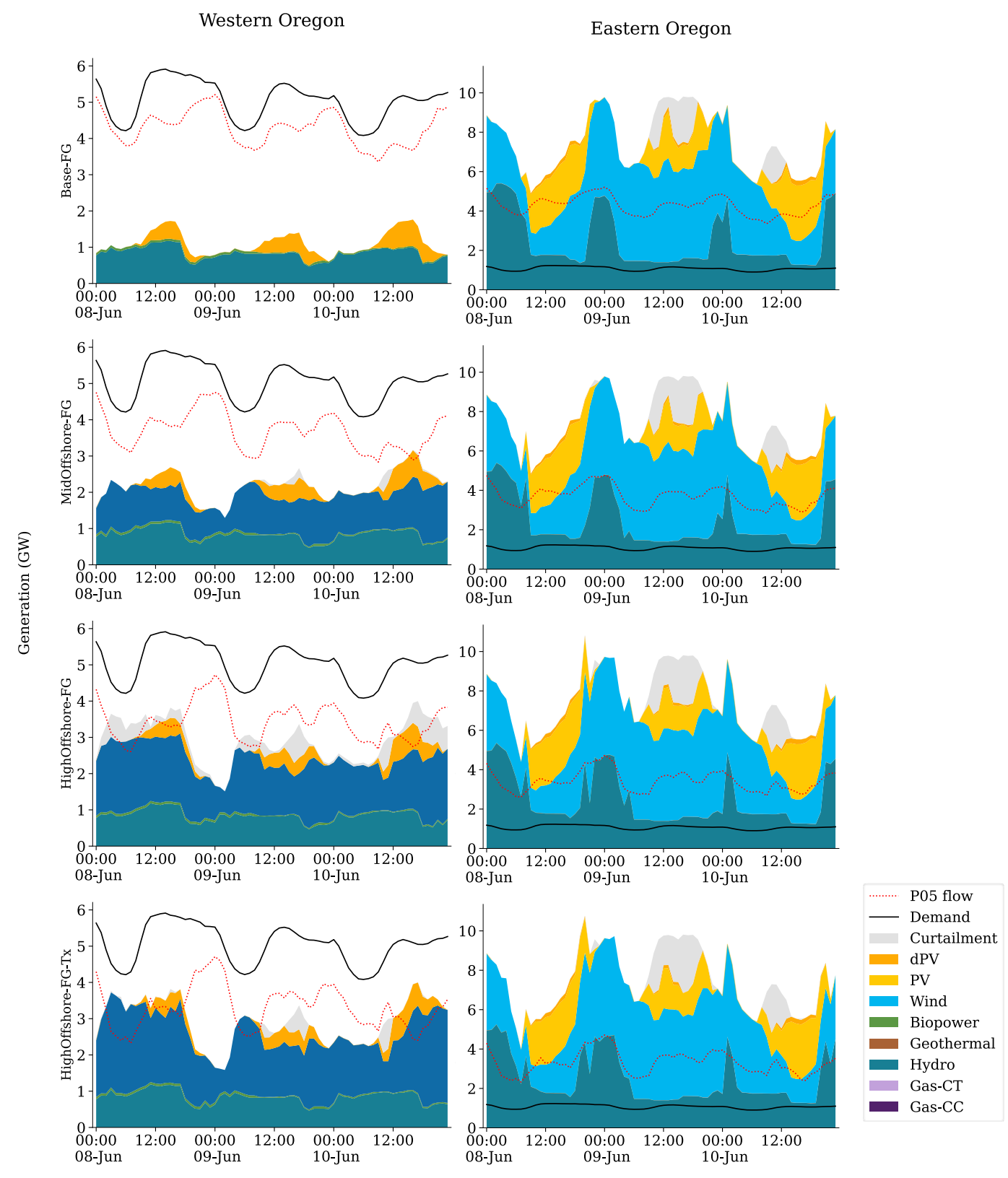

Figure 29. Dispatch stacks for the three-day period surrounding the day with the highest curtailment in Eastern Oregon, June 9, for Western Oregon (left) and Eastern Oregon (right). P05 flow is shown with the dotted red line.

Finally, the system benefits of offshore wind can carry over into periods with little to no offshore wind resource nor a corresponding change in P05 flow. Summarized in Figure 30, September 19-20 are the two lowest offshore wind days in the simulation (averaging $18 \mathrm{MW}$ and $11 \mathrm{MW}$, respectively). There is therefore little change during this period between scenarios. However, average and larger offshore wind generation during other periods in this month allow hydropower operations to store and allocate more water for generation on days with little contribution from offshore wind, as its operational constraints allow. Additionally, a 250-MW gas-CC unit is committed in the $0-\mathrm{GW}$ offshore wind base case from noon on September 19 to midnight on September 22. However, in the Mid Offshore and High Offshore wind scenarios, 
increased hydropower generation in Eastern Oregon allows this unit to be turned off a day early, at midnight on September 21. Elsewhere in the Western Interconnection, the reallocation of water to be used on different days leads to the displacement of $95 \mathrm{GWh}$ of mostly gas-CC generation over the three-day period of low to no offshore wind generation.

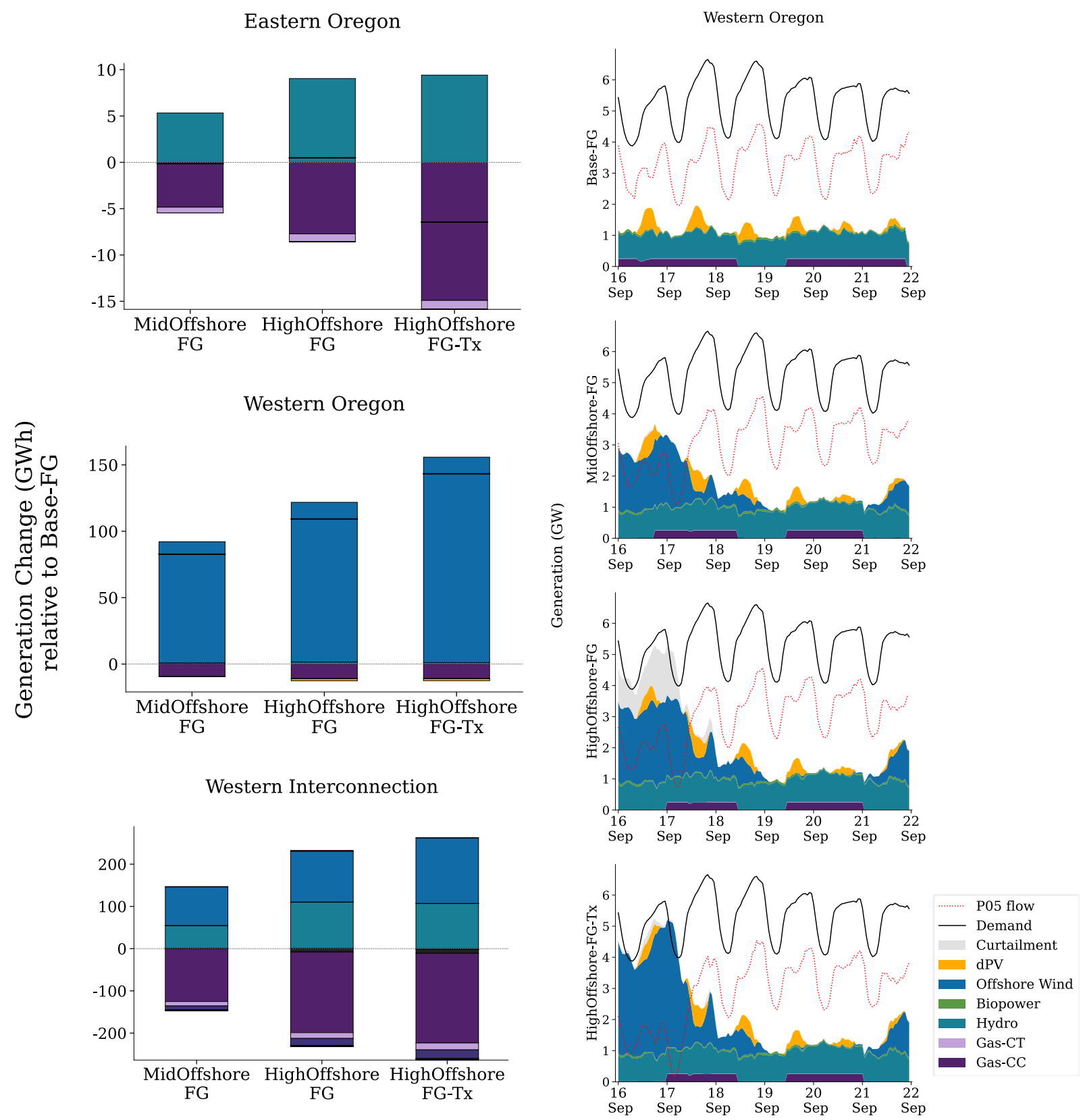

Figure 30. Summary of a three-day period with no P05 flow reduction, shown with total generation difference by technology type (left) and time series dispatch stacks (right). The black line on plots on the left is the net generation change relative to the Base-FG scenario.

Although P05 flow during the low offshore wind dispatch period shown in Figure 30 is not especially high, there are other periods with low offshore wind that do correspond to periods of high P05 flow. As seen in the duration curves in Figure 31, P05 flow rises above $6 \mathrm{GW}$ during 
some hours in all scenarios. Transmission planners design new transmission investments considering peak flow conditions, and thus we now analyze the peak P05 flow hours to understand offshore wind's contribution during peak conditions.

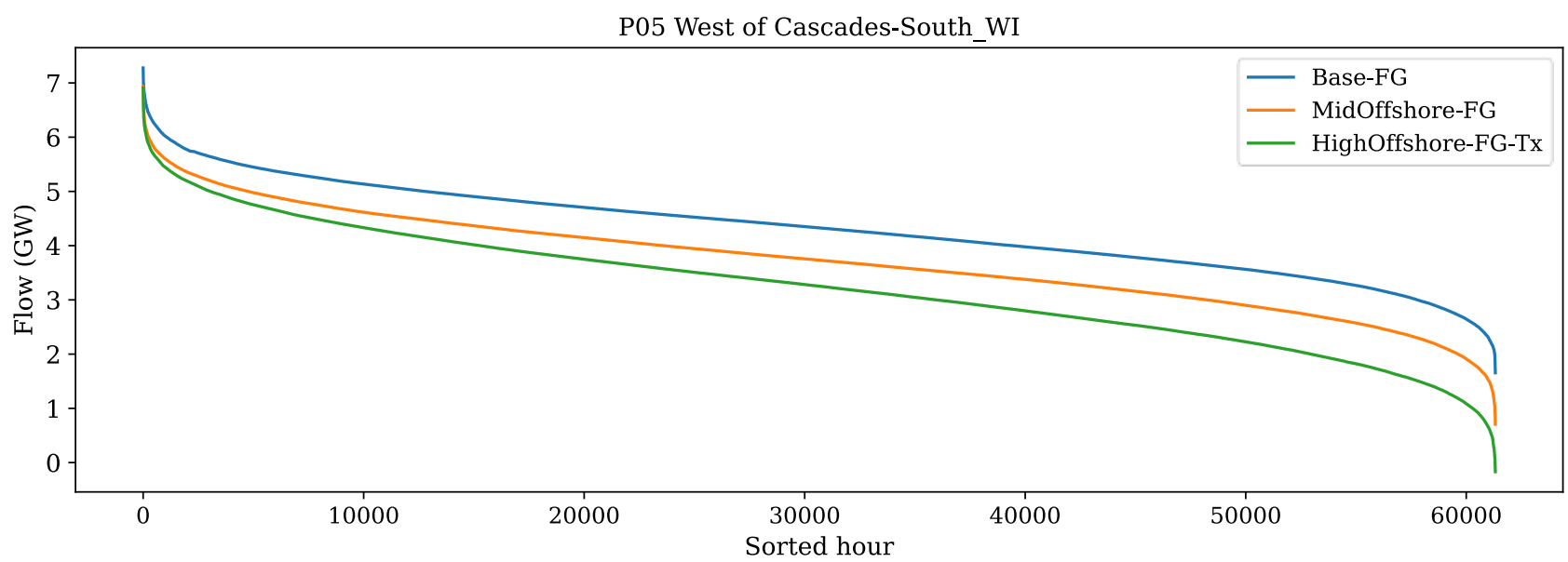

Figure 31. Flow duration curve of the P05 interface for all three offshore wind penetration scenarios in future. Data from all seven meteorological years is combined.

The most significant source of value for offshore wind transmission alleviation is the extent to which offshore wind operates during periods of high flow in the $0 \mathrm{GW}$ base case. Because the P05 thermal limits vary seasonally, we split the results into summer (June through September) and winter. Figure 32 breaks the summer P05 flow data into 1-GW bins and includes box and violin plots for the offshore wind power within each of these bins. The boxplots represent the $25^{\text {th }}, 50^{\text {th }}$, and $75^{\text {th }}$ quartiles, and the whiskers plot 1.5 times the interquartile range. The colored violin distributions in Figure 32 are a fitted histogram and help visualize the concentration of offshore wind. The number of simulation hours that fall into each bin is indicated by the $n$ value below each violin plot. Figure 33 shows the same results for the winter months.

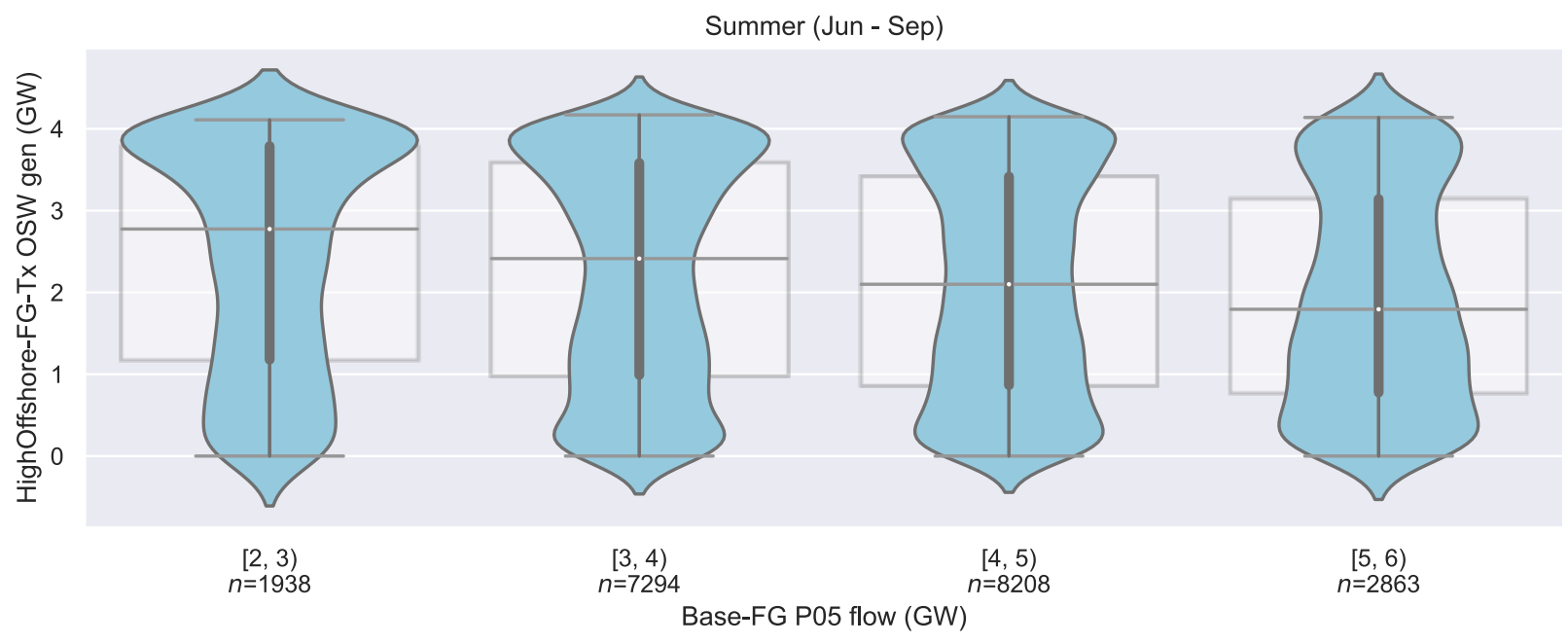

Figure 32. Offshore wind performance during the 0-GW offshore wind base case P05 summer flow hours (June through October). The set of violin plots breaks every hour of the summer into 1-GW bins. Data from all seven meteorological years is combined. 
Across the seven years of PCM simulation, we see the median offshore wind generation steadily decrease from $2.5 \mathrm{GW}$ in the lowest P05 flow bin, to $1.9 \mathrm{GW}$ in the highest P05 flow bin. The right-most violin plot in Figure 32 represents the 2,863 peak summer flow hours across the entire 7 -year data set during which $\mathrm{P} 05$ flow is greater than $5 \mathrm{GW}$. The violin distribution shows that this bin has a noticeably lower percentage of hours near maximum offshore wind output. The fifth percentile of injected offshore wind power during these high P05 flow hours over the seven years is only $103 \mathrm{MW}$, suggesting that at least this much offshore wind power could be counted on during periods of high flow. Using the robust 2:1 relationship between hourly offshore wind generation and P05 flow reduction discussed earlier in the section, offshore wind generation could reduce the need of up to $54 \mathrm{MW}$ of transmission capacity on P05 in the summer.

While the potential of offshore wind to alleviate P05 transmission flow in summer is limited, there may be slightly more alleviation potential in winter, though still limited. The winter flow hours are plotted in Figure 33. During the 1,066 winter hours across the 7-year data set when P05 flow is greater than $6 \mathrm{GW}$, the fifth percentile of offshore wind performance is $154 \mathrm{MW}$. Similar to the summer P05 flow, applying the ratio determined above suggests that offshore wind could reduce the need for up to $81 \mathrm{MW}$ transmission capacity during the peak winter hours.

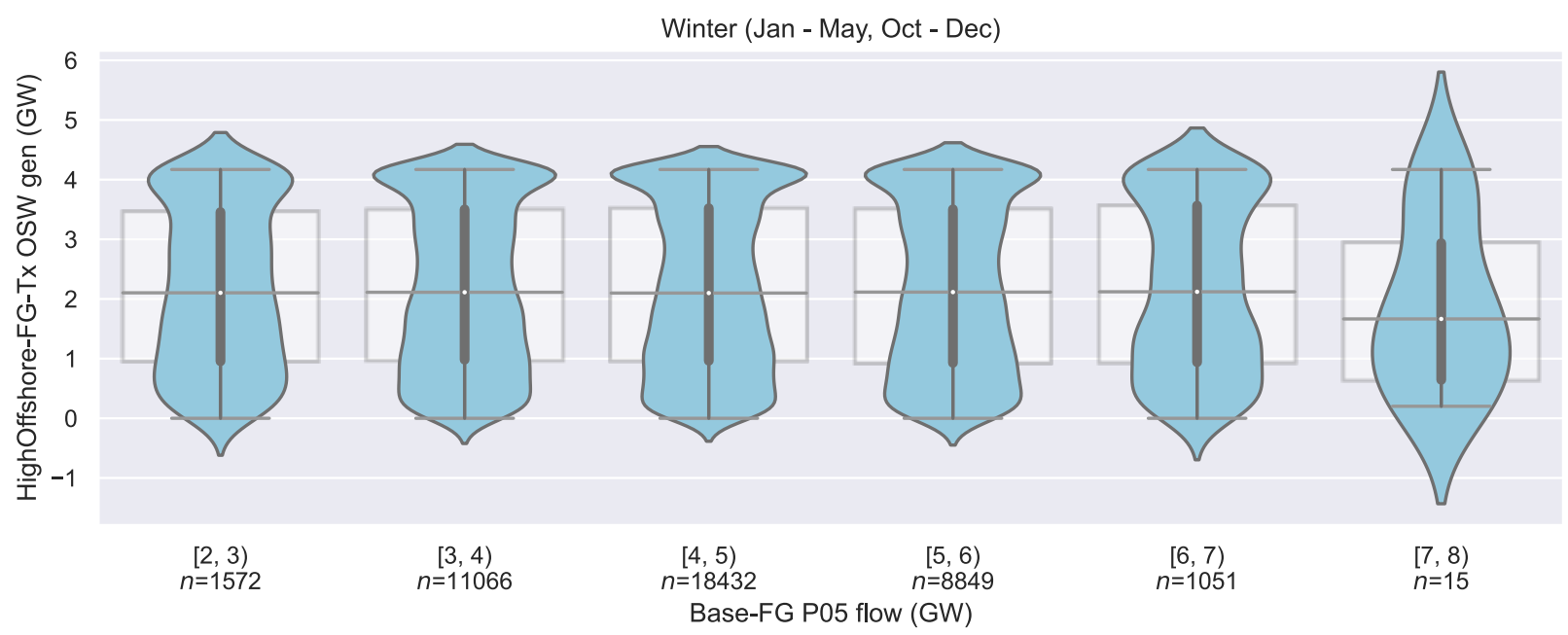

Figure 33. Offshore wind performance during the 0-GW offshore wind base case P05 winter flow hours (January-May, November-December). The set of violin plots breaks every hour of the winter into 1-GW bins. Data from all seven meteorological years is combined.

In this section, we demonstrated a strong 2:1 relationship between offshore wind generation and P05 flow. This relationship impacts generation east of the Cascades, but hardly displaces the generation equivalent to the reduction in P05 flow. For example, land-based variable renewable generation is not curtailed at the same rate as the P05 flow reduction. Eastern Oregon hydropower operation also changes to allocate its available generation to periods of low offshore wind generation. However, even though we see a strong relationship between offshore wind and P05 flow, this does not necessarily suggest that offshore wind could be a viable non-wires alternative to P05 transmission capacity. We found little relationship between high P05 flow hours and offshore wind generation potential. In other words, there are hours of high wind generation output and hours of low output when P05 flow is high. However, more analysis is needed to draw a more definitive conclusion. Our modeling is based on an economic 
optimization. Models instead tuned to address the reliability or resource adequacy of the system may suggest the system could operate reliably with more offshore wind and reduced (or not expanded) P05 transmission capacity. Without running a dedicated resource adequacy model, we cannot conclude that offshore wind provides a viable alternative to P05 upgrades.

\subsection{Opportunities for Offshore Wind to Mitigate Net Load "Duck Curve" Challenges}

Higher penetrations of solar PV in California over the last decade has led to a shift in the net load curve and increasing need for generation resources to ramp up quickly to meet steep evening peaks in net load, especially in the summer. This impact, termed the "duck curve," has been widely reported and studied for over a decade. ${ }^{34}$ As renewables continue to provide higher percentages of the region's energy, the challenges associated with the duck curve will continue to grow. The key resource adequacy risk will shift away from summer peak loads and instead to periods with lower total load but higher peak net loads in the evening (Novacheck et al. Forthcoming). As variable renewable penetrations increase, ensuring there is enough generation capacity during these hours will be one of the central concerns for grid operators and planners. Fully managing these challenges in the long term will require both "fattening" (i.e., increasing the flexibility of the power system) and "flattening" (i.e., shifting supply and demand in time using energy storage and demand response) the duck- (Denholm et al. 2015). While the duck curve is not unique to California, our future scenario suggests the duck curve will continue to be a greater concern in California than in Oregon and the Pacific Northwest. Example duck curves for CAISO generated from our model using the future scenario are shown in Figure 34.

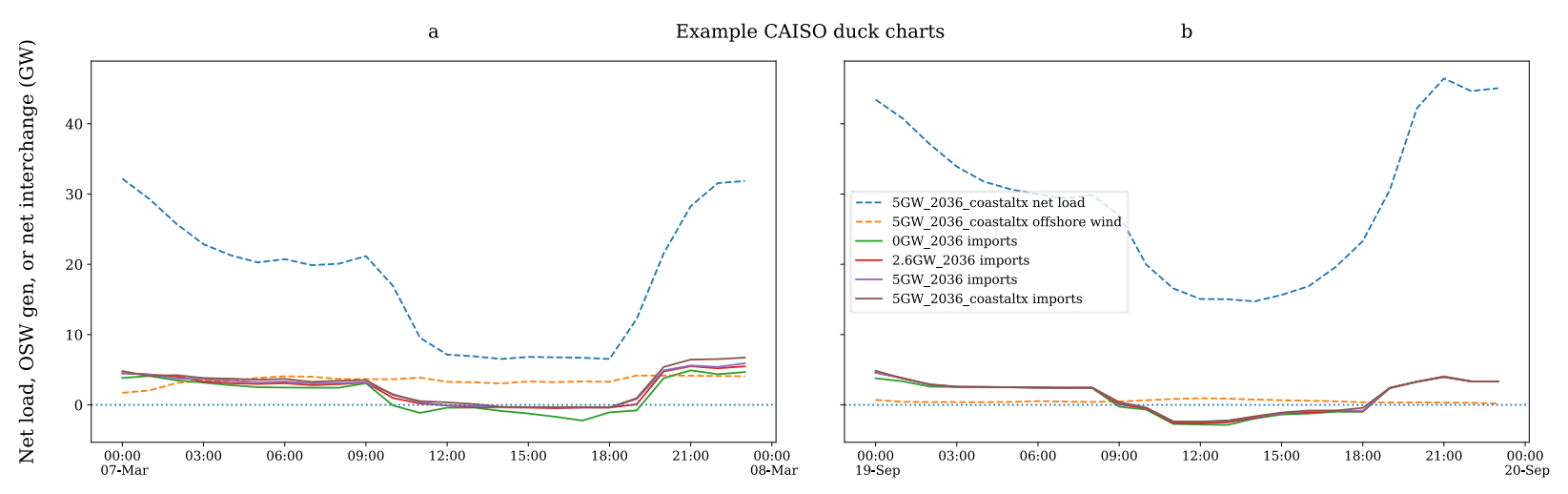

Figure 34. Net load plots for example days in CAISO, which illustrate the famous "duck curve" behavior. Net imports from Oregon and offshore wind generation are also plotted. The left plot is a day with high offshore wind resource and noticeable changes in Oregon to California imports, while the right plot is a day with little to no offshore wind.

Offshore wind could be part of the solution when paired with enough transmission capacity. To understand Oregon offshore wind's possible contribution to serving the peak net load in California, we focus on CAISO's electricity imports from Oregon-specifically how imports change with more offshore wind capacity and generation. Figure 34 shows two days from the 2012 meteorological year simulation. Both days show strong parallels between net load in

\footnotetext{
34 "Ten Years of Analyzing the Duck Chart." News article, National Renewable Energy Laboratory. February $26^{\text {th }}$, 2018. https://www.nrel.gov/news/program/2018/10-years-duck-curve.html.
} 
CAISO and net transmission flow from Oregon to California, with imports spiking during the evening peak. March 7, shown in Figure 34 (left), is a high offshore wind generation day and in scenarios with more offshore wind capacity, imports increase at all hours of the day relative to the base case. This increase is particularly apparent during the evening net load ramp and $0 \mathrm{G}$ peak. In contrast, September 19, shown in Figure 34 (right), has little offshore wind generation, and we observe little change in the net interchange between Oregon and California between scenarios.

We summarize these patterns for the entire year by calculating the correlations between the change in Oregon-to-California transmission flow relative to the $0-\mathrm{GW}$ offshore wind base case and the injected offshore wind power. The resulting correlation coefficients are 0.36 and 0.45 for the Mid Offshore-FG and High Offshore-FG-Tx scenarios, respectively. This suggests that as more offshore wind is injected into Oregon's coastal grid, it frees up more generation to export south to California.

While Oregon offshore wind helps manage CAISO's duck curve challenges, interstate transmission congestion limits its ability to provide more energy during the evening ramp. At least one Oregon/California transmission line is congested during 41\% of CAISO's evening ramps in the High Offshore-FG-Tx scenario. During 17\% of the evening ramps in CAISO, at least one Oregon/California transmission line in this scenario experiences congestion that did not experience congestion in the $0-\mathrm{GW}$ offshore wind base case. Here we define the evening ramp as any hour between 4 p.m. and 8 p.m. to capture seasonal time-of-day differences and match CAISO's convention.

Finally, offshore wind can help serve CAISO's summer net load peak, which has recently been identified as occurring during the $8 \mathrm{p} . \mathrm{m}$. hour from June through October. CAISO recommended that the California Public Utilities Commission increase its planning reserve margin specifically during this period to $17.5 \%$ (CAISO 2021). The average offshore wind capacity factor in our simulation during this summer hour, averaged across all seven meteorological years, is $52 \%$ and $49 \%$ in the Mid Offshore-FG and High Offshore-FG-Tx scenarios, respectively. This suggests that, depending on the offshore wind capacity penetration, 1,364 and 2,460 MW of offshore wind from Oregon could be relied upon to serve CAISO's new PRM at 8 p.m. in the summer, when paired with the needed transmission capacity.

\subsection{Impact of Storage Co-Located with Offshore Wind}

As discussed in Section 3.1, curtailment of offshore wind occurs almost exclusively due to congestion on the trans-coastal transmission system. Without trans-coastal transmission upgrades, storage can reduce curtailment in the $5 \mathrm{GW}$ scenario by $\sim 15 \%$, as shown above in Figure 12.

However, the storages in our simulation were sized relatively small, with a maximum power equal to $10 \%$ of the co-located offshore wind plant. Larger storage might further reduce curtailment. Our simulation contains a significant proportion of hours when the curtailment of offshore wind at each individual point of interconnection is greater than the charge rate of its associated co-located storage. Duration curves for these hours are plotted in Figure 35. The yaxis in Figure 35 corresponds to the difference, in MW, between the instantaneous power curtailment of offshore wind at the point of interconnection and the concurrent charge rate of its 
associated storage. The x-axis corresponds to the hours of curtailment. "Storage capacity constrained", corresponds to hours when the associated storage capacity is full, while "power capacity constrained" reflects hours when the storage is charging at its maximum power. For instance, during 28 hours of the year, the offshore wind energy connected to the Clatsop substation is curtailed by at least $500 \mathrm{MW}$ while the Clatsop storage is full. Similarly, during 137 hours of the year, this offshore wind energy is curtailed by at least $350 \mathrm{MW}$ while the Clatsop storage is charging at its maximum rate of $100 \mathrm{MW}$.

The sum of these additional curtailment reduction opportunities across the five offshore wind points of interconnection, broken down by storage constraint type, are listed in Error!

Reference source not found. These represent the areas under the duration curves in Figure 35.

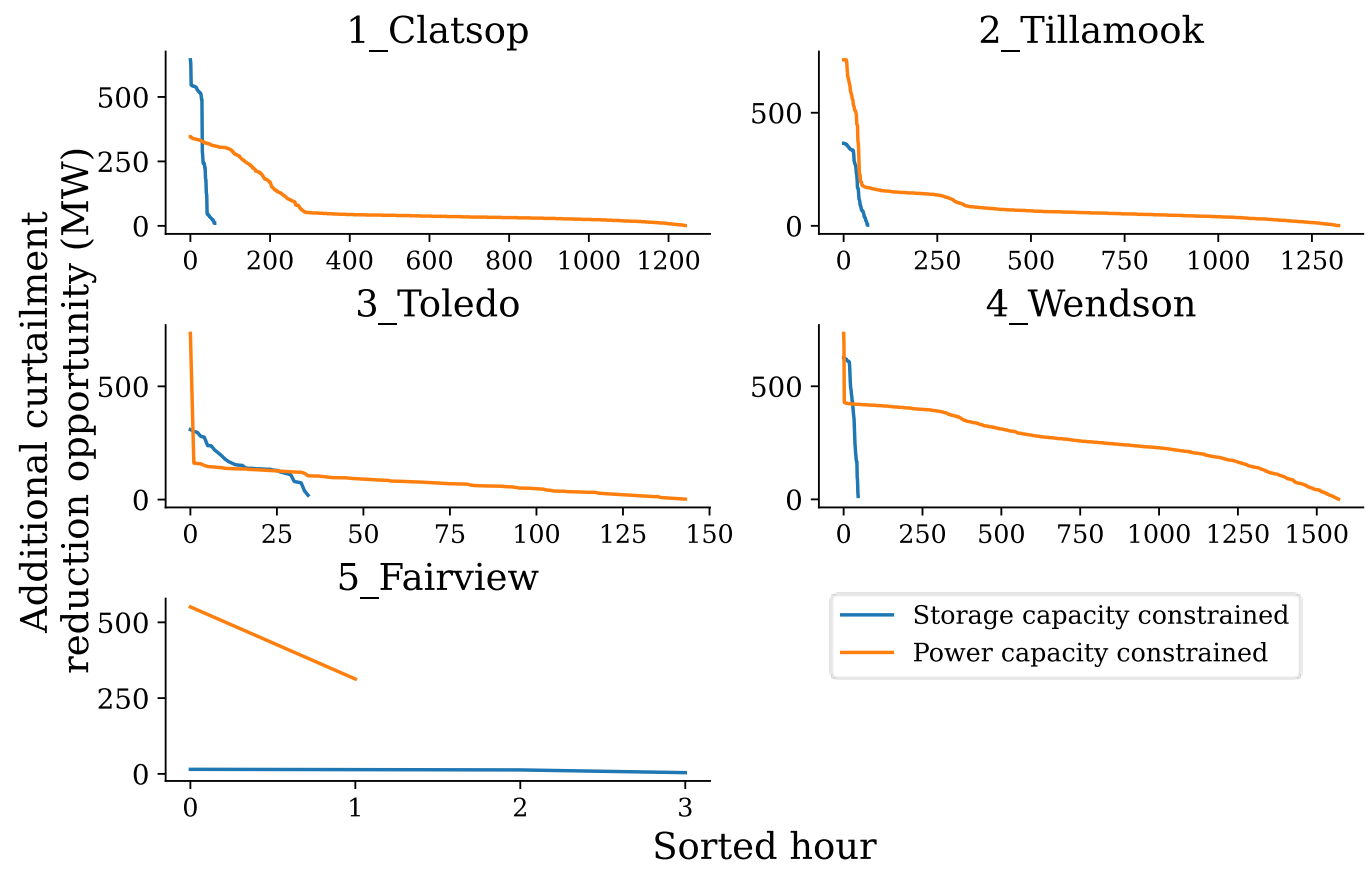

Figure 35. Duration curves for all hours that represent opportunities where larger storage might further reduce offshore wind curtailment. The orange and blue lines represent hours where curtailment reduction opportunities might be provided by upgrading the storage power and capacity, respectively.

While the upgrading the storage generators at Clatsop, Tillamook, and Wendson might reduce offshore wind curtailment during a significant number of hours, the energy storage generators at Toledo and Fairview are rarely $(2 \%$ and $<1 \%$ of the year, respectively) constrained by either their storage or charging capacity. 
Table 7. Additional Curtailment Opportunities for Each Co-Located Offshore Wind Energy Storage Generator, Broken Down by Constraint Type

\begin{tabular}{|l|l|l|}
\hline $\begin{array}{l}\text { Energy } \\
\text { Storage } \\
\text { System }\end{array}$ & $\begin{array}{l}\text { Additional Curtailment That } \\
\text { Could Be Avoided by } \\
\text { Increasing Storage Capacity }\end{array}$ & $\begin{array}{l}\text { Additional Curtailment That Could } \\
\text { Be Avoided by Increasing } \\
\text { Charging Capacity }\end{array}$ \\
\hline Clatsop & $19 \mathrm{GWh}$ & $95 \mathrm{GWh}$ \\
\hline Tillamook & $14 \mathrm{GWh}$ & $112 \mathrm{GWh}$ \\
\hline Toledo & $6 \mathrm{GWh}$ & $11 \mathrm{GWh}$ \\
\hline Wendson & $21 \mathrm{GWh}$ & $402 \mathrm{GWh}$ \\
\hline Fairview & $0.05 \mathrm{GWh}$ & $0.8 \mathrm{GWh}$ \\
\hline
\end{tabular}

Curtailment of offshore wind is also reduced when energy storage is deployed in conjunction with trans-coastal transmission upgrades. However, the curtailment reduction due to the colocated energy storage is much lower than that of the trans-coastal transmission upgrades. energy storage achieves this curtailment reduction by storing offshore wind energy (and occasionally other outside generation) and dispatching it in periods of low wind resource. This helps smooth output during relatively short periods of low wind, but even assuming 24-hour storage technology becomes viable, the benefit is limited during multiday wind droughts.

Figure 36 shows an example three-day period with short term dips in wind resource where energy storage provides value by filling in some of the generation gap. Between $11 \mathrm{a} . \mathrm{m}$. and 3 p.m. on November 17, available offshore wind energy drops from its maximum (834 MW at each site, totaling $4,170 \mathrm{MW}$ ) to $31 \%$ its maximum. The resource then almost returns to its maximum by $7 \mathrm{p} . \mathrm{m}$. The next day, the offshore wind resource drops from its maximum to zero output in 3 hours - from 3 p.m. to 6 p.m. - and remains at zero for three hours before partially recovering at $47 \%$ its maximum by 10 p.m. 

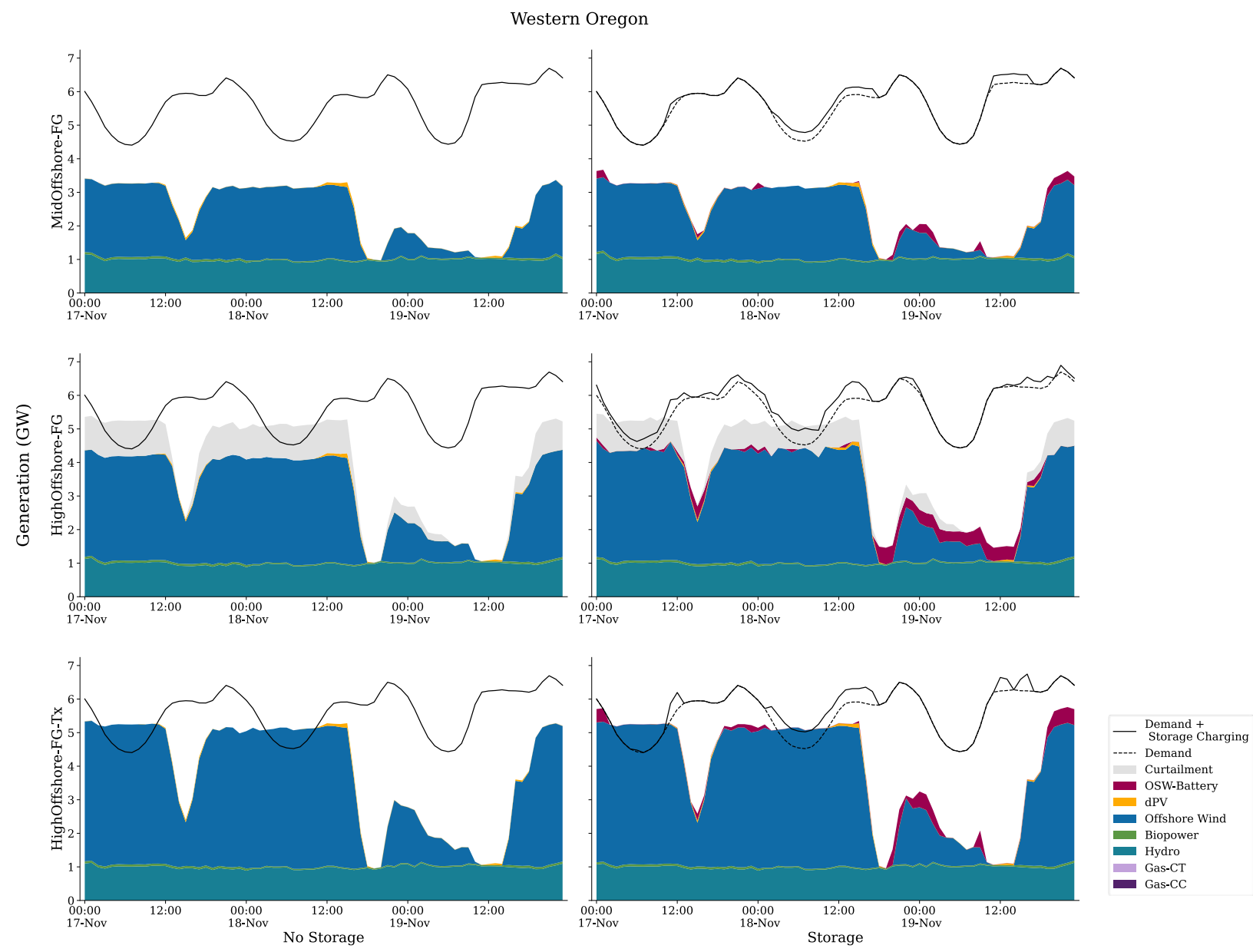

Figure 36. Dispatch stacks for Western Oregon during three-day periods with short-term dips in wind resource.

In the no transmission upgrades scenario, nearly a fifth of the offshore wind generation potential is curtailed when wind potential is at its maximum throughout November 17 and 18. During this time, the energy storage charges at or near its full capacity in the High Offshore-FG scenario, as indicated by the difference between the solid total load line (input load plus storage charging) and the dotted line (input load only) in the middle row, second column of Figure 36 . The midday dip in offshore wind potential on November 17 represents $10.0 \mathrm{GWh}$ energy compared to what would have been produced if the resource remained constant. During the dip, the storage generates 1.2 GWh. However, when trans-coastal transmission upgrades are included, storage only generates $0.3 \mathrm{GWh}$ during this dip. The storage continues to dispatch the stored offshore wind energy throughout the low offshore wind period from the evening of November 18 through 2 p.m. on November 19. It generates a total of 8.4 and 3.5 GWh in the High Offshore-FGStorage and High Offshore-FG-Tx-Storage scenarios, respectively. The lower energy storage dispatch in the latter scenario is due to the fact that expanded trans-coastal transmission eliminates the significant offshore wind curtailment before the dips, leading to a lower state of charge of the energy storage. In this example, when trans-coastal transmission is expanded, the storage responds more to outside system effects than deficits in offshore wind. 
The energy storage behaves quite differently during multiday wind droughts, as the storage does some preparation ahead of prolonged wind droughts. One such drought is plotted in Figure 37. In the High Offshore high curtailment scenario (without trans-coastal transmission upgrades), storage takes advantage of the high offshore wind curtailment by charging at least half its maximum capacity during most hours of September 16, reaching over $90 \%$ state of charge by 5 a.m. on September 17. Rather than dispatch this stored energy during the evening net load peak later that day, the storage maintains its charge to serve the following two evening net load peaks on September 19 and 20. Then, forecasting the gradual return of the offshore wind resource throughout the day on September 21, the storage dispatches most of its stored energy and reaches a minimum state of charge for the three-day period of $18 \%$ at midnight on September 22. As mentioned above in Section 2.4, this simulation assumed that the energy storage controllers have perfect 24-hour foresight of the system at a 4-hour resolution, including perfect wind, solar, and load forecasts. The operation of the energy storage, particularly during the multi-day wind drought plotted in Figure 36, might look significantly different were we to deploy a different control logic and foresight schedule. 

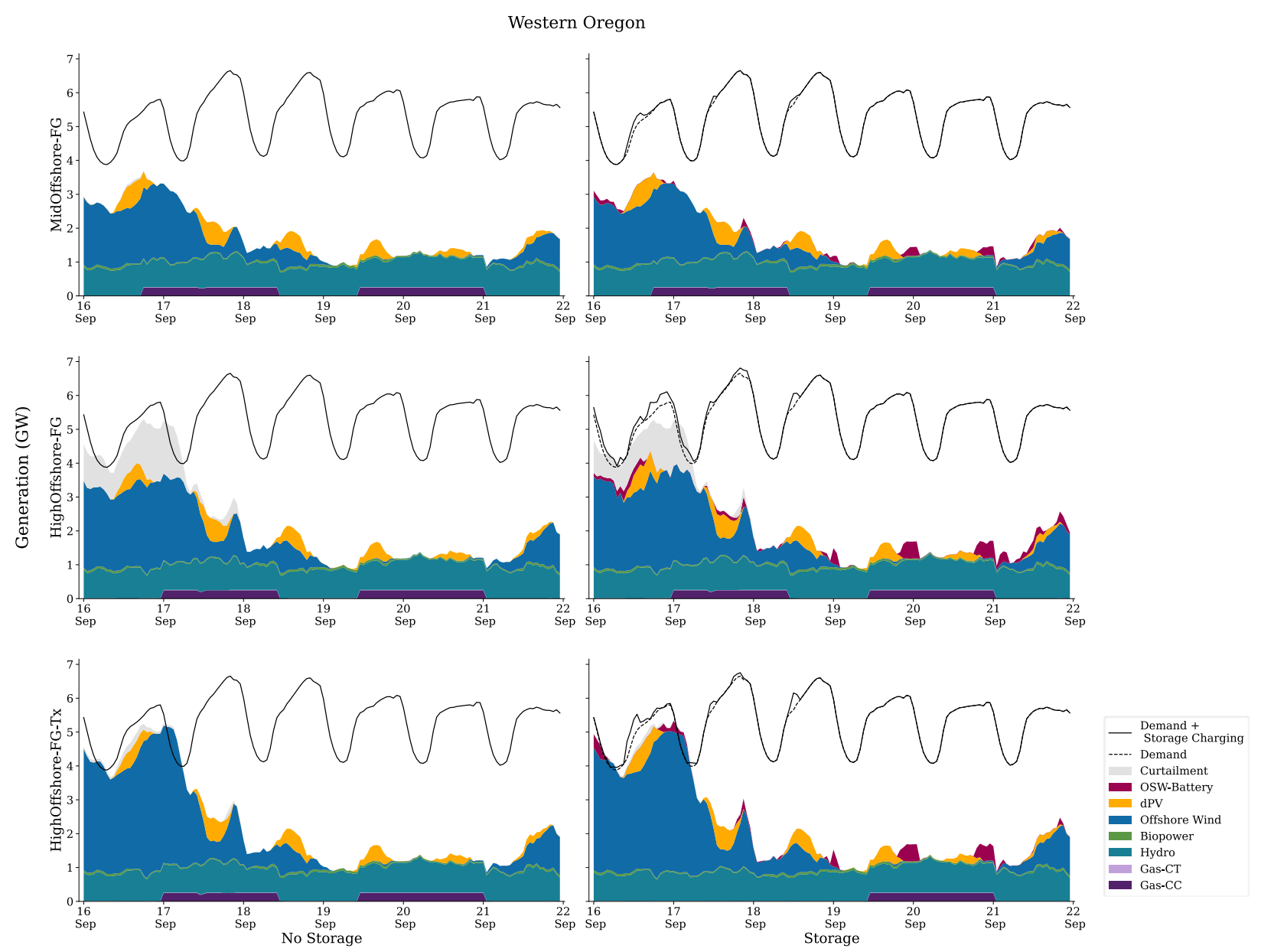

Figure 37. Dispatch stacks for Western Oregon during a three-day period with multiday wind droughts

As shown Figure 38, energy storage generally allows more offshore wind energy to reach the wider system by shifting energy in time. In some cases, this time-shifting is also associated with a change in flow across the trans-coastal transmission lines. One of the strongest examples of sustained change in trans-coastal flow due to the addition of energy storage occurs on the northernmost line, Clatsop-to-Driscolt, and is plotted in Figure 38. During this example threeday period, net flow from the coast to the I-5 corridor decreases by $1.7 \mathrm{GWh}$ along this line. As shown with the red dotted line in Figure 38 (left, bottom), periods of storage charging correspond to periods when Clatsop-to-Driscolt flow decreases by about $100 \mathrm{MW}$ between the storage and no storage scenarios. Still, at least $500 \mathrm{MW}$ of power flows east throughout the period along the Clatsop-to-Driscolt line. This indicates that adding energy storage siphons some offshore wind power away from the I-5 corridor in this example period, but most of it still travels over the trans-coastal range. When the stored energy is released, Clatsop-to-Driscolt flow increases relative to the no storage scenario, as indicated by the positive spikes in the red line.

The end result is more power generation in the region. Total generation in Western Oregon during this example three-day period increases by $7.7 \mathrm{GWh}, 0.7 \mathrm{GWh}$ of which comes directly from reduction of offshore wind curtailment. This change in flow is rare, however, as indicated 
by the duration curves in Figure 39. During most hours, energy storage changes the flow by less than $100 \mathrm{MW}$.
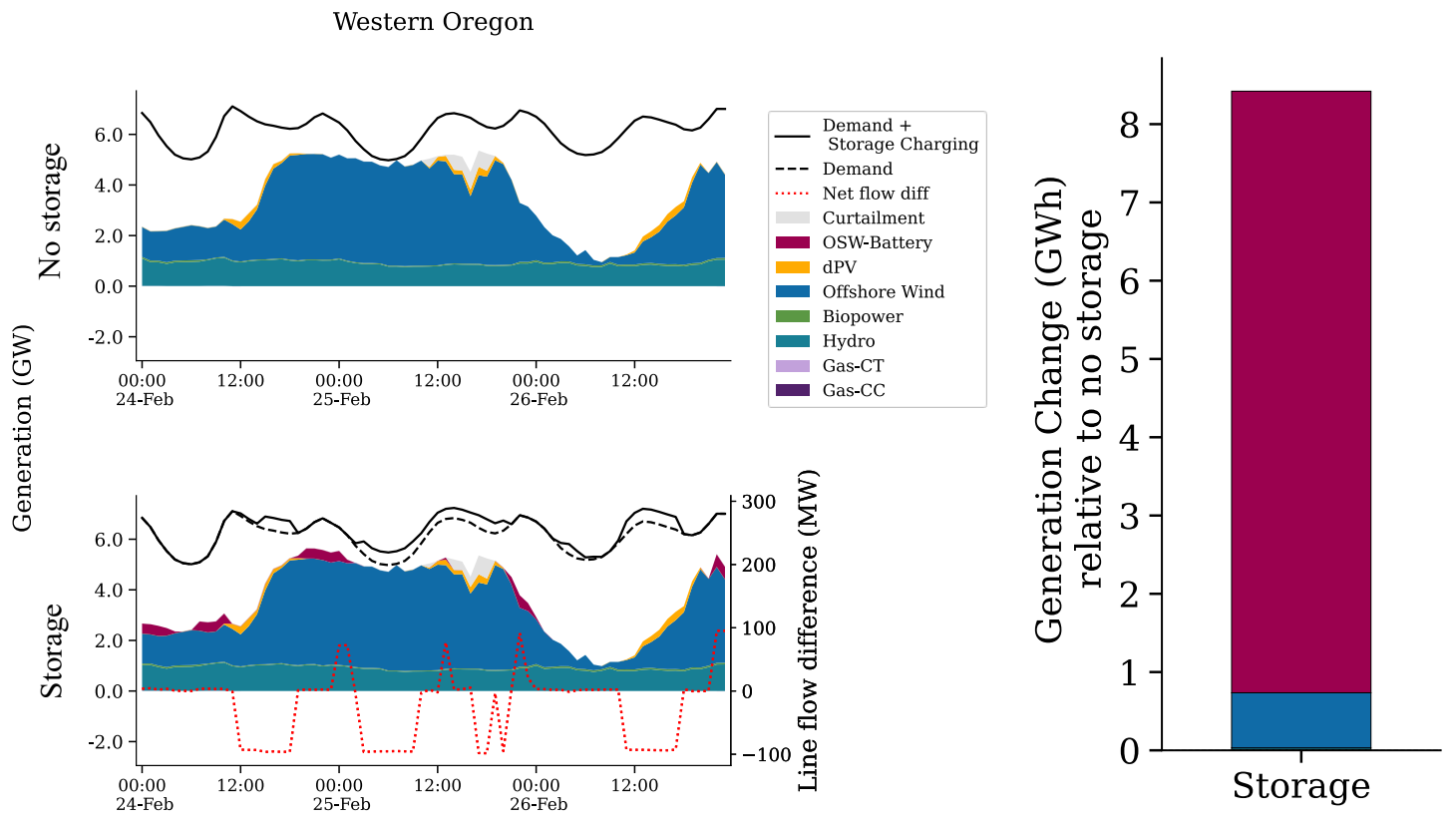

Figure 38. Dispatch stack for the three days surrounding the day with the highest change in Clatsop to Driscolt flow due to the addition of energy storage (left), along with the total generation change for these three days (right). Both scenarios include High Offshore penetration and transcoastal transmission expansion. The difference in Clatsop to Driscolt flow is plotted in the dispatch stacks with the dotted red line along the right axis. Positive values indicate more easterly flow in the energy storage scenario. 

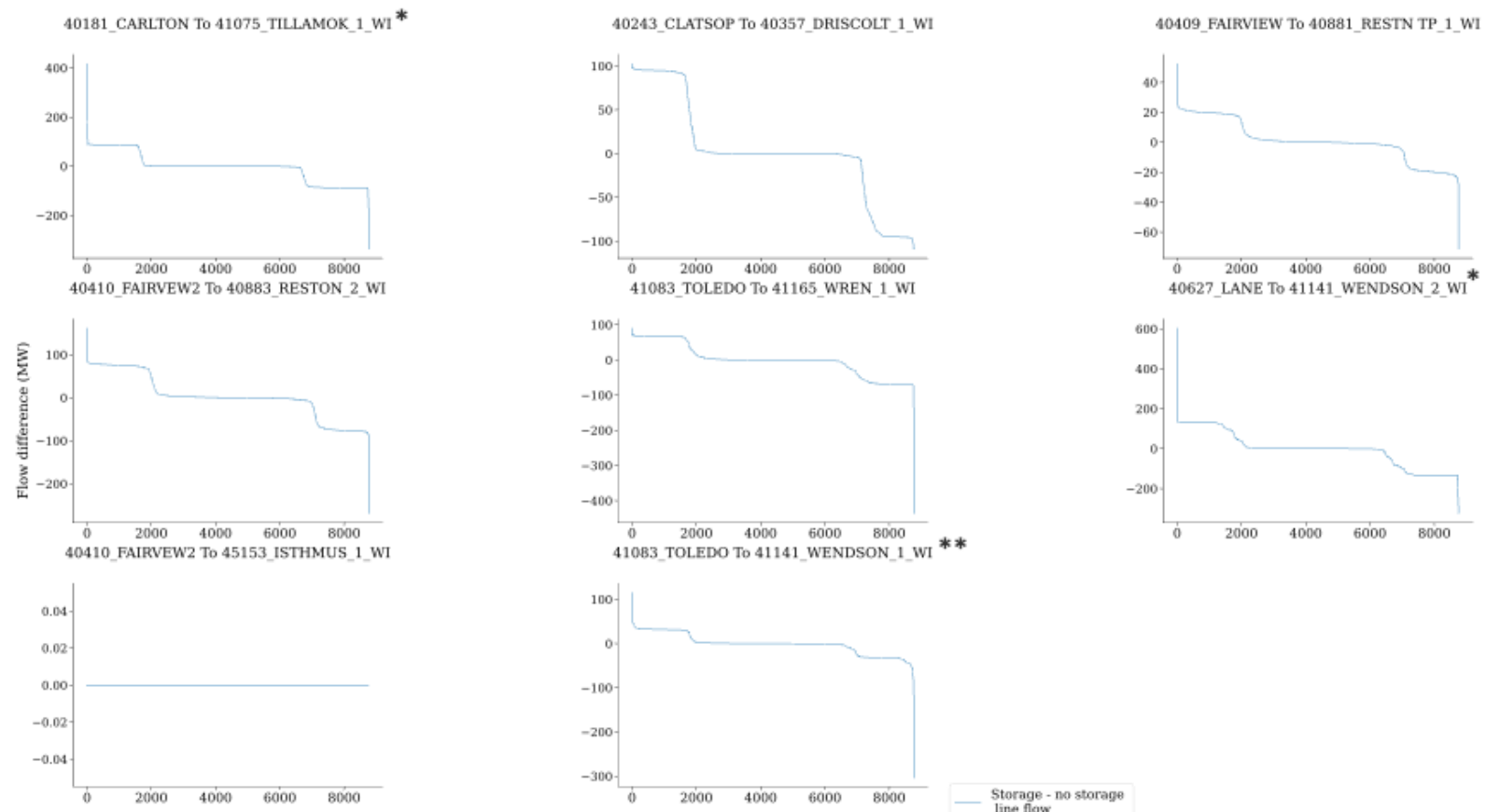

Figure 39. Duration curves plotting the difference in flow for all relevant trans-coastal transmission lines, between the two High Offshore future upgraded trans-coastal transmission scenarios with and without storage. In general, a reduction in flow (storage-no storage) across the trans-coastal range to the $\mathrm{I}-5$ corridor is indicated by positive values. However, in plots marked by a single asterisk, this reduction is indicated by negative values. The Toledo to Wendson line, marked by a double asterisk, flows north to south from the Florence node to the Coos Bay node.

In addition to the impact of energy storage on transmission utilization, upgrading trans-coastal transmission occasionally changes the times during which storage charges. Figure 40 plots an example three-day period that contains some of the largest storage net generation changes between the High Offshore scenarios with and without trans-coastal transmission expansion. A single day showcases an hour with one of the greatest positive differences (the Western Oregon demand peak at 11 p.m. on February 19, shown by the tan lines in Figure 40), and one of the greatest negative differences (11 a.m., shown by the brown lines in Figure 40). Without expansion, trans-coastal transmission congestion limits the opportunity for storage to discharge during the morning and evening peaks. Rather, storage discharges throughout the middle of the day and the late evening when demand is relatively low. By upgrading transmission, energy storage can take advantage of solar energy peaks outside of Western Oregon. It shifts from discharging throughout the day to charging midday during the solar peak and discharging during the morning and evening load peaks, when capacity is most needed. The ability for storage to dispatch more consistently during load peaks suggests it has a higher capacity value, though a dedicated resource adequacy study would be needed to definitively determine this. 


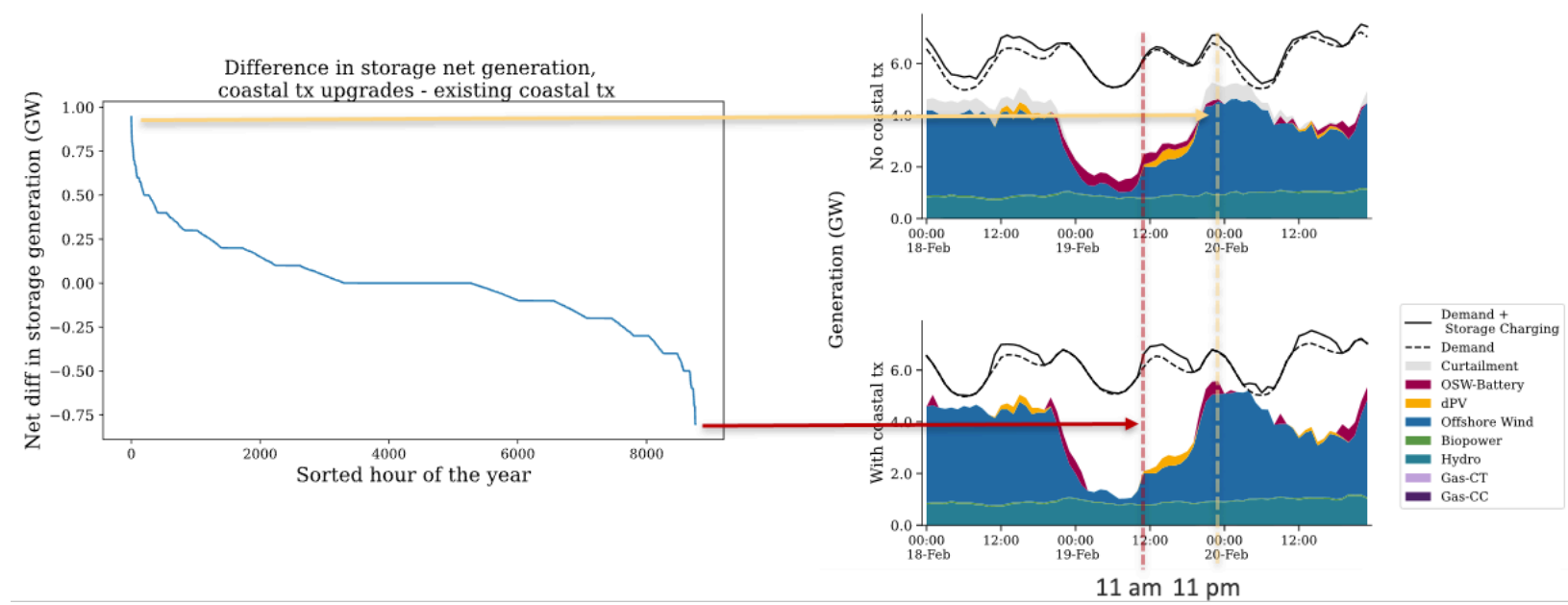

Figure 40. Impact of trans-coastal transmission upgrades on energy storage dispatch. The duration curve on the left plots the change in net energy storage generation (dispatch-charging) between the upgraded and existing trans-coastal transmission scenarios. 


\section{Conclusion}

This analysis used high resolution offshore wind data and a detailed production cost model of the Western Interconnection to explore the value and operational impact of integrating offshore wind along Oregon's coastline. Leveraging local technical stakeholder expertise and input, we determined a set of scenarios to explore. These scenarios varied offshore wind penetrations and explored the differences of integrating offshore wind in the current grid and a potential future grid. This allowed us to determine how changes to the rest of the system and increasing penetrations of offshore wind affected our findings.

We found that trans-coastal transmission congestion is the key driver to curtailment of offshore wind. Once power can be delivered into the Willamette Valley, there are few system constraints that lead to significant curtailment. We determined $2.6 \mathrm{GW}$ of nameplate capacity of offshore wind $^{35}$ could be integrated into Oregon's transmission system without significant curtailment. This penetration would be spread across the five main points of interconnection along the Oregon coast, while not requiring major upgrades to the existing trans-coastal transmission system. ${ }^{36}$ To reach $2.6 \mathrm{GW}$, the offshore wind capacity is not evenly distributed amongst coastal substations, rather the capacities were chosen based on the ratings of the of associated transcoastal lines while maximizing southern offshore due to its stronger winds and superior capacity factor.

When trans-coastal transmission is expanded to accommodate $5 \mathrm{GW}$ of offshore wind, curtailment would remain low. Without transmission congestion, there are few system constraints that would lead to offshore wind curtailment in either the current system or the future system with a higher penetration of land-based wind and solar generation. Offshore wind generation does not directly compete with land-based VRE. Adding offshore wind does increase curtailment of land-based VRE; for every 1,000 GWh of offshore wind generation, there is roughly $100 \mathrm{GWh}$ of land-based VRE. Furthermore, only $15 \%$ of the increase in land-based curtailment comes from VRE in Eastern Oregon.

Offshore wind can also serve coastal loads irrespective of the availability of trans-coastal transmission. Depending on the meteorological year ${ }^{37}$, offshore wind can serve between $84-88 \%$ and $90-93 \%$ of the hourly coastal load in the Mid Offshore and High Offshore scenarios, respectively. The capacity credit of offshore wind, when only considering coastal net load, ranges between $37-57 \%$ and $36-58 \%$ for the two scenarios. In other words, depending on the weather year, 960-1,480 MW and 1,800-2,900 MW can be counted on to serve peak coastal net loads for the Mid Offshore and High Offshore scenarios, respectively.

\footnotetext{
${ }^{35} 2.6 \mathrm{GW}$ of nameplate capacity would inject a maximum of $2.1 \mathrm{GW}$ at any hour given internal planned losses.

${ }^{36}$ Some targeted upgrades may still be required after more detailed power flow studies are performed. All points of interconnection would require transmission to connect the offshore site to land, and, in some cases, additional landbased transmission would be needed to reach the in-land substation for the point of interconnection. The design and cost of this transmission is not considered in this study.

${ }^{37}$ We studied the meteorological years of 2007-2013 to arrive at this finding.
} 
The range of system value ${ }^{38}$ provided by offshore wind ranges between $\$ 65 / \mathrm{MWh}$ and $\$ 85 / \mathrm{MWh}$ across the various scenarios considered. This range is above $\$ 63 / \mathrm{MWh}$, the average 2032 LCOE for Oregon offshore wind reported by Musial et al. 2021. The 2032 LCOE includes generic assumptions about submarine and land-based infrastructure need to integrate offshore wind into the bulk system, but may be an under or over estimate for the specific infrastructure needed to build out the offshore wind assumed in this modeling. The system value of offshore wind is highest in the current grid scenarios, exceeding $\$ 80 / \mathrm{MWh}$. As more land-based VRE is added to the system and least efficient gas and coal are retired, the value drops closer to \$70/MWh. All offshore wind value categories - energy, capacity, and emissions - drop in value in the future grid scenario but remain slightly above the average 2032 LCOE.

We also tested the robustness in the system value to changing hydrological conditions. Adding offshore wind does change hydropower operations, shifting when water is used on a daily and hourly basis, while complying with technical and regulatory constraints on the water resource. However, the interannual variability of the offshore wind and water availability were uncorrelated and water availability had little impact to the system value of offshore wind. This finding is based on the limited 2007-2013 weather data set and should be verified with a more comprehensive data set.

Besides offering value to the system, offshore wind has a direct impact on how power moves throughout the Western Interconnection. The impact is especially pronounced on cross-Cascade power flow in Oregon along the defined WECC P05 South of Cascade interface. On an hourly basis across all scenarios, we found a robust relationship of a 500-550 MW decrease in flow along the P05 interface for every 1,000 MW of offshore wind generation. However, we found little correlation between hours of high P05 flow in the base case and offshore wind generation. At times we found strong offshore wind potential at hours of high P05 flow in the base case, which in turn reduced the flow along the P05 interface in those hours. But at other hours of high P05 flow there was very little offshore wind generation, and thus P05 flow in those hours was largely unchanged when offshore wind was added to the system. This suggests offshore wind is not a good alternative to cross-Cascade transmission that might be needed to address reliability or resource adequacy concerns. However, more research is needed using reliability and resource adequacy focused tools to more fully address this.

Similarly, the integration of offshore wind influences the interchange between Oregon and California, with offshore wind generation leading to increased exports to California during its peak net load hours after sunset. This occurs both because offshore wind is better correlated with the Western Interconnection and California net load than land-based wind and solar, and because hydro is more optimally scheduled to generate during periods of high net load in scenarios with offshore wind. However, the benefit is limited by transmission congestion that arises between the two states.

We also investigated the value of co-locating energy storage at the point of interconnection of offshore wind. More research is required to assess optimal size and duration of these batteries.

\footnotetext{
${ }^{38}$ System value considers the value of displacing thermal generation, an estimate of the capacity value, and internalizing the value of displaced carbon emissions.
} 
However, we did find that 24-hour storage with a power rating equal to $10 \%$ of the installed capacity of offshore wind could reduce transmission congestion induced curtailment of offshore wind. But energy storage can also provide value in conjunction with trans-coastal transmission upgrades, during which there is little curtailment reduction value. Storage operation with transcoastal transmission tended to follow a more consistent diurnal pattern, generating mostly in the morning and evening on either side of Western Interconnection solar generation. In contrast, storage operation without trans-coastal transmission upgrades tended to be allocated to filling gaps in offshore wind generation and when trans-coastal transmission was not at risk of being overloaded.

In summary, our modeling and analysis showed integration of offshore wind off the Oregon coast adds robust value to the overall system, even as the rest of the system became more reliant on land-based VRE. This analysis suggests that offshore wind can contribute to Oregon's power system while outlining key considerations for decision makers when including offshore wind in future planning. There are also key next steps to further investigate offshore wind integration into Oregon's power system. First and foremost, future work could explore options for new transmission and targeted upgrades of existing transmission to connect offshore wind to the five substations identified in this report. We assume this infrastructure gets built in our analysis, but we do not make any specific design assumptions. There are multiple options to connect to the substations that have cost, right-of-way, and robustness tradeoffs and these should be considered in future work. Next, deeper study into the trans-coastal and coastal transmission systems would be valuable. For this study we relied on the best available data and received input from local experts on the limitations and constraints of these systems; however, it is clear that there is uncertainty about their true limitations. A future study should explore this uncertainty in greater detail and identify small, targeted upgrades to the trans-coastal and coastal transmission systems that would better facilitate the integration of offshore wind. Another important next step is to further explore offshore wind's ability to be a non-wires alternative to cross Cascade transmission and transmission along other corridors using tools more explicitly focused on reliability and resource adequacy analysis. Finally, a more robust analysis of co-location of energy storage with offshore wind should be conducted to explore the sizing of such systems and how those systems could be paired with offshore wind and increase offshore wind penetration without large investments to the trans-coastal transmission system. 


\section{References}

Beiter, Philipp, Jessica Lau, Joshua Novacheck, Qing Yu, Gord Stephen, Jennie Jorgenson, Walter Musial, and Eric Lantz. 2020. The Potential Impact of Offshore Wind Energy on a Future Power System in the U.S. Northeast. Golden, CO: National Renewable Energy Laboratory. NREL/TP-5000-74191. nrel.gov/docs/fy20osti/74191.pdf.

Brinkman, Gregory, Dominique Bain, Grant Buster, Caroline Draxl, Paritosh Das, Jonathan Ho, Eduardo Ibanez, et al. 2021. The North American Renewable Integration Study: A U.S.

Perspective. Golden, CO: National Renewable Energy Laboratory. NREL/TP-6A20-79224. https://www.nrel.gov/docs/fy21osti/79224.pdf.

CAISO. 2012. Annual Report on Market Issues and Performance. Folsom, CA: CAISO. Accessed May 2, 2014: http://www.caiso.com/Documents/2012AnnualReport-MarketIssuePerformance.pdf.

Denholm, Paul, Matthew O’Connell, Gregory Brinkman, and Jennie Jorgenson. 2015. Overgeneration from Solar Energy in California: A Field Guide to the Duck Chart. NREL/TP6A20-65023. https://www.nrel.gov/docs/fy16osti/65023.pdf.

Douville, Travis, Dhruv Bhatnagar, Rebecca O’Neil, and Kendall Mongird. 2020. Exploring the Grid Value Potential of Offshore Wind Energy in Oregon. PNNL/AC05-76RL01830/BOEM Interagency Agreement M17PG00047.

Frew, Bethany, Brian Sergi, Paul Denholm, Wesley Cole, Nathaniel Gates, Daniel Levie, Robert Margolis. 2021. "The curtailment paradox in the transition to high solar power systems." Joule, Volume 5, Issue 5. Pages 1143-1167, ISSN 2542-4351.

https://www.sciencedirect.com/science/article/pii/S2542435121001446.

Jorgenson, Jennie, Sarah Awara, Gord Stephen, Trieu Mai. 2021. A systematic evaluation of wind's capacity credit in the Western United States." Wind Energy.

https://doi.org/10.1002/we.2620.

Lazard. 2020. LAZARD'S LEVELIZED COST OF ENERGY ANALYSIS-VERSION 14.0. https://www.lazard.com/media/451419/lazards-levelized-cost-of-energy-version-140.pdf.

Mills, Andrew, R. Wiser. 2012. An Evaluation of Solar Valuation Methods Used in Utility Planning and Procurement Processes. LBNL-5933E. Berkeley, CA: Ernest Orlando Lawrence Berkeley National Laboratory. Accessed May 2, 2014: http://emp.lbl.gov/sites/all/files/lbnl5933e 0.pdf.

Mills, Andrew, Dev Millstein, Seongeun Jeong, Luke Lavin, Ryan Wiser, and Mark Bolinger. 2018. "Estimating the Value of Offshore Wind Along the United States' Eastern Coast." Environ. Res. Lett. 13 094013. 10.1088/1748-9326/aada62.

Musial, Walter, Philipp Beiter, Jake Nunemaker, Donna Heimiller, Josh Ahmann, and Jason Busch. 2019. Oregon Offshore Wind Site Feasibility and Cost Study. NREL/TP-5000-74597. nrel.gov/docs/fy20osti/74597.pdf. 
Musial, Walt, Patrick Duffy, Donna Heimiller, and Philipp Beiter. 2021.Updated Oregon Floating Offshore Wind Cost Modeling. NREL/PR-5000-80908.

https://www.boem.gov/sites/default/files/documents/regions/pacific-ocs-region/environmentalscience/PR-20-OWC-presentation.pdf.

Novacheck, Josh, Sharp, Justin, Schwarz, Marty, Donohoo-Vallett, Paul, Tzavelis, Zach, Buster, Grant, and Rossol, Michael. (Forthcoming). The Evolving Role of Extreme Weather Events in the U.S. Power System with High Variable Generation Penetrations. Golden, CO: National Renewable Energy Laboratory.

Optis, Mike, Alex Rybchuk, Nicola Bodini, Michael Rossol, and Walter Musial. 2020. 2020 Offshore Wind Resource Assessment for the California Pacific Outer Continental Shelf. Golden, CO: National Renewable Energy Laboratory. NREL/TP-5000-77642.

https://www.nrel.gov/docs/fy21 osti/77642.pdf.

Roger Collanton, Ivancovich Anthony, Pinjuv Jordan. 2021. Order Instituting Rulemaking to Oversee the Resource Adequacy Program, Consider Program Refinements, and Establish Forward Resource Adequacy Procurement Obligations: Track 3B.1 Proposals of the California Independent System Operator Corporation.

System Advisor Model Version 2020.11.29 (SAM 2020.11.29). National Renewable Energy Laboratory. Accessed December 27, 2020. https://sam.nrel.gov . 